\title{
DRAWING IN PERSPECTIVE
}

A Proposition for a Discursive Architecture in the age of Digital Representation.

Laura Coates 

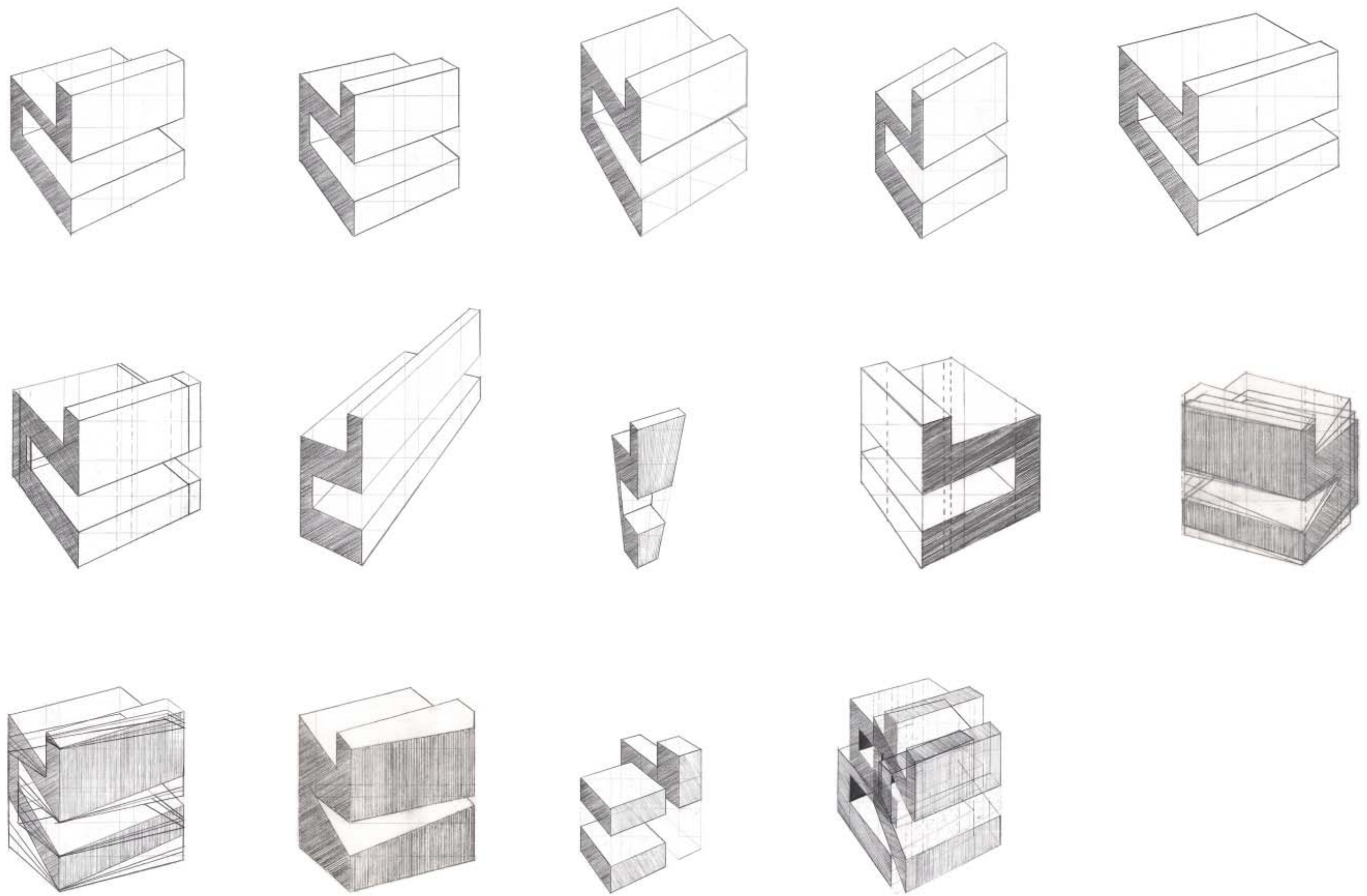

A thesis submitted in partial fulfillment of the degree Masters of Architecture (Prof). Victoria University, School of Architecture and Design 2011 


\section{Abstract}

Contemporary architectural practise has come to depend upon digital representation as a means of design and for the production of architectural drawings. The computer is common place in architectural offices, relegating the drawing board as a machine of the past. Today, the architect is more likely to draw with mouse than a mechanical pencil. The proposition of this research suggests such a dramatic shift within representational technology will not only affect how architects design, but also, what they design.

Digital modes of architectural representation are reliant on mathematical code designed to artificially simulate visual experience. Such software offers strict alliance with a geometrically correct perspective code making the construction of perspective as simple as taking a 'snap shot'. The compliance of the digital drawing to codes prescribed by a programmer distance the architect from the perspectiva representation, consequently removing the architect's control of the drawing convention. The universality of perspectival views is enforced by computer programmes such as Google Sketch-Up, which use perspective as a default view.

This research explores the bias of linear perspective, revealing that which architects have forgotten due to a dependence on digital software. Special attention is drawn to the lack of control the architect exerts over their limits of representation. By using manual drawing the perspective convention is able to be unpacked and critiqued against the limitations of the system first prescribed by Brunelleschi. The manual drawing is positioned as a powerful mode of representation for it overtly expresses projection and the architect's control of the line. The hand drawing allows the convention to be interpreted erroneously. The research is methodology driven, focusing on representation as more than a rudimentary tool, but a component of the design process. Thus, representational tools are used to provide a new spatial representation of a site.
Computer aided design entered wide spread architectural practice at the end of the 1980's, a decade that provided an ideal setting for speculative drawn projects. Such projects proved fruitful to architects critically approaching issues of representation and drawing convention, treating the drawing as more than utilitarian in the production of architecture. Whilst the move into digital imagining is not a paradigm shift for the act of drawing, it fundamentally shifted the way architects draw, separating drawing conventions onto visually separate 'sheets'. The architectural drawing known today was that discovered in the Renaissance, Renaissance architects, the first to conceive of architecture through representation, thus was their endeavour to produce a true three dimensional image. The Renaissance architect executed absolute control of perspective, control, which has since defined the modern architect.

Positioned within research by design, the 'drawing-out' process is a critical interpretation of perspective. In particular the drawing of instrumental perspective is unpacked within the realm of scientific research. The picture plane, horizon line and ground plane remain constant as the positions of these are well documented. The stationary point, vanishing point (possibly the most speculative components of the drawing) or the relationship between the two, behave as independent variables.

In breaking the assumptions that underlie linear perspective as a fixed geometric system we may ask ourselves if we are in control of representational methods, or if they control us. Since architects are controlled by their means of representation this question is paramount to the discipline, particularly today, when digital drawing has shifted the relationship between architect and representation. The implications of this new relationship may result in monotony across the architectural disciple, where the production of critical architecture is secondary to computer technology. 


\section{Contents}

ABSTRACT

CONTENTS

LIST OF FIGURES.

ACKNOWLEDGEMENTS

ix

TIMELINE OF PERSPECTIVE.

INTRODUCTION

SITUATING BRUNELLESCHI..

Before Brunelleschi

Disregarding Euclid

The Inaugural Demonstration

Orthographic Projection...

The Vanishing Poin

THE 'MECHANICAL EYE'

Imposing Perspective

A study in voyeurism.

Peepshow.
The Act of Looking.

TACTILE CONTROL.

Drawing Architecture .......................................................................................................

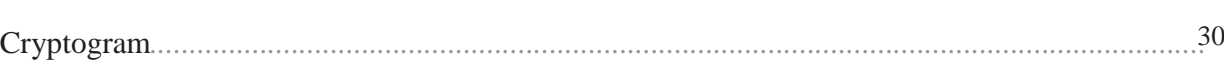

Hand as Tool .................................................................................................................... 31

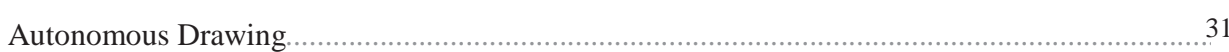

Technogram.....................................

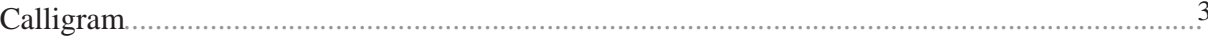

UNPACKING THE CRYPTOGRAM

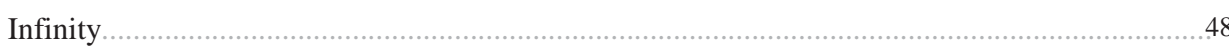

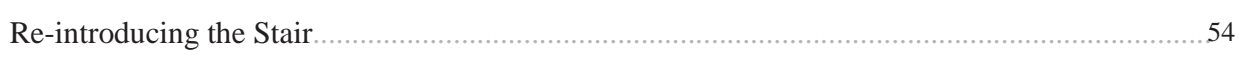

Building the Drawing .............

DISCUSSION

CONCLUSION

BIBLIOGRAPHY

APPENDIX

1:1 scale drawings. ... 3 


\section{List of Figures}

FIGURE 1 Erwin Panofsky: “Angle Perspective”, 1991.

FIGURE 2 Brunner: San Giovanni Baptistry, Florence, 1994

FIGURE 3 Leon Battista Alberti: Perspectival construction of the checkerboard-type, circa 1435- 1436.

FIGURE 4 Albrecht Dürer: Method of Drawing a Portrait, 1525.

FIGURE 5 Samuel van Hoogstraten: A Peepshow with Views of the Interior of a Dutch House, 1655-1660.

FIGURE 6 Erwin Panofsky: Modern “linear perspectival” construction, 1991.

FIGURE 7 Hubert Damisch: Brunelleschi's first experiment: overhead view of Florence Cathedral and the Baptistry, 1994.

FIGURE 8 Robin Evans: Perspective and its Analogues: The Arrested Image, 1995.

FIGURE 9 Penelope Haralambidou: The Act of Looking, 2007.

FIGURE 10 Robin Evans: Perspective and its Analogues: The Arrested Image, 1995.

FIGURE 11 Brunner: San Giovanni Baptistry, Florence, 1994

FIGURE 12 Hubert Damisch: Plan of the San Giovanni Baptistry, 1994.

FIGURE 13 Abraham Bosse : Les Perspecteurs, 1648.

FIGURE 14 Duccio di Buoninsegna: Last Supper from the Maestà, 1301-1308.

FIGURE 15 Erwin Panofsky: Linear Perspective and “Angle Perspective”, 1991.

FIGURE 16 Rosalind Krauss: Reconstruction of Brunelleschi's first experiment of perspectival representation, 1994

FIGURE 17 Frank Dubery and John Willats: Drawing showing the relationship of the two baptistry panels, 1972

FIGURE 18 Erwin Panofsky: Modern "linear perspectival” construction, 1991.

FIGURE 19 Frank Dubery and John Willats: A drawing of the baptistry made from plan and elevation, 1972.

FIGURE 20 A. Parronchi: Tavoletta San Giovanni, [n.d].

FIGURE 21 Albrecht Dürer: Method of Drawing a Lute, 1525.

FIGURE 22 Piero della Francesca: The 'Other Method', before 1482
FIGURE 23

FIGURE 24

FIGURE 25

FIGURE 26

FIGURE 27

FIGURE 28

FIGURE 29

FIGURE 30

FIGURE 31

FIGURE 32

FIGURE 33

FIGURE 34

FIGURE 35

FIGURE 36

FIGURE 37

Hedrich Blessing: Drawing office at Ford’s Willow Run bomber plant at Ypsilanti, Michigan, circa. 1942.

FIGURE 38

edrich Blessing: Drawing office at Ford’s Willow Run bomber plant at Ypsilanti, Michigan, circa. 1942.

FIGURE 39

Hedrich Blessing: Drawing office at Ford's Willow Run bomber plant at Ypsilanti, Michigan, circa. 1942

FIGURE 40 Leon Battista Alberti: Perspectival construction of the checkerboard-type, circa 1435- 1436

FIGURE 41 Filarete: Sforzinda, circa. 1464

FIGURE 42 Filarete: House of Virtue and of Vice, circa. 1464 
FIGURE 43 Saul Steinberg: View of the World from 9th Avenue, 1976

FIGURE 44 Author: Drawing 4, 2010

FIGURE 45 Author: Illustration of instrumental perspective, 2010

FIGURE 46 Author: Illustration of instrumental perspective, 2010

FIGURE 47 Author: Illustration of instrumental perspective, 2010

FIGURE 48 Author: Illustration of instrumental perspective, 2010

FIGURE 49 Author: Drawing 5, 2010

FIGURE 50 Author: Drawing 6, 2010

FIGURE 51 Author: Perspective vs. Axonometric projection, 2010

FIGURE 52 Author: Drawing 8, 2010

FIGURE 53 Author: Drawing 9: the vanishing points, 2010

FIGURE 54 Author: Drawing 9: 'reverse engineering', 2010

FIGURE 55 Author: Drawing 10: detail, 2010

FIGURE 56 Author: Drawing 11, 2010

FIGURE 57 Author: Drawing 12, 2010

FIGURE 58 Author: Drawing 14: detail, 2010 


\section{Acknowledgements}

A large number of people have offered me support this year in a number of ways. I am truly thankful to you all.

I am indebted to my teachers over the last five years, particularly Peter Wood for his supervision of this research. If it weren't for his knowledge and support I would not have produced this work.

I am thankful to the technical staff within the university, particularly Arthur Mahon who carefully scanned every one of my drawings completed during the year. In addition I'd like to thank the workshop staff who facilitated my construction of the model.

To my friends for the daily coffee breaks, the support of each other made the last 12 months enjoyable (if only bearable at times).

To Mark, for being the word of reason.

To my brother for his meticulous reading of my words, and to my parents who just let me be. 


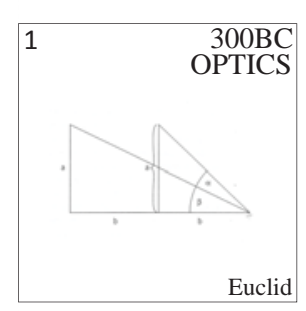

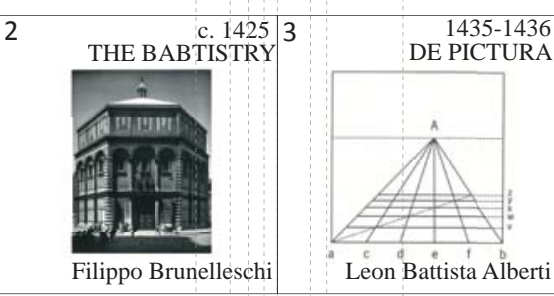

LIFE OF BRUNELLESCHI Antonio Manetti C. $1474-1482$
DE PROSPECTIVE PINGENDI Piero della Francesca

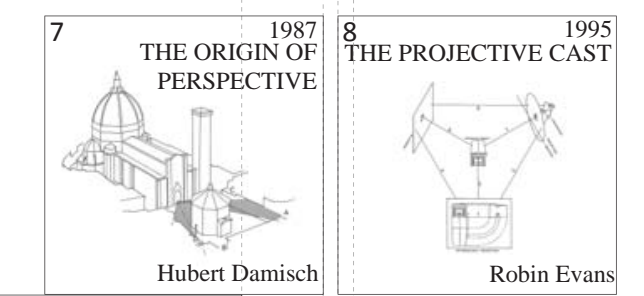
PERSPECTIVE AS $\langle x$

Erwin Panofsky

Timeline of Perspective

Figure 1- Erwin Panofsky, "Angle Perspective", in Perspective as Symbolic Form, by Erwin Panofsky (New York: Zone Books, 1991) p. 136.

Figure 3- Leon Battista Alberti, Perspectival construction of the checkerboard-type, c. 1435-1436, in Perspective as Symbolic Form, by Erwin Panofsky (New York: Zone Books, 1991$)$ p. 64.

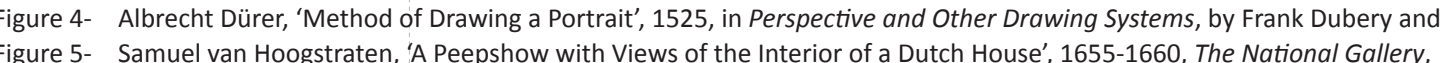

figure 5- Samuel van Hoogstraten, 'A Peepshow with Views of the Interior of a Dutch House', 1655-1660, - he National Gallery,
http://www.nationalgallery.org.uk/paintings/samuel-van-hoogstraten-a-peepshow-with-views-of-the-interior-of-a-dutch-house

Figure 6- Erwin Panofsky, Modern "inear perspectival" construction, in Perspective as Symbolic Form, by Erwin Panofsky (New York: Zone Books, 1991) p. 29.

Figure 8- Robin Evans. 'Peerspective and its analogues: the arrested image', in The Projective Cast, by Robin Evans (Cambridge, Massachuseetts: MIT Presss, 1995) p. 367.

Figure 9- Penelope Haralambidou, 'The Act of looking', in The Blossoming of Perspective: A study by Penelope Haralambidou, by Penelope Haralambidou (London: DomoBaal Editions, 2006) p. 30.

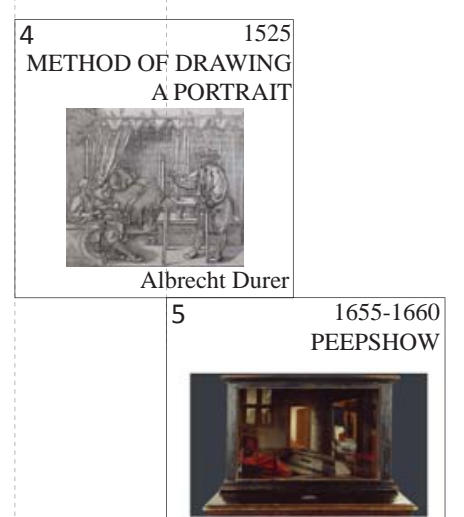

2007
THE BLOSSOMING OF
PERSPECTIVE
Penelope Haralambidou 


\section{Introduction}




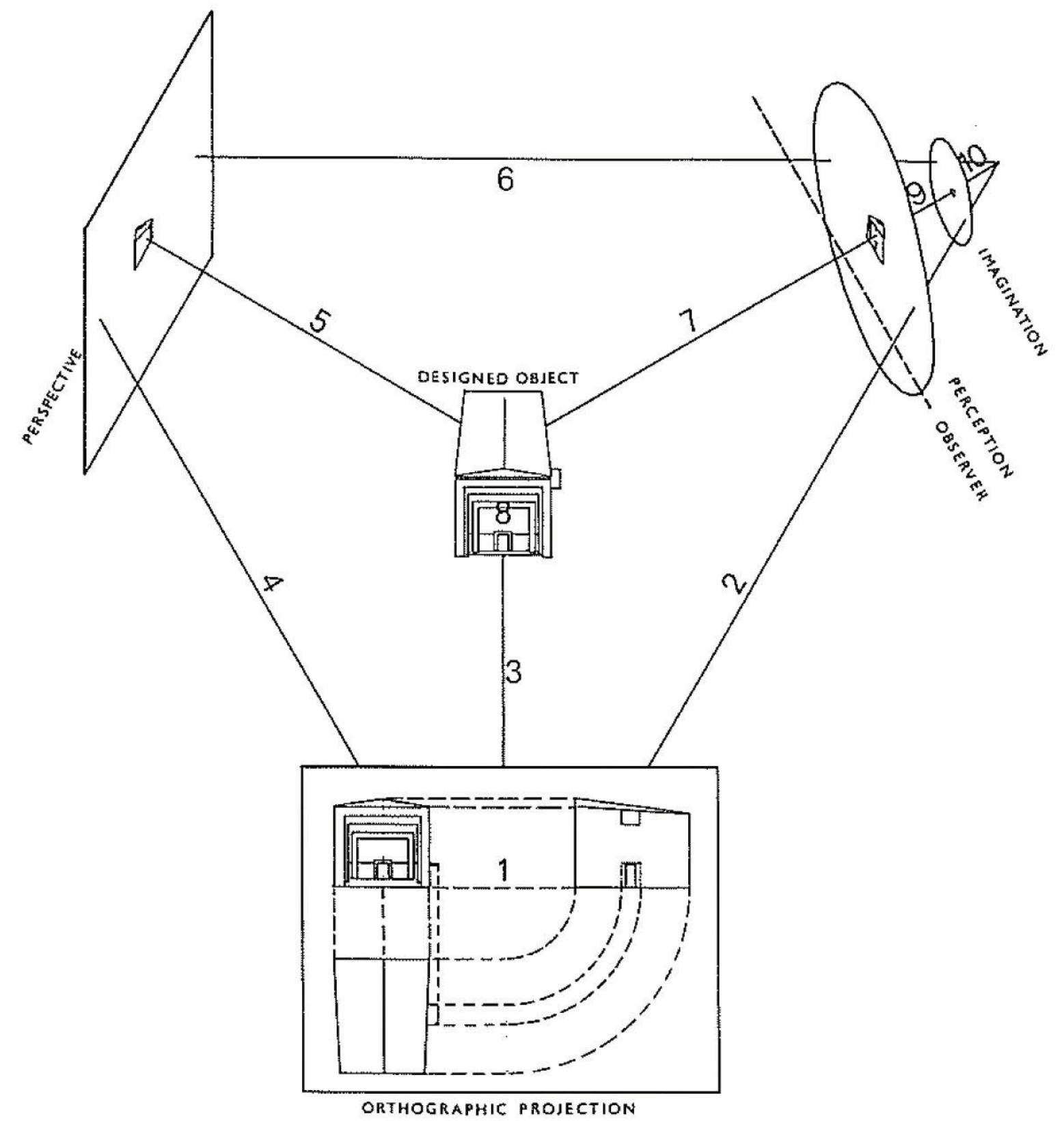

Perspective and its Analogues: The Arrested Image

Figure 10

Robin Evans' diagram illustrates that which is involved in the production of perspective, describing projection within ten fields, with five targets. The diagram suggests that architecture is always situated within a projective cast.

Robin Evans, Perspective and its Analogues: The Arrested Image, 1995, The Projective Cast, by Robin Evans (Cambridge, Massachusetts: MIT Press, 1995) p. 367. 
Linear perspective provides a view of the world around us, but it is not a true representation of how one sees. It has become the dominant means of representation throughout photography, film and computer software. First described by Brunelleschi in the fifteenth century, linear perspective has since informed ones understanding of vision, fixing the technique as a means for picture making. Brunelleschi's method, perspectiva artificialis, depends on a number of assumptions that operate some distance from natura vision, therefore, the perspective formula is a means to rationalize representation rather than vision. The reason linear perspective is accepted as a true description of space within the contemporary world is due to habituation. The photographic camera, an evolution from the camera obscura, offers linear perspective verisimilitude, with both devices modelled according to the assumptions of Brunelleschi's method. Linear perspective, therefore, is as much a contemporary three dimensional image as it was in the Renaissance. Today, perspective images are almost always conceived digitally, as a result, the construction of the perspective is no longer an arduous task of projection, but more alike taking a 'snap shot'. The architec no longer needs control of projective geometry, and consequently has become complacent of perspective construction. Due to this, one cannot be critical about the system of representation, nor control its limits.

Digital tools bear the responsibility for taking representation and translating it into a mode of describing, rather than a critical component of the design process. Subsequently, digital perspective is entirely beholden to the Brunelleschi technique, whilst failing to reference alternative perspective methods. In the fifteenth century, when linear perspective is said to have been invented, or at least gained favour, it was a critical and plural discipline, with the architect, executing complete control over the production of the perspective image. Renaissance perspective defined the modern architect, for the first time placing the architect as the maker of architectural drawings, rather than the maker of architecture, and thus, sealing the future of the architect as one limited in their means of representation. Linear perspective is a dominan example of such representational limits, demonstrated in the systems insistence on deducing vision a monocular and stationary. When these limits are those of the architect producing the drawing they are understood and able to be controlled. However, within a digital paradigm, the limits become those of the computer and the person who wrote the software. The digital drawing demonstrates both the aesthetic an the formal qualities of the software that produces them, impressing a certain set of values onto the representation that are not those of the architect. This research aims to test the bias of perspective drawing within the digital era; critically using representation as a tool within the process of design rather than subservient mode of picture making. This will be done by unpacking the perspective code through manual drawing and projection techniques. The perspective code first demonstrated by Brunelleschi will be the subject for such drawings.

The scope of this research was informed by Robin Evan's diagram Perspective and its Analogues: The Arrested Image. Found at the conclusion of The Projective Cast, it provides the fundamental structure and starting point for this research. The diagram demonstrates projection within ten fields, joined by five targets, and is a guide to the relationships between the perspective construction and its means. ${ }^{1}$ The diagram demonstrates that perspective is not an exclusive pathway between the orthographic set and designed object, but includes the position of the viewer, interpretation and imagination. It is these points, demonstrated by Evan's, which form the limitations to the research. Because instrumental perspective was the only method used as a means to draw the designed object, the projection of the orthographic set is present within every drawing as is the position of the observer (stationary point). Interpretation and imagination occur later in the work and form the bases for how the drawings are concluded. The limitation of the manual drawing (with a $2 \mathrm{~h}$ pencil) placed a dependence on methodology. A great deal of time was spent at the drawing board and every line drawn is shown in the outcome.

Intellectually, the research assimilates the thoughts of Erwin Panofsky, taking perspective as a symbolic form of representation. ${ }^{2}$ Considering perspective within this light provided precedence to pursue the manual drawing as an artefact as well as interpret perspective through new ways for a new understanding of the world. Panofsky claims perspective is defined by its period and the intellect of the time ${ }^{3}$ therefore allowing me to reconsider Brunelleschi's five hundred year old technique for the twenty-first century.

The first part of the thesis covers the background of linear perspective, focusing specifically on Brunelleschi as its forefather. I will demonstrate how Brunelleschi's method was developed with reference to earlier modes of representation which collectively informed his demonstration of systematic space. Often positioned as the sole figure of systematic representation, Brunelleschi's technique will be compared to the equally plausible method of Piero della Francesca as a means to understand why Brunelleschi has remained persuasive whilst other techniques have fallen into obscurity. This chapter highlights a contradiction in Brunelleschi's rule (particularly through the example of Piero), who in

1. Robin Evans, The Projective Cast, Cambridge, Massachusetts: MIT Press, 1995, p. 366 . Erwin Panofsky, Perspective as Symbolic Form, New York: Zone Books, 1991 
opposition to Brunelleschi claims systematic perspective is possible without recall to the vanishing point. ${ }^{4}$ The second chapter explores the implications of Brunelleschi's system on an understanding of space. This chapter highlights how Brunelleschi proposed a singular interpretation of space dependent on mathematics. Brunelleschi's interpretation is in contrast to earlier methods that treated perspective with more flexibility and attempted to represent it with closer ties to ones perception, rather than rationality The scholarship of Panofsky argues that mathematics is outside of human perception, and, therefore, linear perspective can be interpreted as erroneous and arbitrary. ${ }^{5}$

The second part of the thesis further develops the limitations of the digital constructs. The digital perspective is positioned as a tool for picture making that fails to question the conventions behind the representational technique. As such, the digital perspective is framed as a less critical method of design By adopting Marco Frascari's three meanings of drawing, the cryptogram, technogram and calligram, the manual drawing is demonstrated as a more critical tool in the process of design, whilst positioning representation and the making of architectural drawings within a dynamic paradigm. The final chapter demonstrates manual drawing as a critical interpretation of perspective conventions, the result of lengthy time spent at the drawing board, projecting line by line. The drawings demonstrate how representation can be questioned and pushed outside the fixed system prescribed by Brunelleschi, hinting that a new spatial understanding is born through a re-arrangement of what exists. Breaking with the rule of Brunelleschi, perspective is pushed to a new place, where through errors in the system one is no longer drawing that which is repeatable and rational. These drawings demonstrate that architecture encompasses more than static representations for building, but rather, that the process of design can reject Brunelleschi's fixed view of the world in favour of a natural view, complete with pluralism and contradictions. 


\section{Situating Brunelleschi}



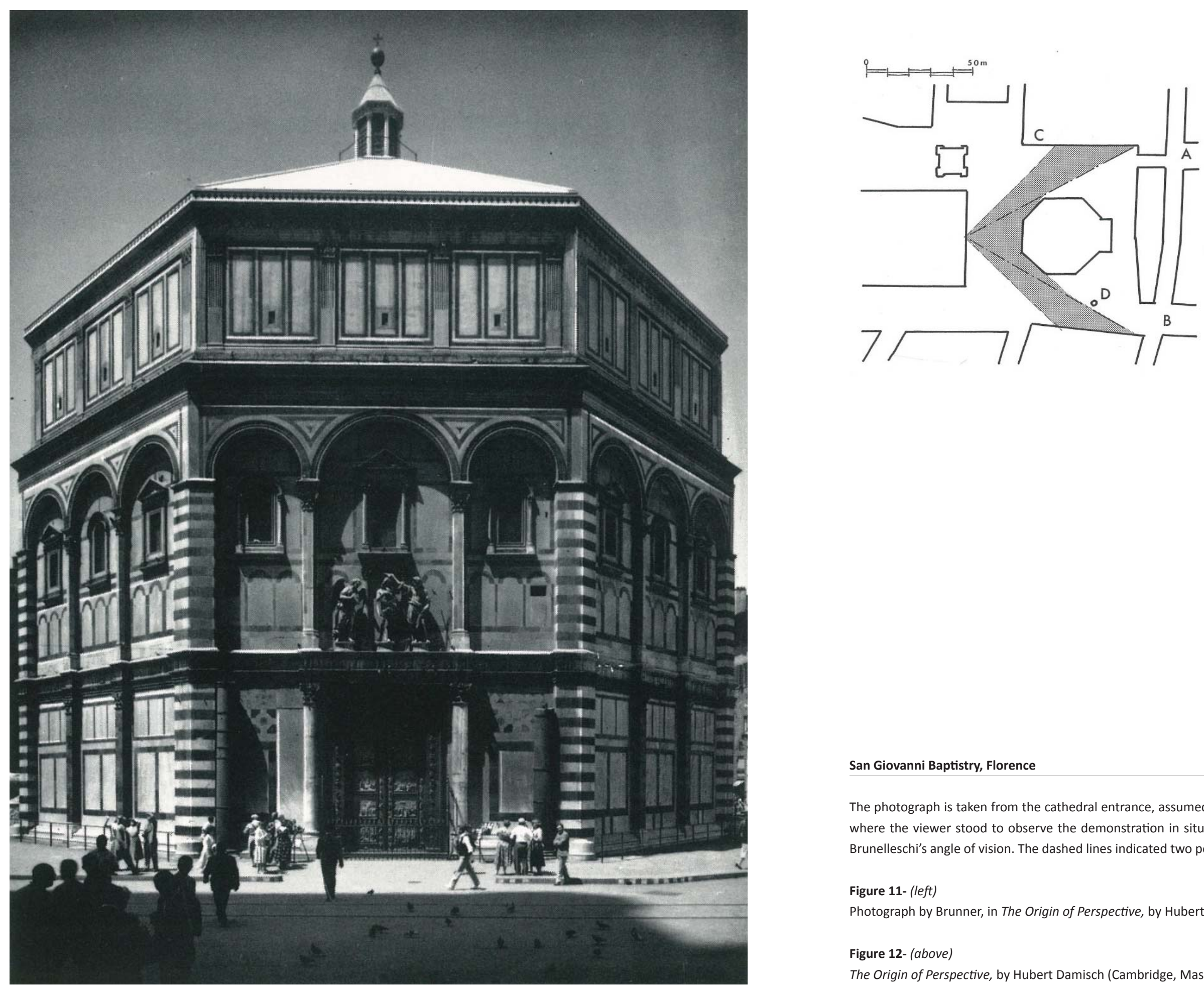

San Giovanni Baptistry, Florence The photograph is taken from the cathedral entrance, assumed to be the same place Brunelleschi stood for his demonstration and
where the viewer stood to observe the demonstration in situ. The plan (above) illustrates this position and what is supposed as Brunelleschi's angle of vision. The dashed lines indicated two possibilities. The smaller angle of vision is that which is photographed. Figure 11-(left)

Photograph by Brunner, in The Origin of Perspective, by Hubert Damisch (Cambridge, Massachusetts: MIT Press, 1994) p. 104. Figure 12-(above) 
Brunelleschi codified linear perspective. His paintings, the first to use a common horizon line, became the dominant example of perspectival representation within architecture. Whilst Brunelleschi was not the only inventor of a perspective system his technique overshadows earlier work as well as paralle demonstrations, including the most rigorous Renaissance treatise of Piero della Francesca. ${ }^{6}$ What set Brunelleschi apart from earlier methods was a systematic representation, which advanced principles of optics, and defined perspectiva artificialis with mathematical concerns, above aesthetic ones.

\section{Before Brunelleschi}

Brunelleschi's demonstration of mathematical perspective took the form of a painting of the San Giovann baptistry in Florence. Prior illustrations of empirical perspective existed, as did scientific explanations for the functioning of the eye. Euclid's optics, circa 300 BC, occur at the inception of most perspectiv methods, proving influential for artists, architects, and in geometries. Euclid was the first to describe how the eye sees and how the principles of vision can be translated into a two dimensional image. By assuming light to travel in straight lines, ${ }^{8}$ Euclid likened rays of light to vision that converges at the poin of the eye. This description of sight as light rays forms the earliest example of the visual pyramid or cone of vision. ${ }^{9}$ Euclid, therefore, explained the geometry of natural vision and natural perspective, rather than the mathematical geometry of imagery. ${ }^{10}$ During the Medieval period the principles of optics were understood in the form of perspectiva naturalis. That is, they were concerned with representing objects as diminishing in proportion to relative distances. ${ }^{11}$ Medieval theories of vision were not concerned with representations of a systematic world, but rather a method that explained the qualities of light, as a means to understand the physical and metaphysical. ${ }^{12}$ This theory (easily confused with optics), concentrated on direct, reflected, or refracted vision. ${ }^{13}$ Hubert Damisch has questioned whether perspectiva artificialis

6. Evans, 1995, p. 143. 7. Other mathematical systess were implemented subsequent to Brunelleschi's discovery. Particularly noteworthy was Piero's 'Other Method'. Yet, despite the systems rigour, no Renaissance character, nor method, achieved the same supremacy over 8. Alberto $\mathrm{P}$ MIT Press, 1997, p. 13.

9. Frank Dubery and John Willats, Perspective and Other Drawing Systems, New York: Van Nostrand Reinhold, 1972, p. 55. 10. Dubery and Willats, 1972, p. 55 .

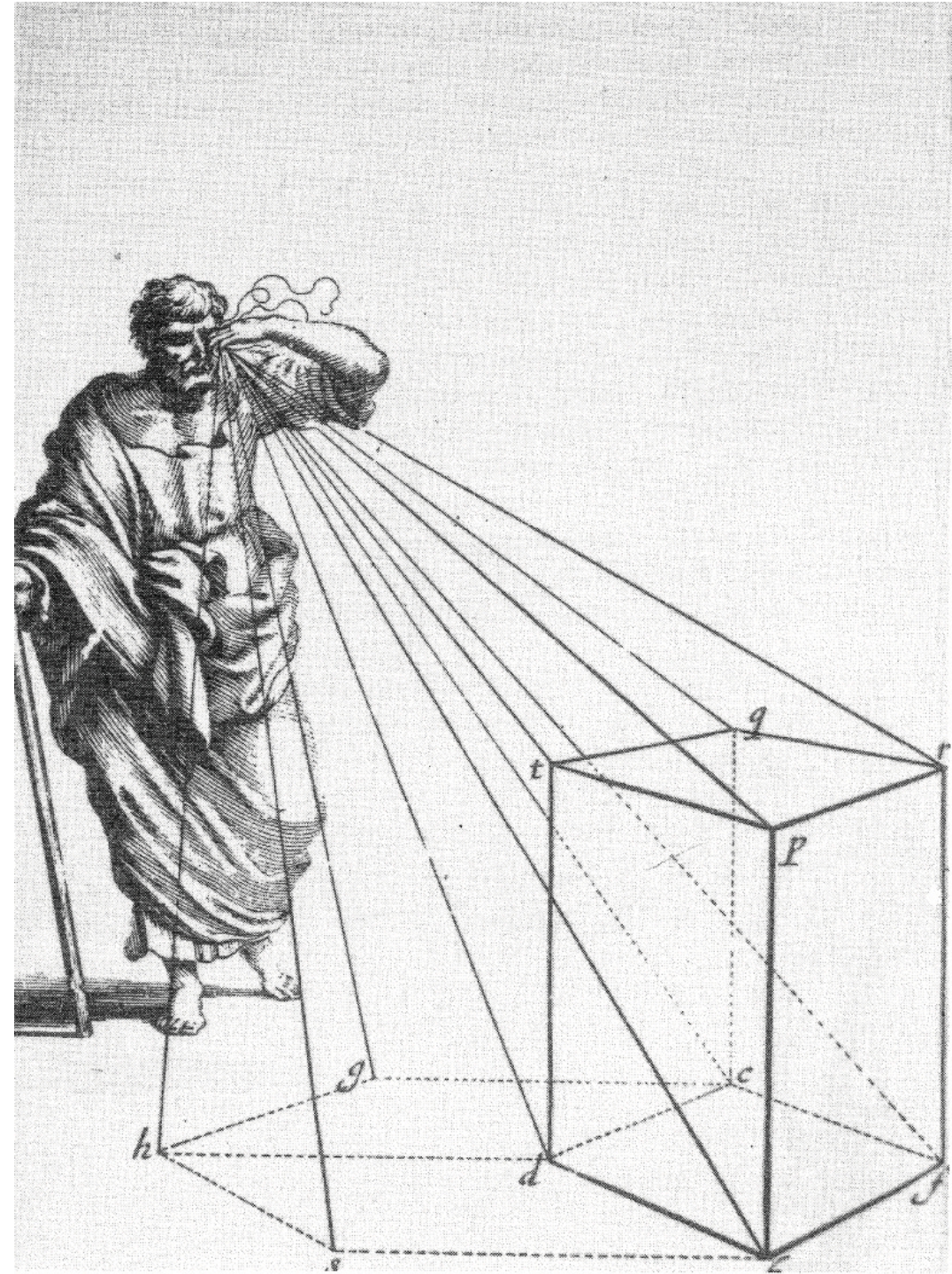

Les Perspecteurs

igure 13-

Demonstration of mans vision controlled by rays of light which all converge to a single eye. The illustration, albeit drawn many centuries after optics, continues to conform to Euclid's description of sight. Les Perspecteurs, from Abraham Bosse's Maniere universelle Mr. Desargues 1648, in Architectural Representation and the Perspective Hinge, by Alberto Pérez- Gómez and Louise Pelletier (Cambridge, Massachusetts: MIT Press, 1997) p. 70. 
was an unforeseeable development, or based on and in these methods. ${ }^{14}$ The evidence prior to Brunelleschi's demonstration suggests precedence; artists' studios in Florence were demonstrating perspectiva artificialis through empirical mean ${ }^{15}$ and Panofsky suggested it was not Brunelleschi, but rather the Trecento artists Giotto and Duccio, who were the true perspective inventors. ${ }^{16}$ Advancing from Byzantine art, where the main concern was symbolic representation, the paintings of Giotto and Duccio demonstrate narratives depicted as if on a stage, illustrating moments of spatial continuity and mathematical order. ${ }^{17}$ Medieval representation was supplanted by the artist's, the representational surface forever changed due to their demonstrations of closed interior space. ${ }^{18}$ Alberti would go on to compare perspective to staring out a window ${ }^{19}$, and this analogy can be used to describe Giotto and Duccio's paintings. In the Last Supper, Duccio achieves partial unification of perspective space, with the convergence of parallel lines in the ceiling panels, the vanishing points meeting at Christ's head. The convergence of parallel lines was previously regarded as incorrect in mathematical systems, as Euclid's fifth postulate asserts parallels never meet. ${ }^{20}$ The convergence of such parallels suggests Duccio understood the construction of perspective through a mathematical guise, rather than a purely optical construct. Brunelleschi, therefore, was not the first to describe the representation of systematic space, rather, offering final words to the codification of linear perspective ${ }^{21}$ through his clarification and systematization of Giotto and Duccio's techniques. ${ }^{22}$ In keeping with the style of Duccio, Brunelleschi too disregarded Euclid's postulate. Advancing from partial unification, Brunelleschi achieved in describing a singular vanishing point and consequently the horizon plane.

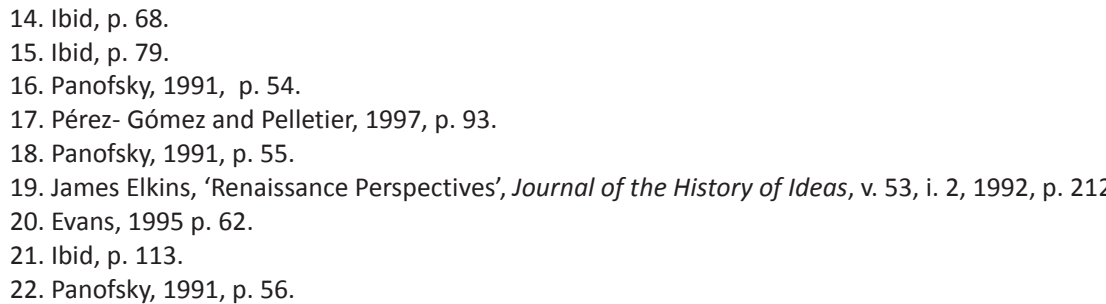



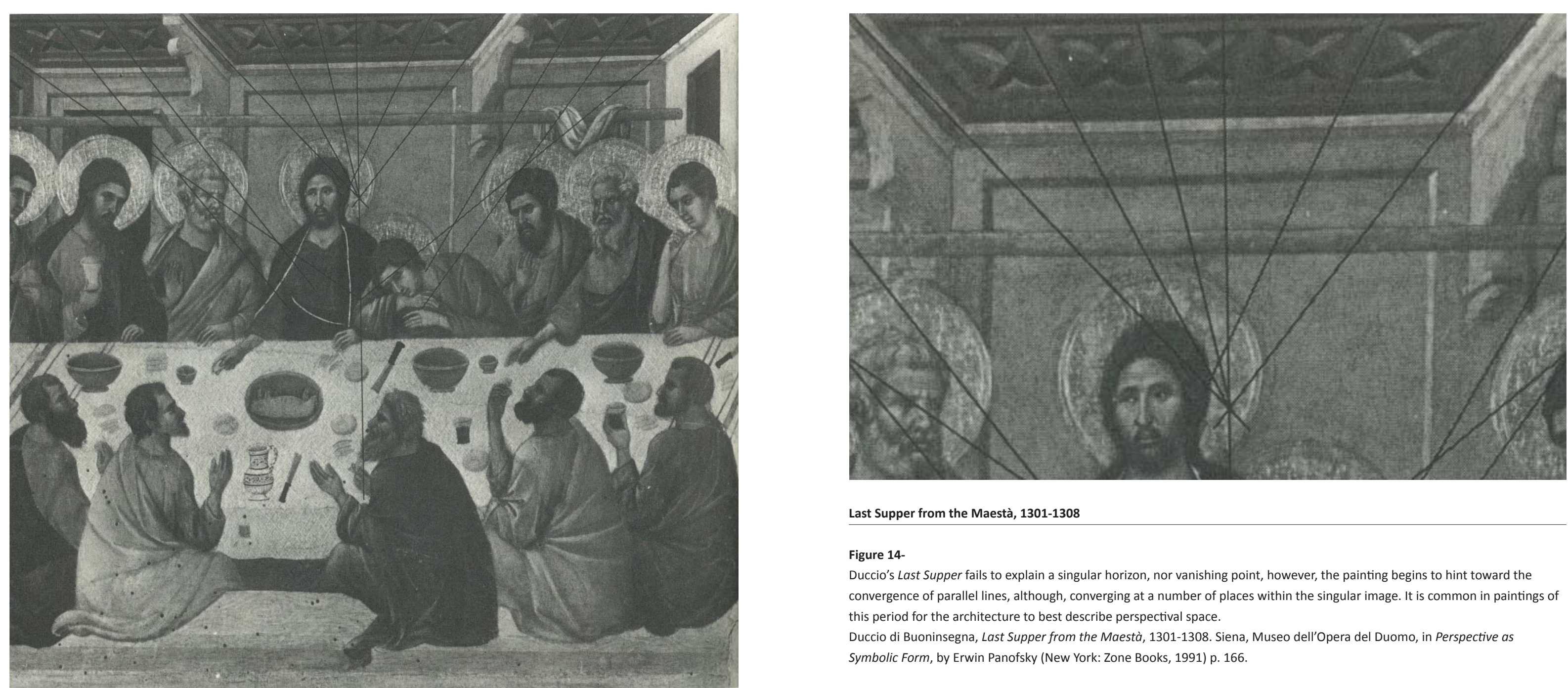

Last Supper from the Maestà, 1301-1308

Figure 14-

Duccio's Last Supper fails to explain a singular horizon, nor vanishing point, however, the painting begins to hint toward the convergence of parallel lines, although, converging at a number of places within the singular image. It is common in paintings of this period for the architecture to best describe perspectival space.

Duccio di Buoninsegna, Last Supper from the Maestà, 1301-1308. Siena, Museo dell'Opera del Duomo, in Perspective as Symbolic Form, by Erwin Panofsky (New York: Zone Books, 1991) p. 166. 


\section{Disregarding Euclid}

Part of Brunelleschi's development of earlier methods can also be accredited to disregarding the angle axiom, or Euclid's eighth theorem, which was responsible for the perspective of Antiquity being subservient to that of the Renaissance. Euclid's eighth theorem states:

the apparent difference between two equal magnitudes perceived from unequal distances is determined not by the ratio of these distances, but rather by the far less discrepant ratio of the angles of vision. ${ }^{2 .}$

Antiquity followed Euclid's theory in that their perspective constructs were concerned with the 'factua structure of the subjective optical impression, ${ }^{24}$ and, therefore, measured distance through widths and angles of vision, not distances of objects. ${ }^{25}$ Panofsky's illustration (Figure 15) shows how the method of Antiquity varied with that of the Renaissance, through interpretations of Euclid's axiom. The left diagram of linear perspective demonstrates how the apparent size of the planes HS and JS are inversely proportional to the plane $\mathrm{AB}$ and $\mathrm{AD}$. This relationship is not present in the right drawing of angula perspective, where the curved line of $\beta$ and $\beta+\alpha$ unsuccessfully demonstrates an inversely proportional relationship to the plane $2 b$ and $b{ }^{26}$ In disregarding this axiom (alike the fifth postulate), Brunellesch was able to represent a measurable world ${ }^{27}$ and a static, fixed perspective system. Wittkower argues that Brunelleschi's measured world stemmed from a desire to explain the phenomenon of buildings diminishing through distance at a constant rate. Whilst the principle of constant diminution was known in the techniques of optics and perspectiva naturalis, Brunelleschi went further, to design a system with mathematical truth that would construct such images, rather than suggesting purely through aesthetics. This signifies how Brunelleschi's premise for linear perspective was architectural in its motivations. ${ }^{28}$
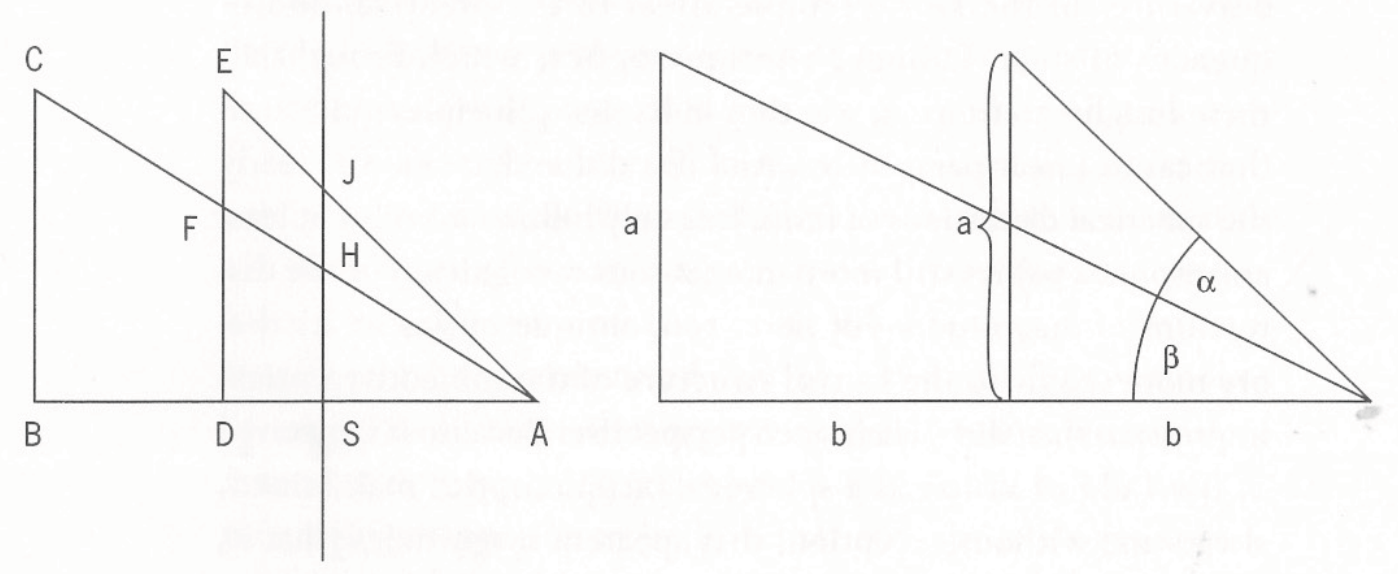

Panofsky's illustration describes the differences between Renaissance linear perspective (left) and Antiquity 'angle perspective' (right). By imagining the eye at the apex of the triangle one can comprehend how the different periods interpreted the intersection of the visual pyramid (planar cross section vs, curved cross section).

Perspective as Symbolic Form, by Erwin Panofsky (New York: Zone Books, 1991) p. 136.

23. Panofsky, 1991, p. 35

24. Ibid, p. 35 .

26. Ibid, p. 36

and Pelletier, 1997, p. 20.

28. Damisch, 1994, pp. 94-95. 


\section{The Inaugural Demonstration}

It is then, no surprise, that Brunelleschi's inaugural demonstration of perspective was concerned with representing Florentine architecture, and that, in order to produce truth, geometry need only be applied to the projection of the building, and not the clouds (Figure 16).

The baptistry demonstration was viewed through a lentil sized aperture on the reverse side of the painting, and was reflected onto a mirror. The distance the mirror should be held from the body to avoid distortion of the visual pyramid is proportional to the distance between where Brunelleschi stood to make the painting and the baptistry. ${ }^{29}$ The aperture, through which the eye viewed the painting, demonstrates Brunelleschi's discovery that the "point of view" (the position of the eye) coincides with the projection of the "vanishing point" (as far as the eye can see) and that these two points are positioned perpendicular to the picture plane, therefore, producing depth on a two dimensional surface (Figure 17). The height of the "point of view" and "vanishing point" correspond to the height of the observer, or "visual pyramid". ${ }^{30}$ What is believed from the baptistry demonstration, is the aperture occurred at the vanishing point of the viewer, if they were standing in the position assumed for the painting, Brunelleschi's demonstration, therefore, achieves truth in a previously unprecedented way. ${ }^{31}$

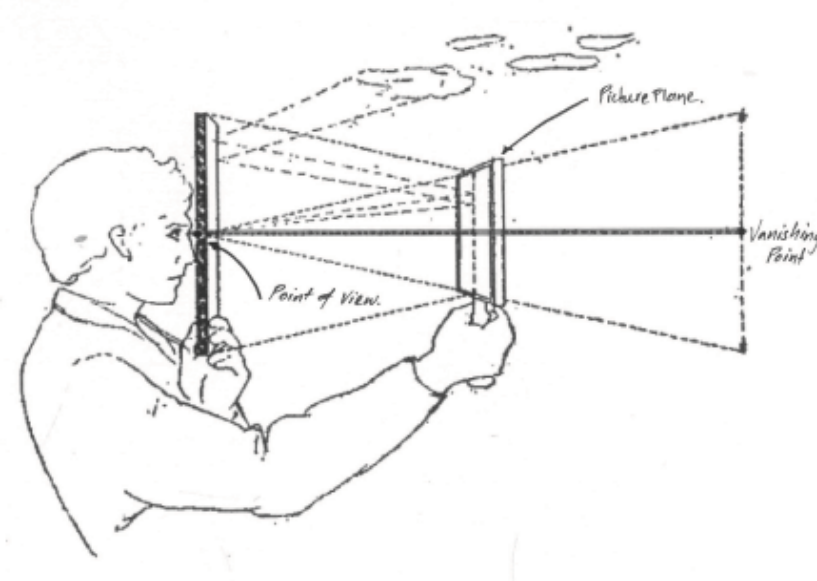

Figure 16-

on of the vanishing point receding into the surface of the picture plane at a perpendicular angle, thus, indicating Brunelleschi's discovery that the "point of view" and "vanishing point" occur on the same axis.

The viewer's visual pyramid is illustrated. Lines of projection from the painted panel reflect onto the mirror. from the drawing surface, but rather from the sky. 'The Grid, The/Cloud/, and The Detail', by Rosalind Krauss, in The Presence of Mies, by Mertins Detlef (New York: Princeton Architectural Press, 1994) p. 132. The drawing demonstrates the clouds are not reflected

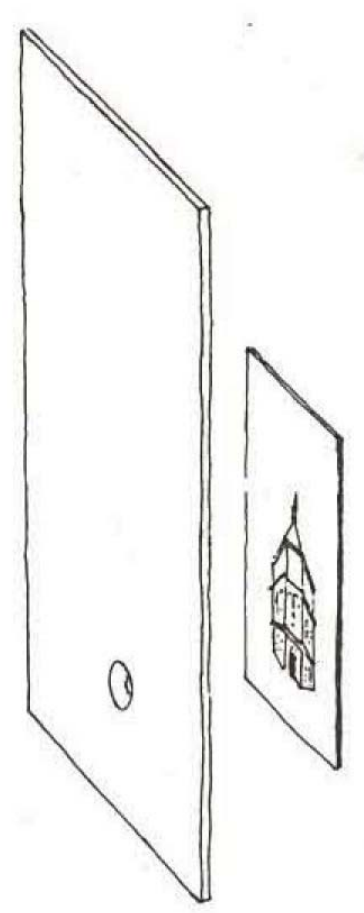

Figure 17-

The two panels highlight the most likely explanation of Brunelleschi's method. The larger panel depicts the baptistry in correct perspective on the side hidden The hole demonstrates where the viewer view the baptistry paintin

Dery Reinhold, 1972) p. 60. 


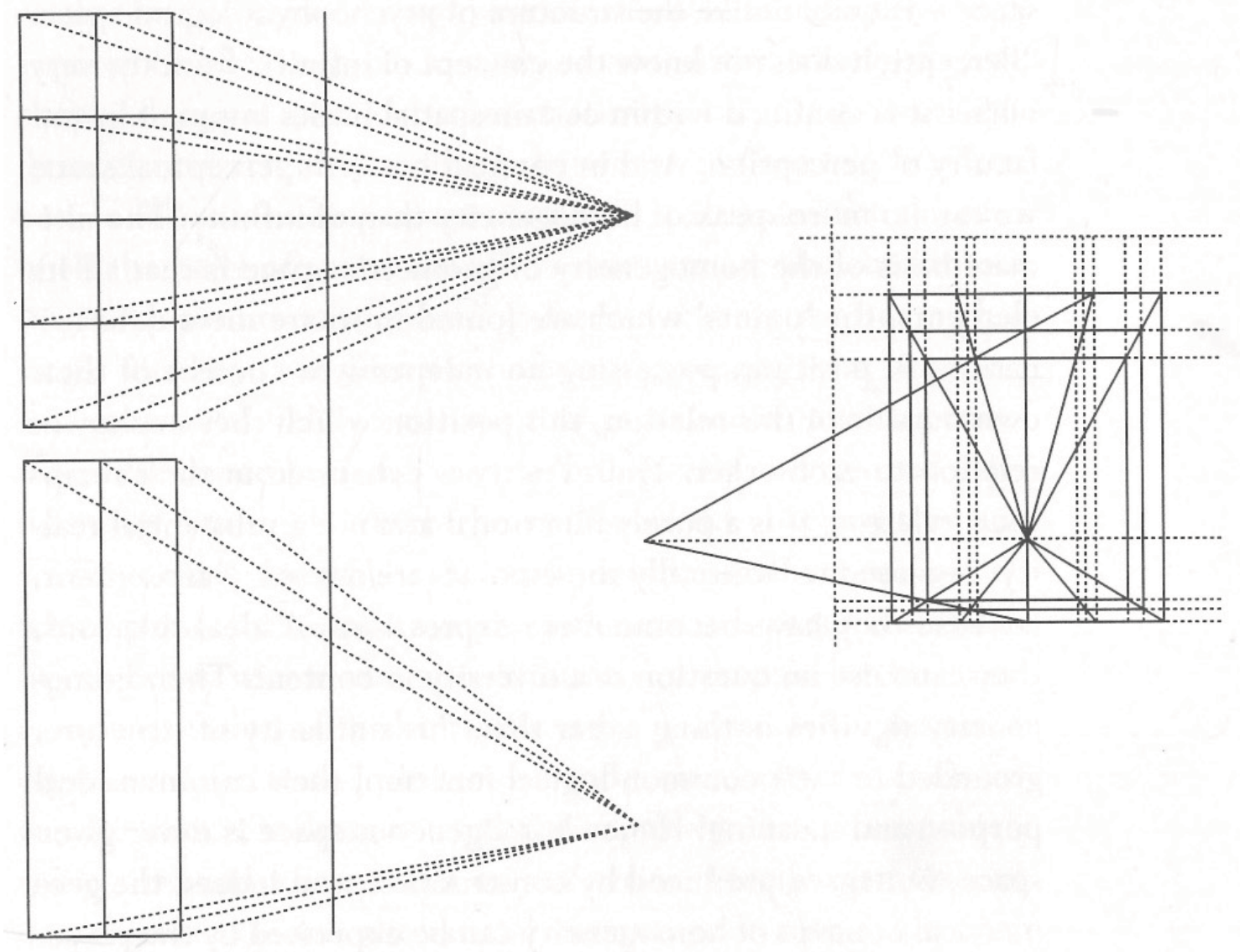

Figure 18-

Modern linear perspective as described by Dürer. The plan is the top left image, the elevation the botton Toden the concept of projection withholds.

Perspective as Symbolic Form, by Erwin Panofsky (New York: Zone Books, 1991) p. 29
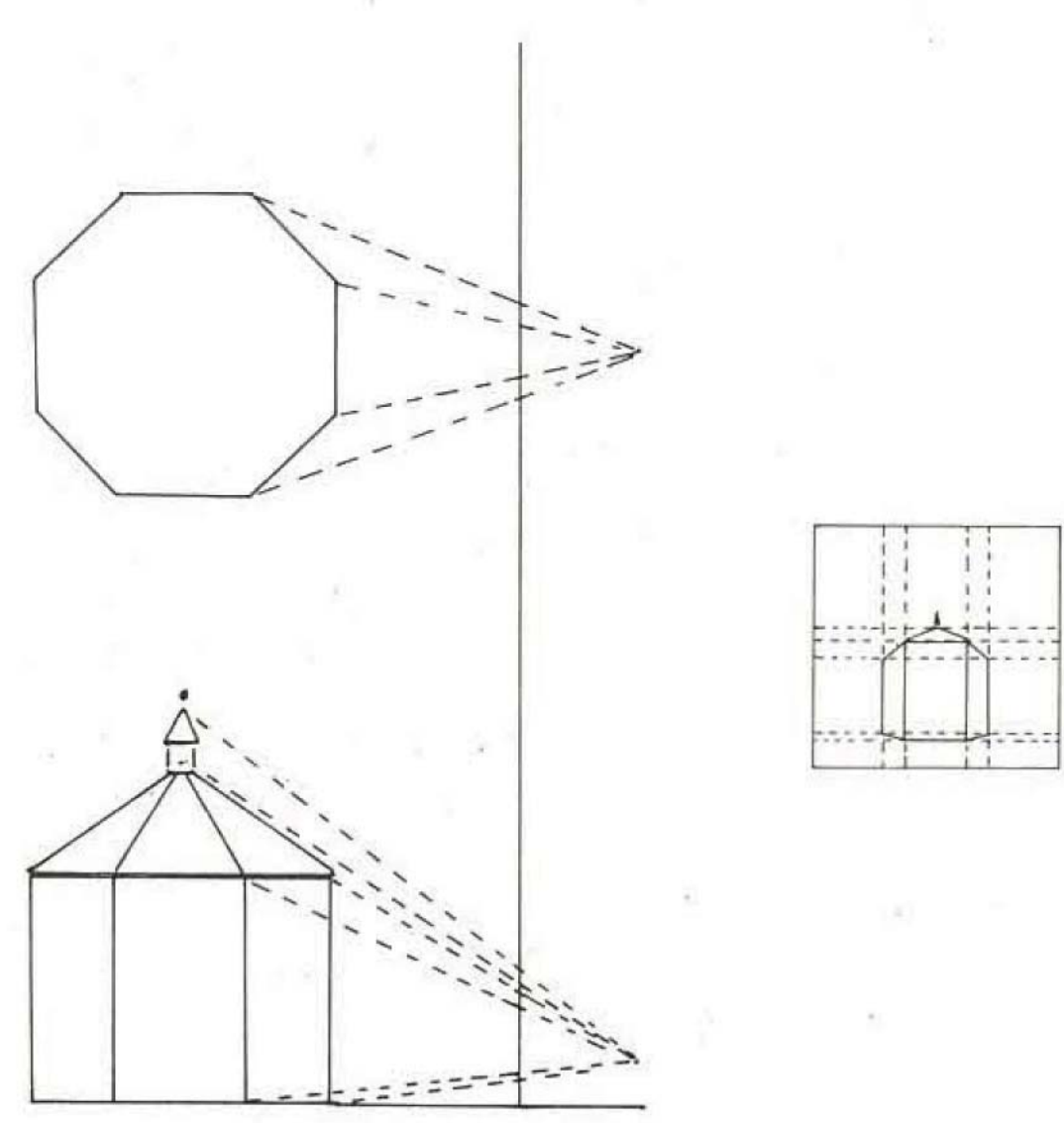

Figure 1

(1)

Perse tive and Other Drawing Systems, by Frank Dubery and John Willats (New York: Van Nostran Reinhold, 1972) p. 61. 
The baptistry demonstration established a relationship between the perspective components that today are essential to perspective construction, through projection of plan and elevation. In Perspective as Symbolic Form, Panofsky cites Dürer's explanation of constructing perspective as a method of modern linear perspective derived through projection. ${ }^{32}$ Dürer's means of construction copied from the discoveries within the baptistry study, referencing the eye at the apex of the visual pyramid ("point of view") and the use of "visual rays" to determine the locality of points. ${ }^{33}$ This system of orthographic projection produces homogeneous, rational and infinite space by abiding to Brunelleschi's assumptions of the planar cross section of the visual pyramid (or Albertian window) and the single immobile eye (the pyramid's apex). ${ }^{3}$ Vasari (who, like Manetti wrote a biography on Brunelleschi), concluded that Brunelleschi was the first to use the system described by Dürer to form the baptistry. ${ }^{35}$ Whilst this could be so, although scholarship usually sides with Manetti, who made no comment on the use of the orthographic set ${ }^{36}$ and was said to have seen the demonstration himself. ${ }^{37}$ This conflict of thought highlights the incompatibility that occurs between Vasari's text and Manetti's, ${ }^{38}$ subsequently offering evidence as to why the background to Brunelleschi's discovery is speculative. Damisch wholly disregards Vasari's text, with regards to the baptistry, claiming it was only a way to fill the gap of previous manuscripts, albeit written a century and a half after completion of the painting. ${ }^{39}$ Consequently, in later decades, Piero della Francesca is commonly referred to as the first to engage with orthographic projection as a means of constructing perspective. ${ }^{40}$ His projection technique, however, varied greatly with that described by Dürer.

What orthographic projection demonstrated was a method of controlling the perspective constructio whilst remaining dependent on the stable and fixed eye of Brunelleschi. Whilst Brunelleschi's perspective may have been produced through the orthographic set, it has since become a plausible method for reproducing the study.

32. Panofsky, 1991, p. 29

33. Ibid, p. 28.

35. Damisch, 1994, p. 93

36. lbid, p. 93.

37. Manetti, 1970, p. 44.

39.

40. Evans, 1995, p. 151

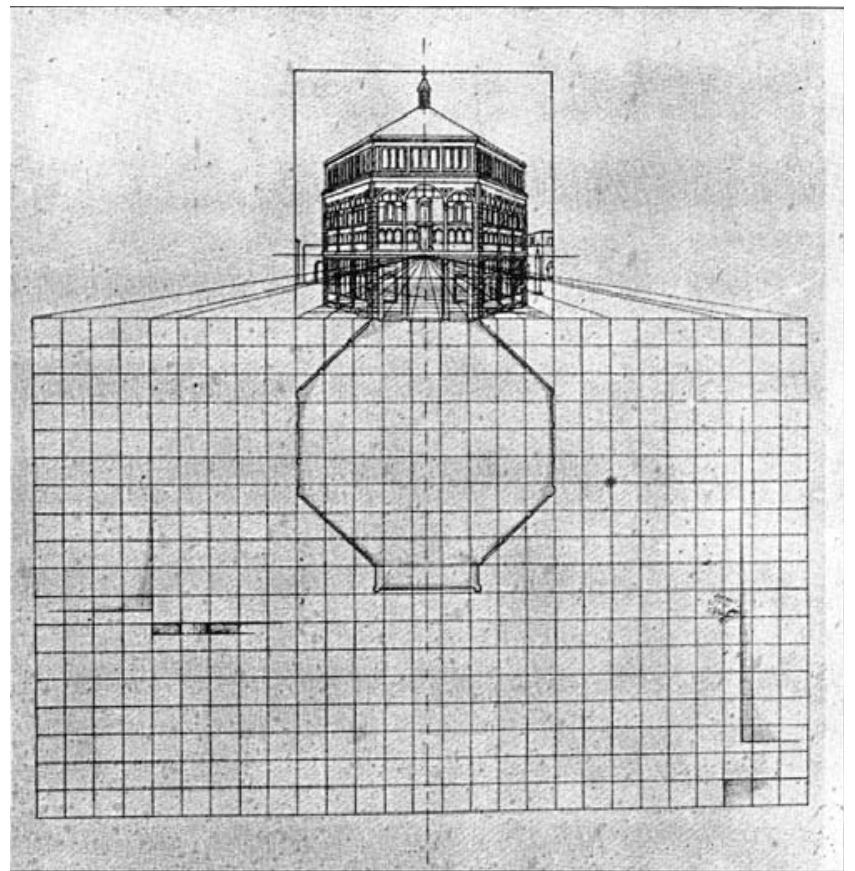

The Tavoletta San Giovanni

Figure 20-

A later demonstration of Brunelleschi's baptistry through orthographic projection

A. Parronchi, Studi su la dolce prospettiva, fig 90. Photo: Bibliotheque Nationale, Paris. In The Origin of Perspective, by Hubert Damisch (Cambridge, Massachusetts: MIT Press, 1994) p. 110. 


\section{The Vanishing Point}

The system of orthographic projection throughout Dürer's description depends on the vanishing point. It is the vanishing point, first attributed to Brunelleschi, which remains an intangible, yet necessary component of the perspective drawing.

For Brunelleschi's perspective it was fundamental to disregard Euclid's optics to find a central vanishing point and explain systematic space. In opposition, Piero's 'Other Method', which was implemented when regular linear perspective had failed ${ }^{41}$ utilized no definitive vanishing point and was based on projection from plan and elevation, Piero proclaiming the drawn perspective to be formed the same way as architecture. ${ }^{42}$ Piero's perspective, similarly to Dürer's, was built through sight lines taken from the eye indicated on the orthogonal drawings. Where lines would intersect between plan and elevation coordinates would be formed for the perspective (Piero's system of plotting being much like Dürer's later Method of Drawing a Lute). ${ }^{43}$ Whilst such a system of reducing an image to dots and co-ordinates was declared as abstracting from reality it seems more rational than relying on an intangible, and arbitrarily selected, vanishing point. ${ }^{44}$

Alberti (who codified the perspective of Brunelleschi), in presenting an argument for natural vision, claimed natural optics occurred at the core of perspectiva artificialis. However, in disregarding two of Euclid's postulates, (which aim to explain natural vision) both Alberti and Brunelleschi fail to implement natural optics within their perspective constructions. ${ }^{45}$ Alternatively, Piero treated Euclid's optics as $\mathrm{fact}^{46}$, presenting what was understood to be a more natural representation. Despite the 'Other Method' being both repeatable and rational, Piero's achievement had little impact on Renaissance painting with his system being 'Condemned to inconsequence ${ }^{47}$ and erased from a progressive history of representation of which Piero's method was deemed to fail at developing. ${ }^{48}$ Perhaps his exclusion of the vanishing point was understood, scientifically, as a step back to more primitive methods.

41. Evans, 1995, p. 149.
42. Ibid, p. 151.

43. lbid, pp. 150-15

44. Ibid, p. 151

55.J. V. Field Piero della Francesca's Perspective Treatise', in The Treatise on Perspective, ed. By Lyle Massey, Washington DC:

National Gallery of Art, 2003

47. Evans, 1995, p. 158

48. lbid, p. 158
Piero's method offers the cultural context for situating Brunelleschi as the father of systematic space. The knowledge of other approaches toward systematic perspective offer insight that the Renaissance was not defined by a singular axiom. ${ }^{49}$ Piero's 'Other Method', on its own, offers evidence to position perspective as a plural discipline with not one correct formula ${ }^{50}$ whilst demonstrating that the vanishing point is not a necessary component to produce a rational representation of space.

The origin of perspectiva artificialis as neither a singular nor correct method, warrants and foreshadows a re-consideration of perspective today, particularly within a digital context. Brunelleschi's perspective, disregarding natural optics, is focused on the intangible notion of the vanishing point, and is not the sole way of describing rational space in three dimensions. It is however, the perspective method coded into computer software. Linear perspective is a method of representation that is flawed, because it fails to represent true vision, and because it misleads one to believe they are seeing true vision. The digital perspective (by adhering to Brunelleschi's rule) wipes clean its limitations, competing methods and contradictions.

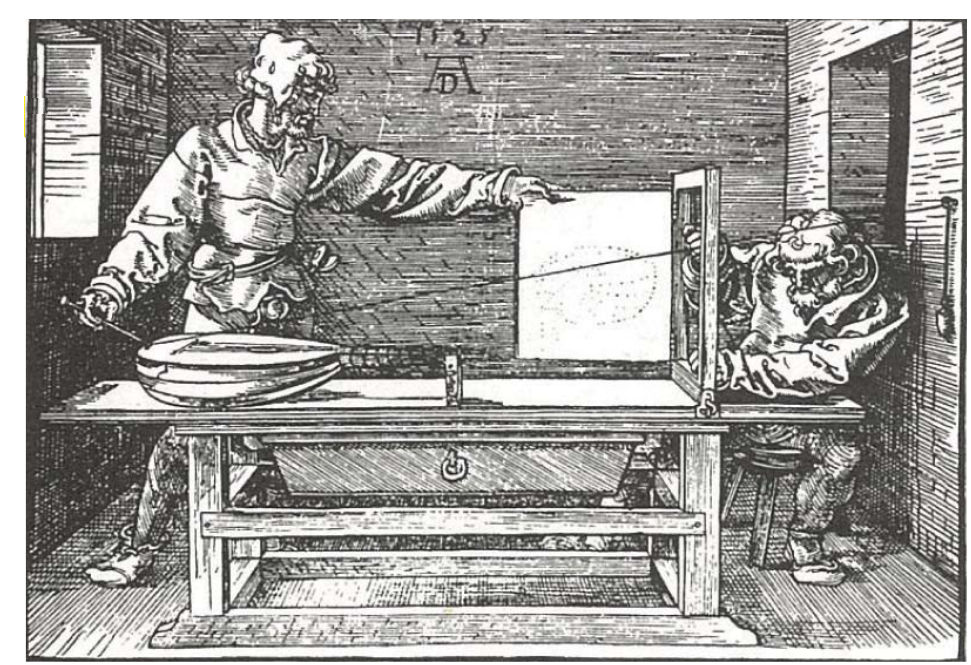

Method of Drawing a Lute

One of Dürer's four woodcuts published in 1525. This woodcut demonstrates the string as the observer's visual pyramid, fixed at the wall to the point of the assumed eye. The string is pulled to reference points on the lute, which are recorded on the drawing through their horizontal and vertical coordinates then plotted on the drawing surface. The coordinates are later joined up to form the perspective image. Albrecht Dürer, Method of Drawing a Lute, 1525, in Perspective and Other Drawing 49. Ekkins, 1992, p. 211. Systems, by Frank Dubery and John Willats 


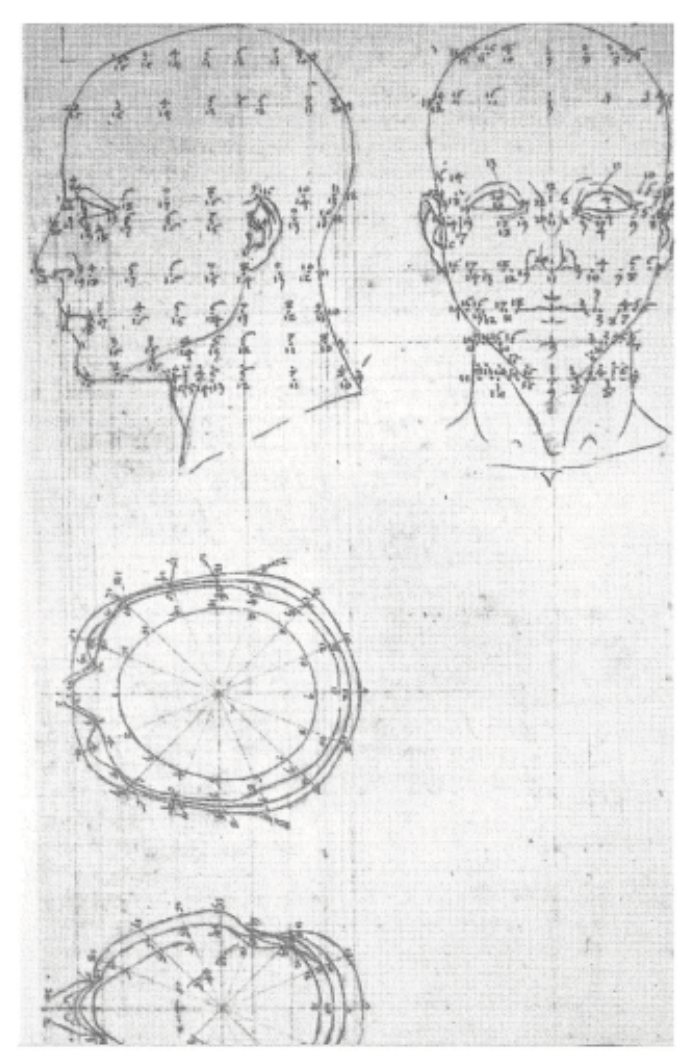

'The Other Method'

\section{Figure 22-}

Piero's method of perspective constructed without reference to a definitive vanishing point. The human head is drawn in plan, front and side elevations. The coordinates are used as a means of breaking the complex geometry into a methodical grid. Piero della Francesca, before 1482, in Architectural RepGómez and Louise Pelletier (Cambridge, Massachusetts: MIT Press, 1997) p. 38.

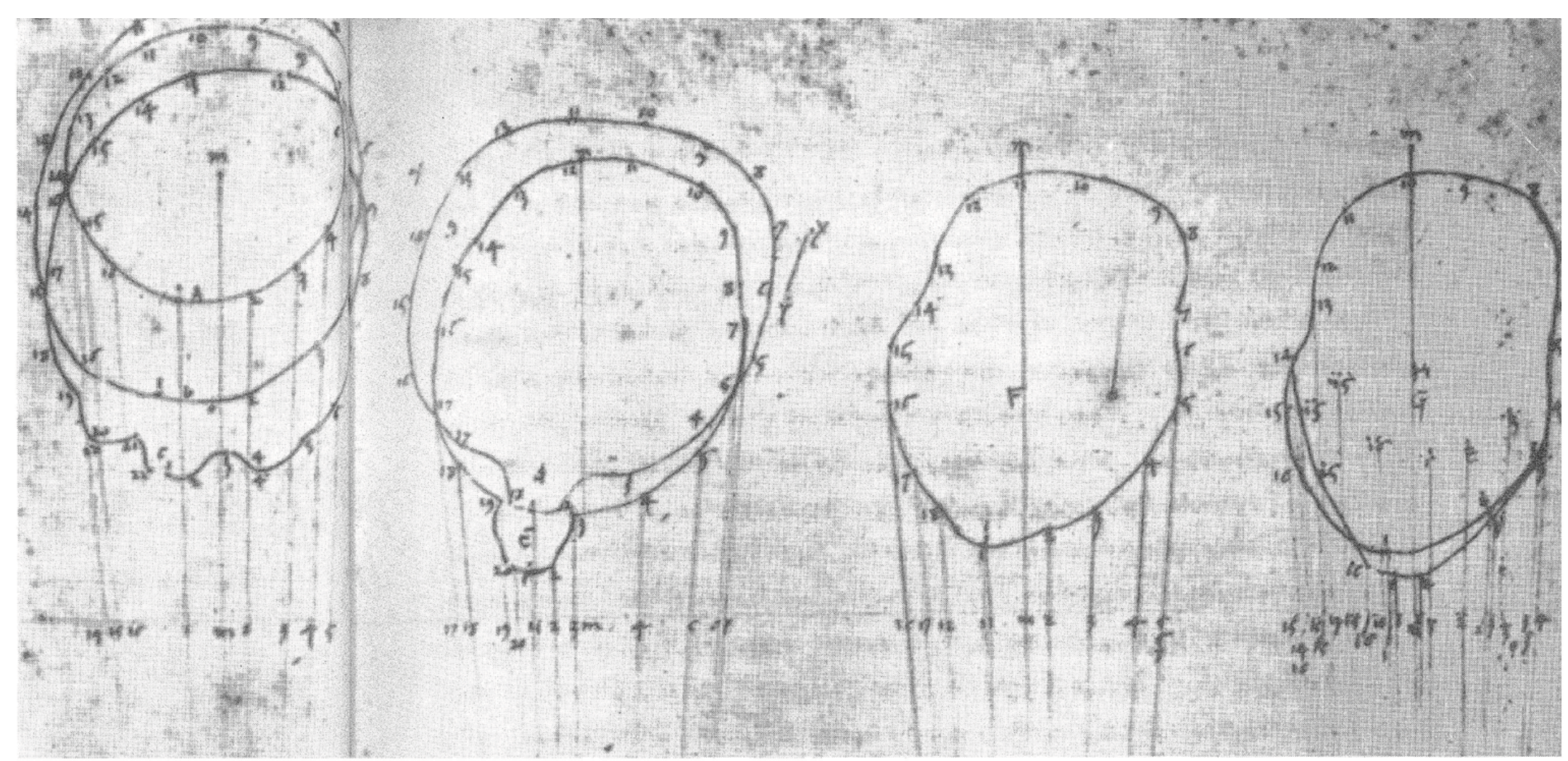

Figure 23-

drawing a lute.

Alberto Pérez- Gómez and Louise Pelletier, 1997, pp. 38-39. 



\section{The 'Mechanical Eye'}




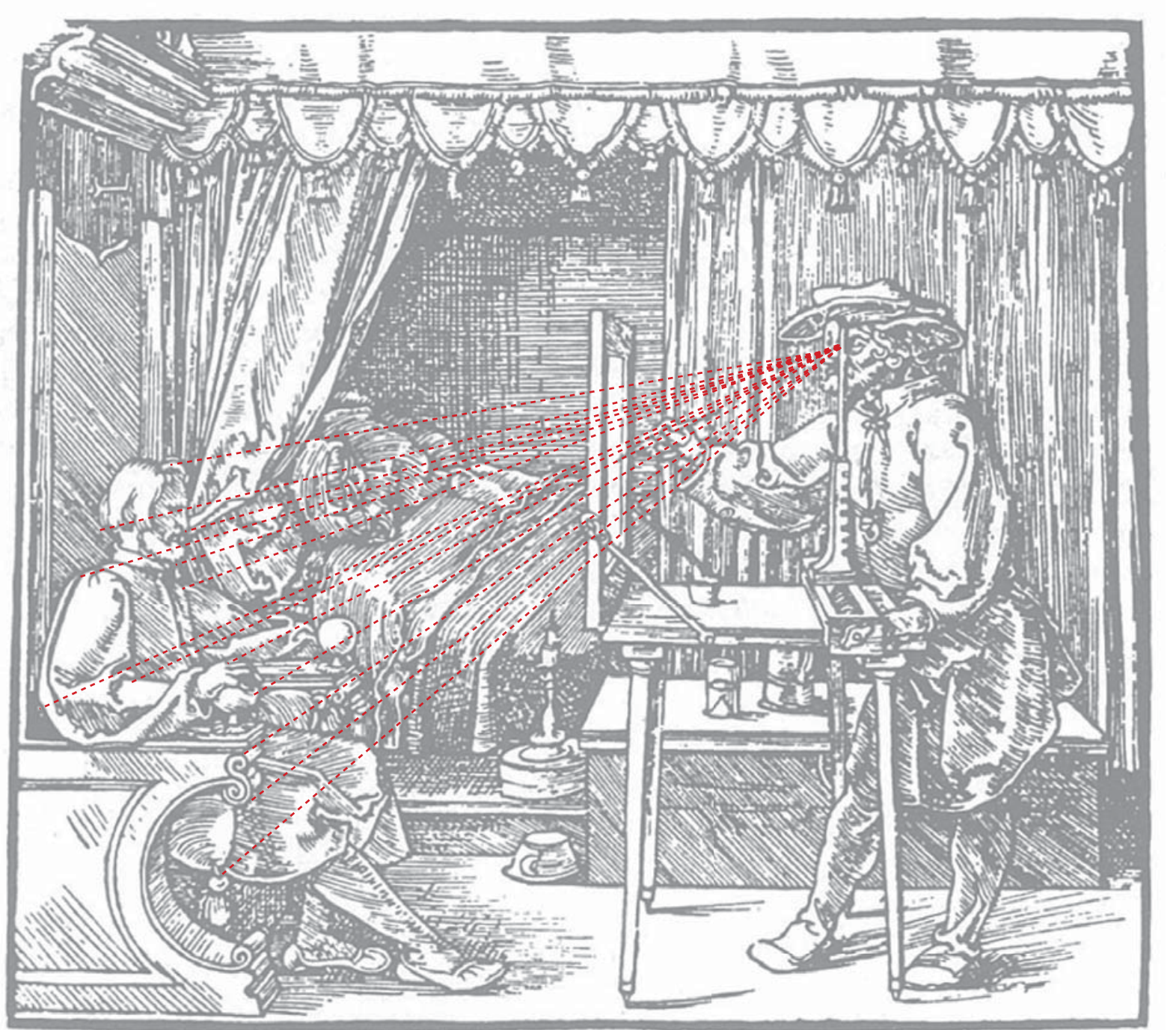

Method of Drawing a Portrait

Figure 24-

Demonstration of an artist drawing a portrait of a man onto a glass surface. The artist is looking through the sight-vane at his model and

painting what he sees directly onto the picture plane. The illustration demonstrates that the eye is fixed at a single point, demonstrating the artist's visual pyramid.

Albrecht Dürer, Method of Drawing a Portrait, 1525, in Perspective and Other Drawing Systems, by Frank Dubery and John Willats (New York: Van Nostrand Reinhold, 1972) p. 68. 
While Brunelleschi wrote the script for a singular interpretation of a stable and fixed view of the world, his methodology is in contradiction to how we see. The Renaissance was marked by this desire to represent the world through systematic vision, a concern not shared by the Ancients and Medievals. ${ }^{52}$ The rules which govern Brunelleschi's perspective subscribe to drawing that is 'fully rational- that is, infinite, unchanging and homogeneous- space. ${ }^{53}$ However, to insure rationality, two assumptions are made in Brunelleschi's construction. First, that one sees not with two eyes, but a single and unmoving eye. And secondly, that the visual pyramid, intercepted by a planar cross section, adequately represents ones true vision. ${ }^{54}$ Moreover, the limitations of Brunelleschi's rational space met their demise in his baptistry demonstration, where geometry failed to represent the sky, which is both transitory and outside the field of geometry.

Today, perspectival representation follows the rule of Brunelleschi, despite this being both an arbitrary and erroneous representation of the retinal image. ${ }^{55}$ Contemporary representational images are chosen by artists, architects and photographers, and with the exception of artists, still based on the rhetoric of linear perspective. ${ }^{56}$ Gyorgy Kepes writes 'Visual images are tools for this progressive control of nature. ${ }^{57}$ And whilst this is true for pre-Renaissance and Renaissance methods, architectural representation has lain largely static since the fifteenth century.

This chapter describes the strategies which are later implemented in the design work of Chapter 4. This work uncovers the paradoxes behind the codification of artificial perspective, particularly questioning the single immobile eye, and the fixed perspective image. For these purposes the scholarship of Erwin Panofsky will be utilised, for he argues linear perspective is limited, due to its representation of space through a mathematical construct, whilst our inhabitation of space is psychophysiological. The consequences of mathematical space are demonstrated in the two examples (both of which can be compared to mechanisms for vision), Samuel van Hoogstraten's, Peepshow box, and Penelope Haralambidou's installation, The Act of Looking.

52. Pérez- Gómez and Pelletier, 1997, p. 12

53. Panofsky, 1991, pp. 28-29.

54. Ibid, p. 29 .
55. Damisch, 1994, p. 6 .

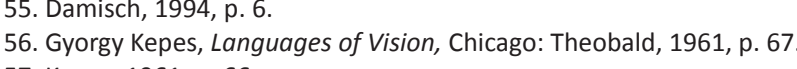

The single immobile eye is clearly articulated in Brunelleschi's baptistry study. The painting, with a small aperture drilled into it, determined where the viewer places the eye, through which a reflection of the painting is viewed. Manetti describes how it was necessary for Brunelleschi to decide on the single point of view for the observer before commencing the painting. This was so there would be no error in the translation from natural vision to representation, a changing point of view manipulating the shape of what is seen. ${ }^{58}$ The reason for monocular vision has been credited to Brunelleschi's earlier survey drawings which relied on equipment that took readings through monocular observation. ${ }^{59}$ Following Brunelleschi in the High Renaissance, Leonardo da Vinci expressed concern in reducing vision to the single eye, particularly demonstrating doubt in Brunelleschi's decision to restrict the spectator to point (or in the baptistry, a hole). ${ }^{60}$ Leonardo also argued against describing vision entirely through geometry. However, such criticism represented a step backward to more primitive methods than what was understood through the science of the era. ${ }^{61}$ Therefore, later experiments or demonstrations remained true to Brunelleschi's single and still eye.

Dürer's woodcut from 1525, Method of Drawing a Portrait, demonstrates an empirical method of drawing perspective, dependent upon a sight-vane to restrict the periphery vision and movement of the artist's eye. Dürer looks through the sight-vane at his subject, painting the perspective onto Alberti's metaphorical window, ${ }^{62}$ an arm span from the looking device. Thus, Dürer's sight-vane is controlling vision in the same way as Brunelleschi's lentil sized hole.$^{63}$ The philosophical implications of restricting vision to a single, immobile eye, as explained by Panofsky, fail to take into account the difference between the "visual image" which is psychologically conditioned from everyday vision into ones consciousness and the "retinal image", that which is physically painted onto the surface of the eye. Linear perspective adopts mathematical and geometrical principles in its description of the eye, attempting to demonstrate the "retinal image". However, due to perspective being formed on a planar surface, and the "retinal image" forming on the curved retina, the "retinal image" is fundamentally opposed to natural vision. Therefore, by restricting vision to a planar surface, linear perspective becomes

58. Manetti, 1970, pp. 42-44 59. Penelope Haralambidou, 'The Stereoscopic Veil', in Architecture Research Quarterly, v. 11, i. 1, 2007, p. 39

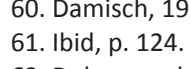

62. Dubery and Willats, 1972, pp. 68-69.

63. Manetti, 1970, p. 44. 
misleading to natural vision, meaning, at the pre-psychological level, that the facts which define linear perspective demonstrate a discrepancy between that which is really seen and its representation. ${ }^{64}$

In contrast to the Renaissance, those in Antiquity intersected the visual pyramid with a curved surface to replicate the curvature of the retina. Interpreting the cross section of the visual pyramid this way failed to produce the systematic image of the Renaissance, as the Antique mode of representation with its "projection circle", was incapable of constantly diminishing widths, depths and heights (Figure 15). ${ }^{65}$ Antiquities approach was true to optics, failing to take the step Brunelleschi did of disregarding the fifth axiom. Whilst the Antique view of the world, in hindsight, is seen to be un-modern, ${ }^{66}$ to some extent it is truer than the Renaissance perspective of Brunelleschi and Alberti, as it was far more concerned with how one actually sees than a mathematical representation of vision. It has already been shown that linear perspective can be described as both erroneous and arbitrary, as the image based on planar projection is not the image which reaches the back of the eye. ${ }^{67}$ Antiquities representation of vision, however attempted to reproduce vision correctly. What these two periods highlight is the fundamental difference between symbolic representation and 'truthful' representation, as mathematics and science granted the Renaissance the impression of truth. ${ }^{68}$ Ernst Cassirer, in The Philosophy of Symbolic Forms, describes the implications of mathematics on vision and how mathematical space is outside of human perception Cassirer introduces the 'real space' of one's perception, the space one occupies with full use of thei senses and how this space is adverse to geometric space. Euclidean space is defined by three constants, continuity, uniformity and infinity. Perception, Cassirer writes, does not know infinity nor does it know homogeneity, however these two concepts define modern perspective. Floating points define geometric space. Where points are dependent on their relationships to one another in terms of magnitude and distance, it is a functional relationship for the making of pictures, but not for seeing. Cassirer confirms that the space of points defined by such magnitudes and distances does not exist in the world of perception. ${ }^{69}$ Panofsky takes from Cassirer that;

Exact perspectival construction is a systematic abstraction from the structure of this psychophysiological space. For it is not only the effect of perspectival construction, but indeed its

64. Panofsky, 1991, p. 31

65. bidid, p. 40 . 43

67. Damisch, 1994, p. 6.

de different to how one sees Was made as early as Euclid's optics where he wrote t t a person experienced did not always coincide with what he or she saw.' Pérez-Gómez and Pelletier, 1997, p. 13. 83-84. intended purpose, to realize in the representation of space precisely that homogeneity and boundlessness foreign to the direct experience of that space. In a sense, perspective transforms psychophysiological space into mathematical space. ${ }^{70}$

These assumptions are not only problematic in that they transform "psychophysiological space into mathematical space. ${ }^{, 71}$ For Brunelleschi, they represent that which is solid, fixed and rational, and not that which is temporary. It is for these reasons that Brunelleschi met the limits of linear perspective in his founding demonstration through his representation of the sky, which is temporary. Rather than drawing clouds in projection, Brunelleschi applied burnished silver to the space where the sky would be painted, he actual sky reflected onto the picture surface, with the clouds seen to move and be momentary, as they are in reality. ${ }^{72}$ The demonstration illustrated that the perspective construct is limited to drawing objects which are fixed and static, able to be conceived in a split second through a single eye, whilst it is unable o capture that which is not. Brunelleschi's representation of the sky was, therefore, more akin to earlier methods of perspective and representations of psychophysiological space, such as the true optical impression of Antiquity. By not subjecting the sky to the same geometry as the baptistry, Brunelleschi achieved a more convincing truth for his viewers, while consequently demonstrating his awareness of the limitations of his codified system. 


\section{Imposing Perspective}

Since Brunelleschi's founding demonstration, the geometry of mathematical perspective has been 'imposed on vision'. ${ }^{73}$ Initially designed as a method for vision control, articulated in the aperture of Brunelleschi's panel, linear perspective now controls how one 'sees'. Today, few understand curvature as those in Antiquity, understandably this is due to habituation, the photograph reinforcing what the linear perspective showed. Through the modern mediums of films, video and computer imagery the perspective has become even more persuasive. ${ }^{74}$

The construction of linear perspective demonstrates that which is specifically for a modern understanding of space and perhaps even a sense of the world. ${ }^{75}$ The camera and photographic image have eternally changed the objective gaze of the viewer, and re-instated mathematical perspective as correct. The camer was modelled from the camera obscura, ${ }^{76}$ which was in turn modelled by the principle of Brunelleschi' description of perspective. The single still eye, replicated through the cameras 'analogous operation'. ${ }^{77}$ The perspective drawing, despite informing the cameras construction 'lost its claim to optica verisimilitude to the supposedly more objective gaze of the camera. ${ }^{.78}$ However, "The lens itself, which had been carefully corrected for "distortions" and adjusted for "errors", is scarcely as objective as it seems, ${ }^{79}$ The camera changed the representational image, and thus gave one a "new standard of vision'.

The implications of such habits mean there is a loss in the understanding of the geometry required to construct three dimensional spaces, as well as the limitations within such constructions. Through such devices our psychophysiological impression of space is translated into a mathematical description.

73. Evans, 1995, pp. 125-126.

74. Brian Mc Grath and Jean Gardner, Cinemetrics: Architectural Drawing Today, London: Wiley-Academy, 2007, p. 19.

75. Panofsky, 1991, p. 34.

and Pelletier, 1997, p. 5

77. Panofsky, 1991, p. 31

78. Jeffery Kipnis, Perfect acts of Architecture, New York: Museum of Modern Art, 2001, p. 9 .

79. Hubert Damisch, Notes for a Phenomenology of the Photographic Image', in Classic Essays on Photography, ed. By Ala

80. Kepes, 1961, p. 67. 


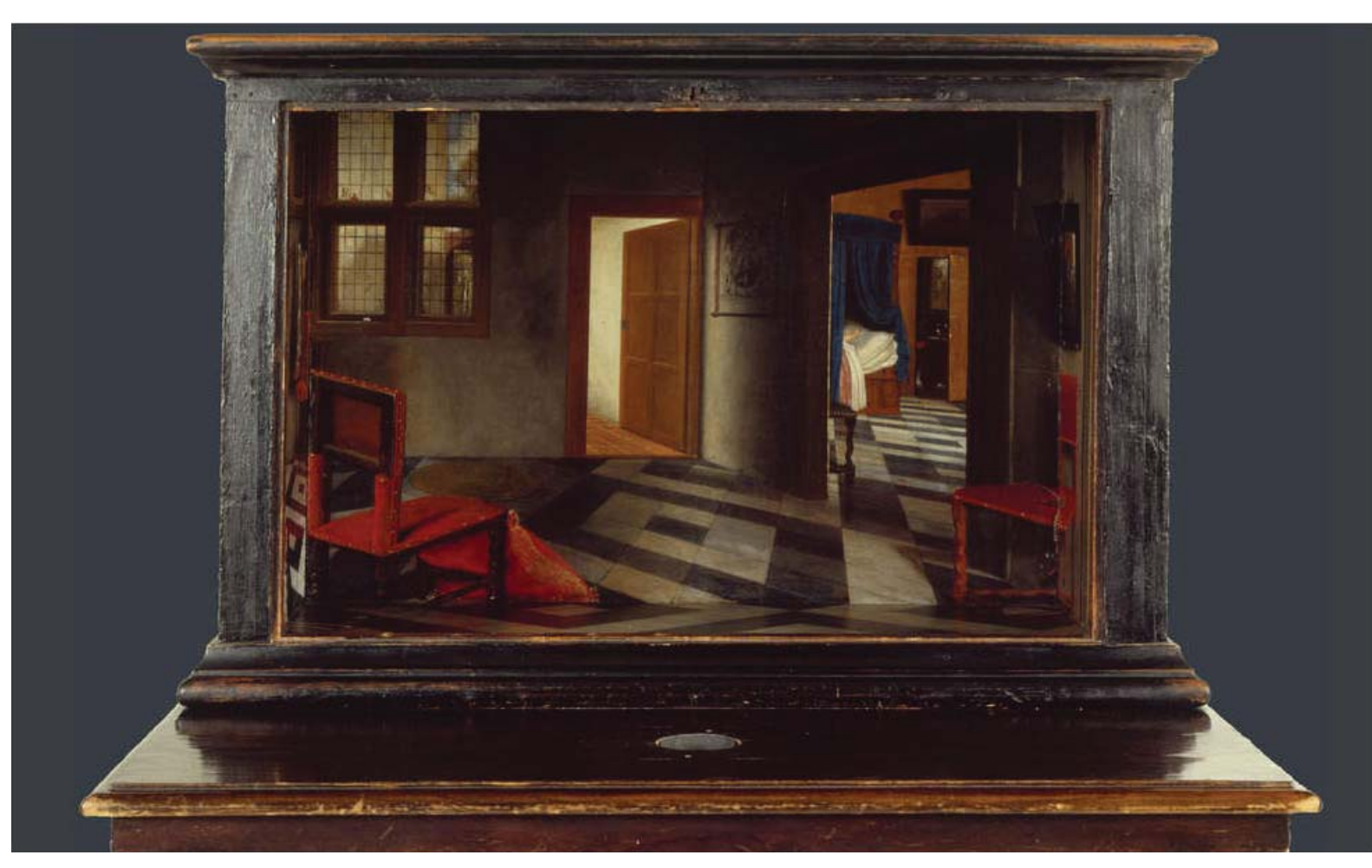

Peepshow

Figure 25-

Photograph looking into Peepshow from a longitudinal plane. Because the Peepshow is not being viewed from its prescribed peep-hole

objects within the space appear anamorphic to the eye, whilst others appear in correct perspective projection.

Samuel van Hoogstarten, A Peepshow with Views of the Interior of a Dutch House, 1655-60. The National Gallery

http://www.nationalgallery.org.uk/paintings/samuel-van-hoogstraten-a-peepshow-with-views-of-the-interior-of-a-dutch-house.
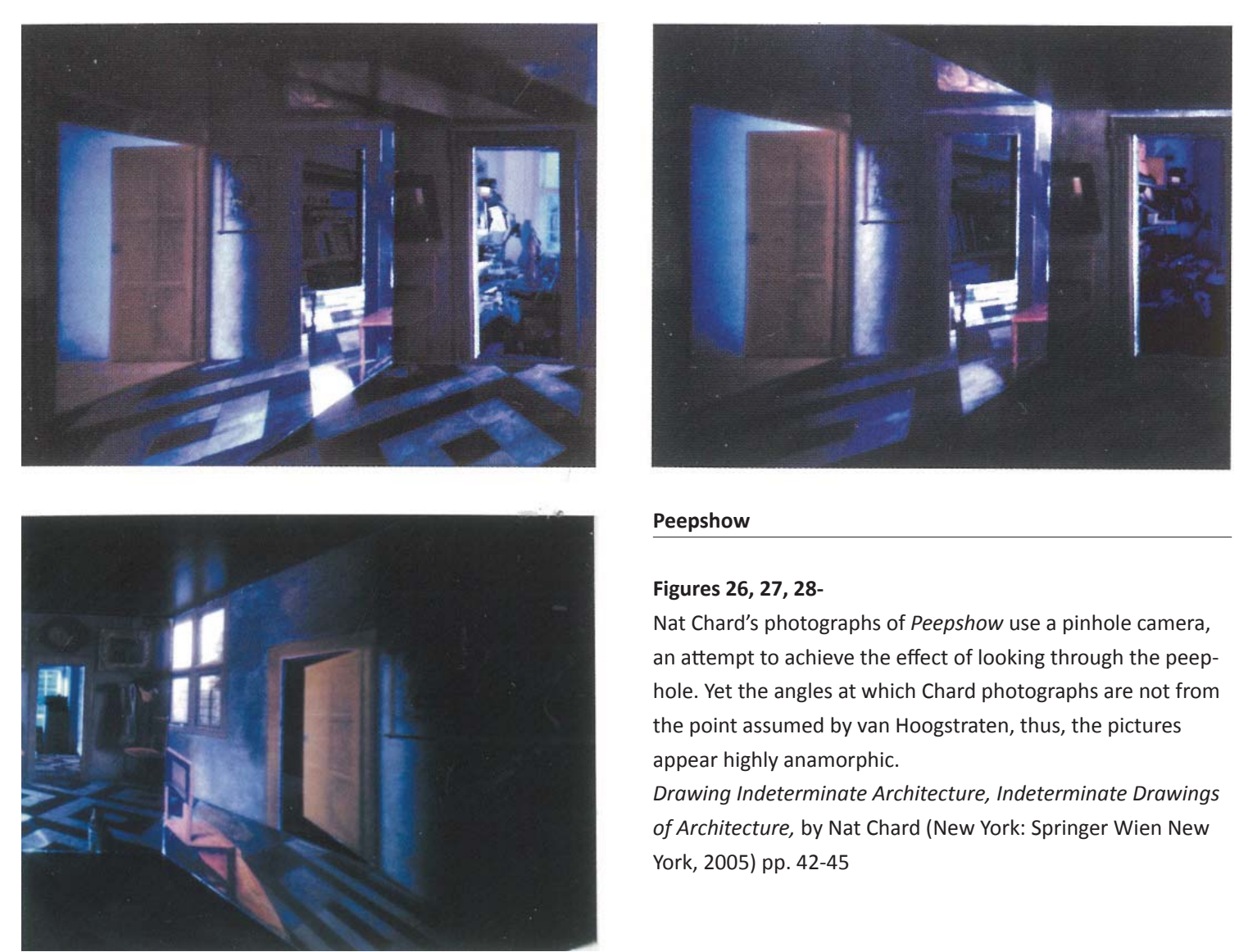

Figures 26, 27, 28-

an attempt to achieve the effect of looking through the peep-

hole. Yet the angles at which Chard photographs are not from

the point assumed by van Hoogstraten, thus, the pictures

appear highly anamorphic.

Drawing Indeterminate Architecture, Indeterminate Drawings

of Architecture, by Nat Chard (New York: Springer Wien New vork, 2005) pp. 42-45 


\section{A Study in Voyeurism}

The two case studies discuss the implications of Brunelleschi's assumptions in the work of other practitioners, demonstrating how perspectives' limits are rectified when a drawing is taken into three dimensions and becomes a commentary on the viewing of perspective. The first example, Samuel van Hoogstraten's, Peepshow box, made in the seventeenth century, exploits the notion of anamorphosis, in order to produce a fixed view of the world. The second study is Penelope Haralambidou's, The Act of Looking, modelled from Duchamp's installation, Given. Haralambidou re-reads Cartesian space through the voyeuristic guise of Duchamp, engaging with the act of viewing perspective images, the eye within the sight-vane.

\section{Peepshow}

Van Hoogstraten's Peepshow cabinet was a seventeenth century experiment in viewing perspective Tutored by Rembrandt and influenced by other Netherlander masters, van Hoogstraten found a unique approach to perspective construction. ${ }^{81}$ Rather than painting the perspectival view onto a planar surface, van Hoogstraten projected the view onto five flat planes which would form a box open at one end. The three sides, ceiling and floor were painted with projections of a Dutch house interior, the remaining side, covered in transparent paper or fabric penetrated by the light of a window or candle. Two peep-holes were placed on the shorter sides of the box, and provided the viewer with entrance into the interior. ${ }^{82}$ For van Hoogstraten to achieve Brunelleschi's fixed view of the world he needed to adopt principles of anamorphosis, a method of perspective concerned with extending the visual limits of usual projection. Anamorphosis means the artist must produce images which appear highly distorted perpendicularly, but correct $^{83}$ when viewed obliquely and monocularly. ${ }^{84}$ Therefore, the Peepshow panels were a combination of correct perspective and anamorphic projection ${ }^{85}$ in order to produce the fixed and stable world when viewed through the peep-hole, and thus proving the limits perspective needs to be pushed for Brunelleschi's view.

81. Jeffery Edwards and George Whale, 'Defining an Alternative Picture Space', in Digital Creativity, v. 15, i. 3, 2004, p. 136. 82. The National Gallery, 'A Peepshow with Views of the Interior of a Dutch House',

hittp://www.nationalgallery.org.uk/paintings/samuel-van-hoogstraten-a-peepshow-with-views-of-the-interior-of-a-dutch-house 83. Correct referring to a geometrically sound construction of perspective, that, which is 'mathematically' correct.

84. Edwards and
85. Ibid, p. 136 .
Within Peepshow the aperture is placed at the fixed point '...exactly with the centre of projection... ${ }^{86}$, following the rule of Brunelleschi that "point of view" and "vanishing point" are on the same perpendicular plane. The viewer is introduced to the one perfect view, the 'eye of god' into the space, both artist and viewer demonstrating explicit control over the image on the retina. Van Hoogstraten's approach was persuasive, yet depended on essential assumptions made within the construction and viewing of linear perspective, principally, the single immobile eye. ${ }^{87}$ The picture needing to be viewed from the peep-hole with the looking eye motionless and the 'other' eye closed ${ }^{88}$ Whilst Peepshow works as an apparatus for the way one should see perspectivally, its construction forgets that in life 'we see not with a single fixed eye but with two constantly moving eyes ... ${ }^{89}$ Nelson Goodman, in Languages of Art, argues for the necessity of scanning, describing the eye as not seeing normally without peripheral vision to shows what is relative. ${ }^{90}$ Under these circumstances, the immobile eye sees almost as little as the blind ey $\mathrm{e}^{91}$ and that which is seen, is carefully controlled and rationalized. The static eye, also present in the demonstrations of Brunelleschi and Dürer, once more describes space through mathematics, limiting active seeing and a psychophysiological understanding of space.

Peepshow depended on the single and immobile eye, combined with the aperture which reveals the scene; it can be compared to the camera obscura. Penelope Haralambidou's The Act of Looking was derived from the notion of the 'other eye' and binocular vision, introducing a new visual understanding ${ }^{92}$ based on the stereoscope, a device which attempted to abolish the truth of the camera obscura, ${ }^{93}$ Peepshow and the Act of Looking are fundamentally different demonstrations. Completed to supplement her $2007 \mathrm{PhD}$, The Blossoming of Perspective, The Act of Looking is a response to binocular vision, rejecting 'normal' linear perspective for a form of representation that better suits natural vision.

86. Evans, 1995, p. 126.
87. Panofkky,1991, p. 29.

88. Nelson Goodman, Languages of Art: An approach to a theory of Symbols, Indianapolis: Bobbs- Merrill, 1968, p. 12. 90. Goodman, 1968, pp. 12-13.

91. Ibid, pp. 12-13.

92. Penelope Haralambidou, 'Given: The Corridor, the Tower and the Fall...', 2007,

tttp://www.domobaal com/resources/penelopeharalambidou/penelope-haralambidou-essay-domobaal. pdf, p. 6 3. Jonathon Crary, Techniques of the Observer: On Vision and Modernity in the Nineteenth Century, Cambridge Massachusetts, 

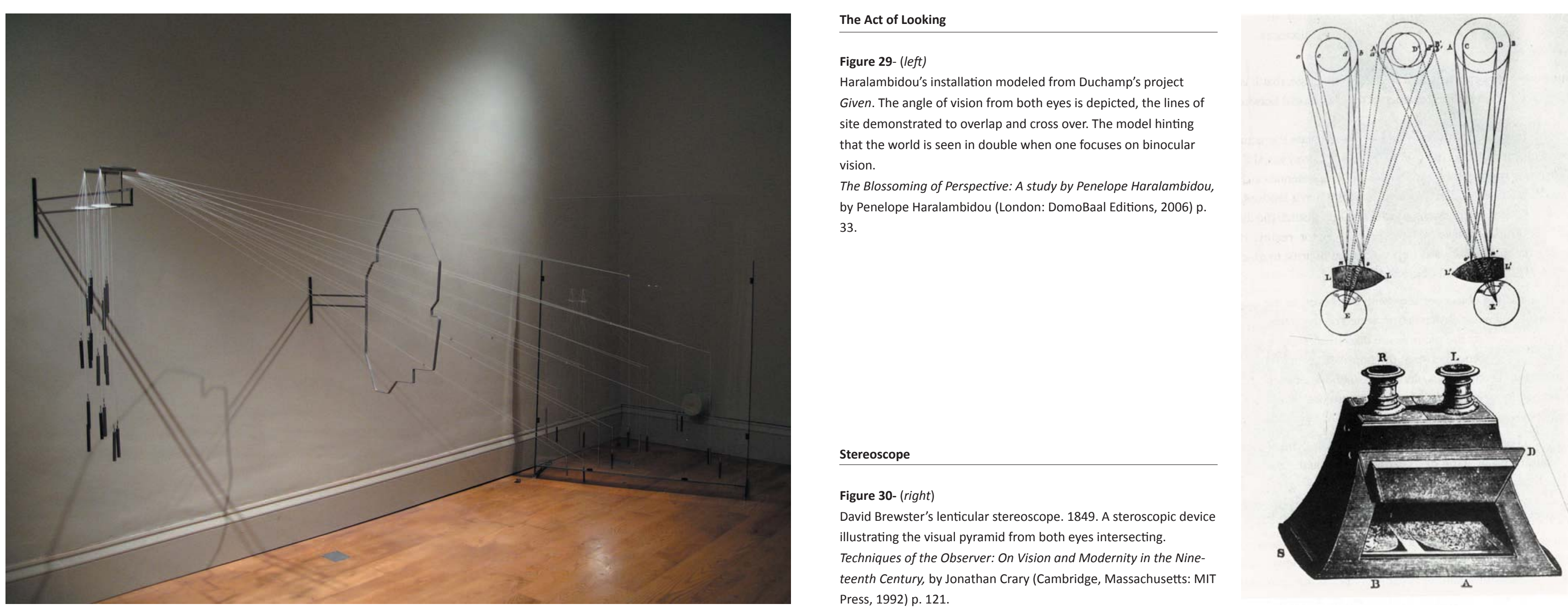


\section{The Act of Looking}

Haralambidou writes that perspective became a way to describe a method of observing architecture through certain devices, rather than a description of vision. ${ }^{94}$ For Haralambidou, the stereoscope (the device of binocular vision) informed her mode of representation.

Binocular vision was understood as early as Antiquity, where it was known that a different image appear on each eye, yet it was not until the nineteenth century that researchers became interested in the rules which had previously governed the visual field as singular. ${ }^{95}$ The concept of binocular vision was put into practice through a stereoscope, a device which greatly interested Duchamp in his lifetime. ${ }^{96}$ Jonathon Crary, author of Techniques of the Observer: On Vision and Modernity in the Nineteenth Century, believes the stereoscope signified the loss of the single point of view, which had historically defined perspective construction. ${ }^{97}$ The stereoscope gave life to a form of vision which reflected truth more wholly than the camera obscura, described by users as making vision tangible. ${ }^{98}$ Wheatstone, the inventor of the stereoscope, described the optical impression to be binocular only when one is representing the object that is near, as from a distance visual rays converge to form a singular point. Therefore, Wheatstone's attempts were not to discover a new way of painting, as painting was already a suitable means of representation, but, like Haralambidou, to find a new way to describe vision, simulating the actual presence of the object. ${ }^{99}$

At the same scale as Given, The Act of Looking models, in three dimensions, the lines of the viewers sight obtained by looking through the two peep-holes. ${ }^{100} \mathrm{~A}$ binocular-type looking device, mounted at the height of the viewer, takes support from the wall. From the dual peep-holes come lines of string demonstrating the visual pyramid of the observer (in keeping with the description of Euclid), however, rather than sight lines coming from just one eye, the string hints at a world seen in double, through binocular vision. The two eyes demonstrate slightly differing viewpoints, ${ }^{101}$ with the lines of vision

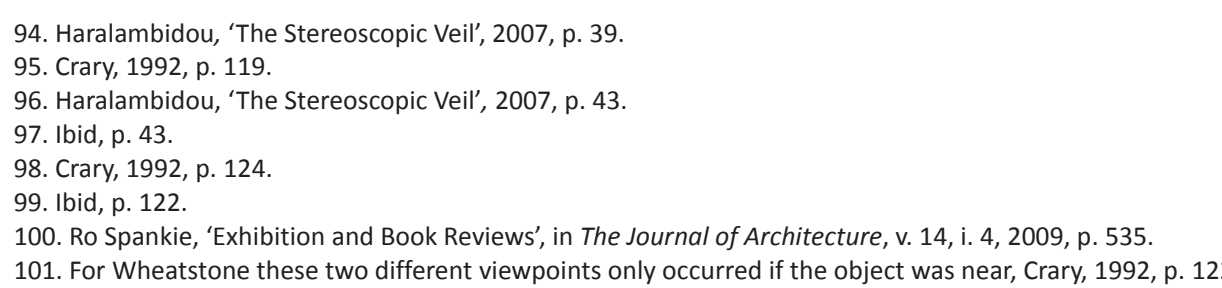




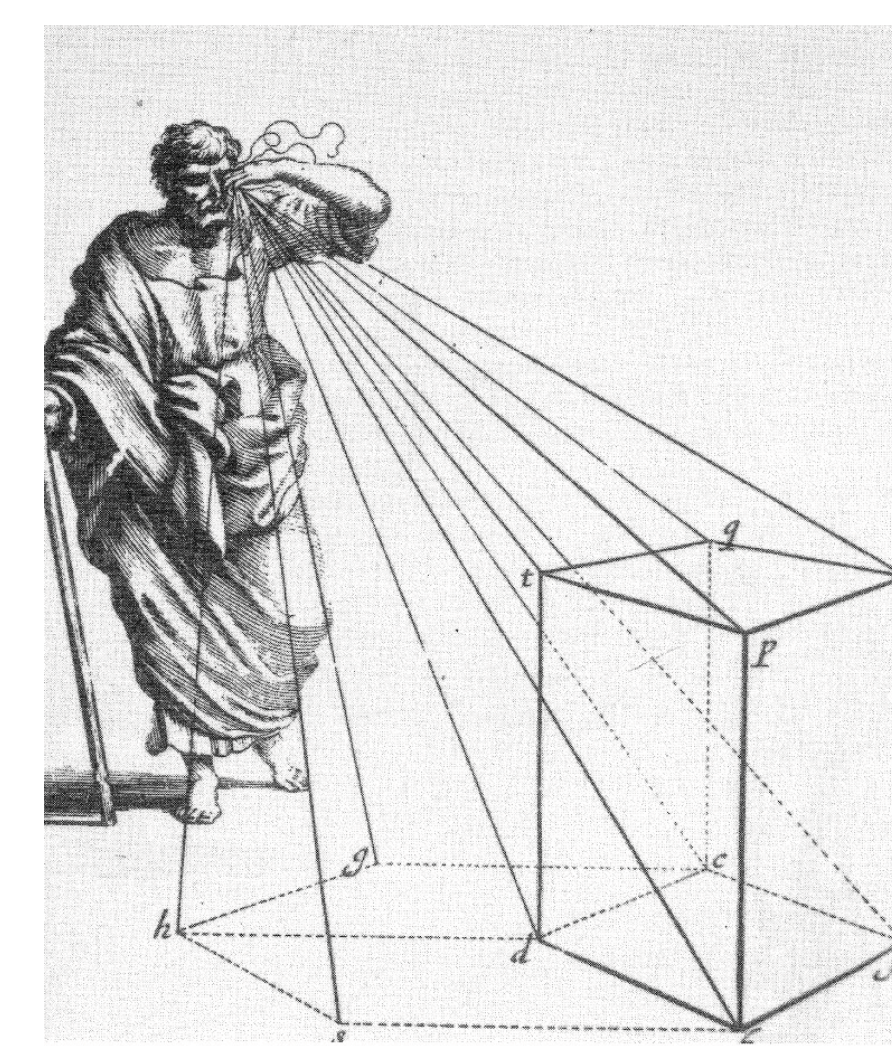

\section{Les Perspecteurs}

Figure 31-(left)

(n)

contrast to Haralambidou's installation. Here the projec-

tion lines from the single eye are called into question by

eyes.

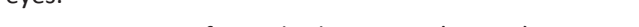

sell Dise Pelletier (Cambridge, Massachusetts: MIT Press 1997) 70

The Act of Looking (detail)

\section{Figure 32-(right)}

The Blossoming of Perspective: A study by Penelope Haralambidou, by Penelope Haralambidou (London: DomoBaal Editions, 2006) p. 30.

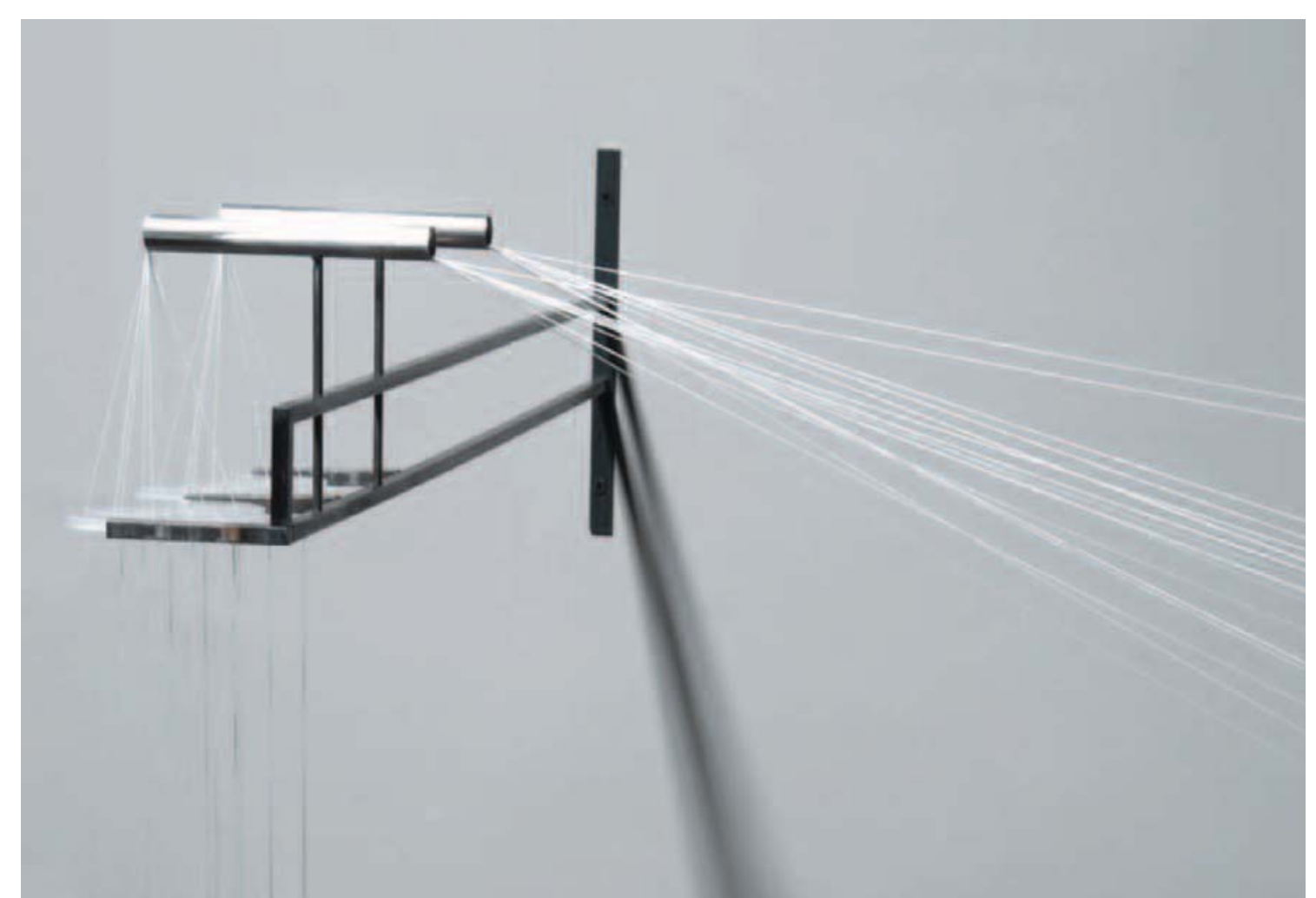


intersecting and illustrating that vision is always in conflict with itself. ${ }^{102}$ Binocular vision, as the entrance into Haralambidou's thesis, offers a retrace of steps into the effects of binocular sight, investigating what binocular vision could mean for drawing, vision and architecture. ${ }^{103}$ What we find in Haralambidou's installations is that the spaces are not conceived through a single point and planar surface, but rather, Haralambidou's models and drawings suggest a process of thought, proposing an architecture which is stereoscopic. ${ }^{104}$ Whilst not caught in the realm of paper architecture, nor architecture of pure function, Haralambidou explores the 'other' side of perspective, ${ }^{105}$ highlighting the architect's power to control representation, rather than be subservient to it. In the words of Jonathon Hill, 'Penelope does not draw buildings. But she builds drawings' ${ }^{106}$ What we find in Haralambidou's work is a willingness to question perspective as singular and static. Moving outside the paradigm of Brunelleschi, Haralambidou engages with representation as a means of finding architecture, rather than accepting singular perspective as a rudimentary mode of representation.

The fixed and static view of Brunelleschi's perspective is understood to represent truth. Yet there is a difference between mathematical truth and symbolic truth. These instances have been highlighted, particularly the mathematical truth of linear perspective and the symbolic truth of Antiquity. The photographic image is understood to be true, ones faith placed into the camera's make-up and correcting lens. The camera, however, is only mathematically true and represents a significant metaphor for how reality is objectified into a scientific mechanism. Comparable to the camera's viewfinder, the sight-vane of linear perspective offers one a personal cone of vision, illustrated by the artist in Dürer's woodcuts. ${ }^{107}$ Therefore the camera, and through association the digital image, have become tools in the rationalization of representation, not vision. The implications of these media within architectural representation mean the relationship between the observer and the representational mode has been reconfigured, invalidating the meanings of observer and representation which have been culturally established. ${ }^{108}$ While the history of perspective has both distanced and objectified that which we see as real, it has also demonstrated the

102. T.J Demos, 'Seeing Double', 2007, http://www.domobaal.com/resources/penelopeharalambidou/penelope-haralambidou-t\}demos-domobaal.pdf, p. 10

104 . Perspective which is formed by painting the image onto both eyes Stereoscopy demonstrtes the intersection of vision, while expanding the visual field beyond monocular vision into true perception. Demos, 2007, pp. 10-11.

105. Demos, 2007, p. 11.

108. Crary, 1992, p. 1 . human desire for control over means of representation. ${ }^{109}$ Brunelleschi, van Hoogstraten and Haralambidou demonstrate control over their system of representation by understanding the fundamentals of the perspective construct. Due to the 'mechanical eye', the ability to control representation within the computer is absent. The next chapter will argue the implications of losing control within the paradigm of digital design, presenting the case for the hand in the production of perspective images 



\section{Tactile Control}

\begin{tabular}{l|l|l|l|l|l} 
Drawing Architecture & Cryptogram & Hand as Tool & Autonomous Drawing & Technogram & Calligram
\end{tabular} 
The invention, and subsequent proliferation of computer aided design software (CAD), introduced the potential of the three dimensional image to be seductive in photo-realistic ways. Thus, CAD has been exploited by most architects and architectural students. Whilst digital tools have expanded beyond the expectations of the architect, the means of representation are still stuck within Brunelleschi's paradigm. Thus digital software fails to interpret perspectives' plural history, in disagreement with Robin Evan position that linear perspective is only one, in a number of perspective conventions. ${ }^{110}$ The critique of the singular digital perspective is discussed in this chapter under the term cryptogram. Cryptogram is one of three terms of drawing borrowed from Marco Frascari, that structure this chapter as an entry into the design work. These terms are used as a means of contrast between digital and manual techniques, yet demonstrate a greater point of difference between tactile understanding of space, and a purely optical understanding. Through this chapters comparison of digital and manual drawing it aims to highlight levels of control within the representation, suggesting the architect's level of control over digital representation is less than the architect's control of manual representation.

\section{Drawing Architecture}

Conceiving of architecture through means of representation began in the Renaissance. 'Prior to the Renaissance, architectural drawings were rare, certainly in the sense that is familiar to us', ${ }^{111}$ therefore, architects reliance on tools of representation were absent. Before the Renaissance, perspective was no codified, nor was the geometric relationship between plan and elevation understood, ${ }^{112}$ so it was not until architecture became a liberal practice, that ideas were conceptualised in accordance with the orthographic set. The establishment of the perspective image as a truthful depiction of the external world demonstrates this fundamental change. ${ }^{113}$ Whilst contemporary architects take orthographic drawing for granted, it was revolutionary during the period, radically departing from theories of classical vision and centred on rationalization of the image through both mathematics and geometry. ${ }^{114}$ With the use of digital software such attention to mathematics and geometry has shifted, consequently removing the architect's control of the perspective image.

10. Evans, 1995, p. 123.

111. Pérez- Gómez and Pelletier, 1997, p. 8

14. Pérez- Gómez and Pelletier, 1997, p. 9 .
In The Origin of Perspective, Damisch warns one should be suspect of the camera, due to its ability as a machine to construct images external to the architect's control. It is for the same reasons one should be suspect of the digital image. Both apparatuses reflect a passive recording of a scene; the likeness to truth suggesting the image is a reflection of reality. ${ }^{115}$ These apparatuses demonstrate contemporary architectural drawings to be as controlled by the 'mechanical eye' as Dürer's portrait was controlled by the sight-vane. The mechanisms involved in the photograph and digital image make the construction of perspective easy and possible without any knowledge of how the image is produced. ${ }^{116}$ The ease of creating the perspective forms distance between the author and image that is not present in a manual drawing, this is because it is no longer the author who designs the perspective, but the software engineer. Thus whilst the manual drawer exerts a tactile relationship with the drawing construction, the digital drawer can only demonstrate an optical relationship, deciding only the eyes position in space and the angle of view. Therefore, the photographic image and digital perspective reflect a mathematical understanding of space, in opposition to Panofsky's psychophysiological space.

In order to understand perspective through Panofsky's guise as a symbolic form, I suggest one must move outside of current digital representation and engage in what Panofsky terms a great 'recoil'; a retreat back to more primitive methods in order to expand on old problems, ${ }^{117}$ much like Leonardo did with the single immobile eye. This retreat aims to re-gift the architect with the representational control which they had in the Renaissance.

\section{Cryptogram}

In the Oxford dictionary, cryptogram is defined as 'a text written as code'. For perspective drawing, the cryptogram refers to the code which defines the drawings construction. Today, that code is largely reliant on what Brunelleschi demonstrated in the fifteenth century. The geometric relationships prescribed in this code are those written into computer software. A manual interpretation of the cryptogram demonstrates how linear perspective can be drawn with contradiction to Brunelleschi's rule. The digital perspective is not as flexible.

115. Damisch, 1994, p. Xv.

116. bid, pp. xv-xvi.

Whe same premises, appears unlikely to bear fruit, the result is often a great recoil, or perhaps better, a reversal of direction'. Panofsky 
In Horizons at the Drafting Table, Marco Frascari describes linear perspective as a cryptic bridging device between the mysterious world where drafting takes place and the legible outcome of the drawing. ${ }^{118}$ Within the computer this bridging has become obscured, the perspective drawing constructed outside of the user's control, so that, like the camera, an understanding of the code has become superfluous. Because the architect has no control over the use of the code, they are unable to question critically the construction of the perspective. Drawing with the hand is fundamentally different as the architect is dealing directly with the code. The pencil can easily be manipulated and interpret the code outside of convention, so rather than demonstrating that which is defined and unshakeable within digital software, the hand is able to illustrate that which is 'grey'. The manual drawing allows the autho ambiguity in the design process, in opposition to digital representation which is locked within a fixed world concerned only with static images for the purpose of building.

\section{Hand as tool}

The hand does not only bridge the gap between the drafting and the drawing by illustrating the process in the outcome, but it is also a better thinking/drawing tool than the mouse. In Sketching, Computing and Knowledge Engineering, M. Bechir Kenzari writes that sketching with the hand is an acquired skill, a product of a lengthy education. For CAD software to reach a level of sophistication that could generate ideas, it too, needs a long process of study, adaptation and fine tuning. Kenzari also writes that tools were derived from the hand as model. ${ }^{119}$ This is in keeping with the argument made by Juhani Pallasmaa in The Thinking Hand where the pencil is described as an extension of the fingertip. ${ }^{120}$ Pallasmaa suggests that the hand encapsulates a tactile knowledge of picture making, rather than the optical knowledge we read in digital images, this is due to the hands presence in the drawn line. Tactile knowledge describes a closer sensory relationship between observer and representation. Examples can be sought in great architectur drawings that unavoidably describe the presence of the maker, the surface of the drawing projecting both the author's body and gestures of the hand. ${ }^{121}$ In Les mains de Le Corbusier, Andre Wogenscky reports on Le Corbusier's hands in the production of his architecture, claiming that Le Corbusier's hands, big an deeply furrowed, expressed his feelings, anxiety's, disappointment and hope, revealing the doubt hidden

118. Marco Frascari, 'Horizons at the Drafting table: Filarete and Steinberg', in Chora Five: Invervals in the Philosophy of

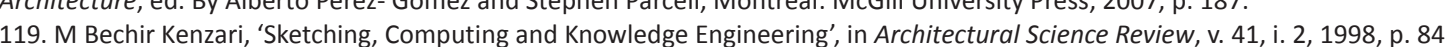
120. Juhani Pallasmaa, The Thinking Hand: Existential and Embodied Wisom in Architecture, West Sussex: John Wiley \& Sons, 2009 p. 60 on his face. Le Corbusier produced his buildings through his hands, sealing his fate as a designer through the making of such drawings ${ }^{122}$ and a tactile understanding of design.

\section{Autonomous Drawing}

Historically, there has been a distinguishable relationship between maker and means of representation, ${ }^{12.3}$ the architect capable of controlling how their work was observed. Even, when in the 1980's habituation of the manual drawing lost favour for the autonomous drawing, the architect continued to control the relationship between observer and representation. Architects such as Peter Eisenman strived for autonomous manual drawings, devoid of both the architects hand and the process of making. The computer, therefore, came of age at a time when its autonomous drawing technique was admired, the hand of the maker easily hidden within prescribed line weights and styles. Consequently, the autonomous drawing has become prolific in architectural design. Yet, after three decades of CAD, research suggests the computer drawing is in fact far from autonomous. In observing the work of certain architects, Gres Lynn has found that the forms those architects design expose the software package that produced them, thus suggesting that digital modes are hardly as autonomous as hoped. ${ }^{124}$ This observation, has also been made by Harry Mallgrave in The Architect's Brain. Mallgrave demonstrates concern for what software packages inadvertently deliver to the process of design, recalling student projects from around the world that demonstrate a homogeneity in design approach. ${ }^{125}$ Both Lynn and Mallgrave argue that the 'hand' of the computer program is coming to the fore within design proposals, controlling how, and what, architects' design. In my work the hard pencil and rigidity of the orthographic set help to hide the presence of the maker, yet, smudging, erasure, notation and errors illustrate the work as tactile. Subsequently, the re-interpretation of the cryptogram demonstrates my control of the representation.

Demonstration of working processes also endows the manual drawing with a tactile quality that is absen within the transparency of the computer. Nat Chard's interest in the process of design can be found in his research into how drawings can become architecture, and how the author's or observer's relationship with

\section{Kenzari,1998, p. 82.}

124. Nat Chard, 'Drawing Instruments', in Architectural Design, v. 75, i. 4, 2005, p. 23.

125. Harry Mallgrave, The Architect's Brain: Neuroscience, Creativity, and Architecture, West Sussex: John Wiley \& Sons, 2010, 


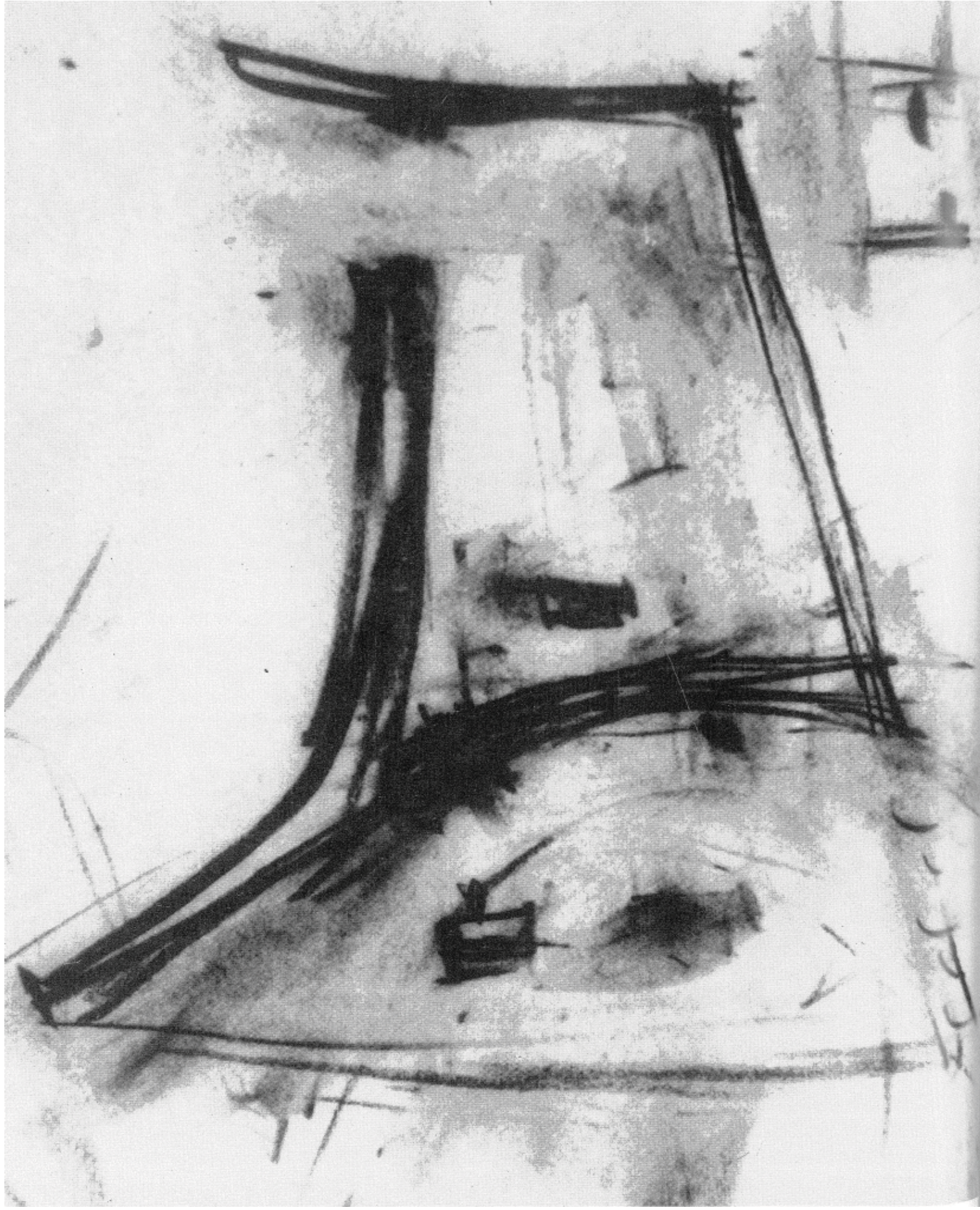

the drawing can encourage this. ${ }^{126}$ Thus, Chard occupies the drawing in much the same way the building is occupied. Chard writes: 'Anyone truly interested in the design process will always consider architectural drawing as the relic of a process of making that binds maker to the artefact', ${ }^{127}$ architectural drawings being the tangible proof of this relationship. ${ }^{128}$ The manual drawing must never be considered passive, as it holds the ideology of the maker - drawings used as tools to express the author's objectives and actions. ${ }^{129}$ The manual drawing clearly articulates to the viewer the construction, the process, and the duration fused into the surface of the image. ${ }^{130}$ Digitally, the drawings construction is hidden within the computers perspective code, therefore, (in returning to the cryptogram) isolating drafting from the drawing. The drafting of the digital drawing fuses seamlessly into an outcome that floats on a sheet without either duration or habitation. Thus, the digital drawing occupies a mathematicised and abstract world, ${ }^{131}$ 'far removed from the world of human sensory experience', ${ }^{132}$ whilst the hand drawing as a tactile demonstration of space, occupies the physical world, which we inhabit and where buildings and drawings materialise. ${ }^{133}$

2005, p. 15 Archietcture Society of Atlanta in collabortany

129. Ibid, p. 44.

130. Pallasmaa, 2009, p. 90

131. Ibid, p. 96 .

133. Mallgrave, 2010, p. 214 


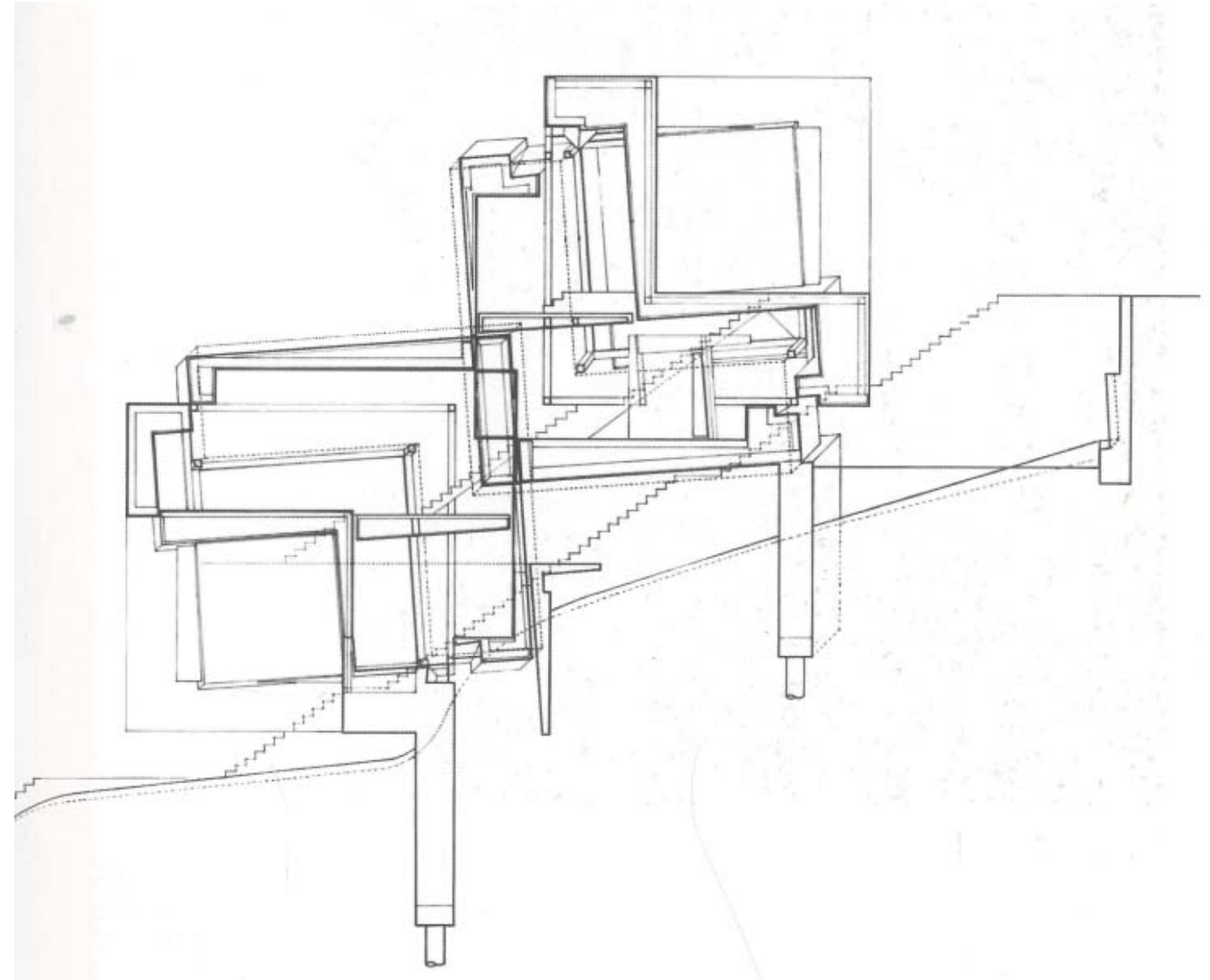

Figure 33- (facing page)

Consier's hand is present in the sketch, particularly through the use of charcoal which illustrates a tactile relationship to the drawing surface. Le Corbusier, sketch site plan for the Chape at Drawings, by Daniel Herbert, (New York: Van Nostrand Reinhold, 1993) p. 60 .

Figure 34-(above)

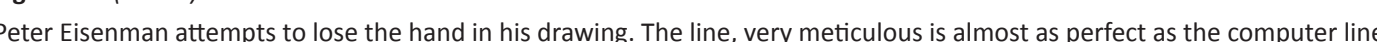
Peter Eiseman, Guardiola House, 1988, in, Feints, by Peter Eisenman (Milan: Skira, 2006) pp. 130-131.

Figure 35- (right)

An example of a perspective drawing completed within the research. The hand of the author is present in the drawing despite the meticulous pencil work. The use of notation and construction lines hint at the process of making and the hand of the maker Author, Drawing 11, 2010

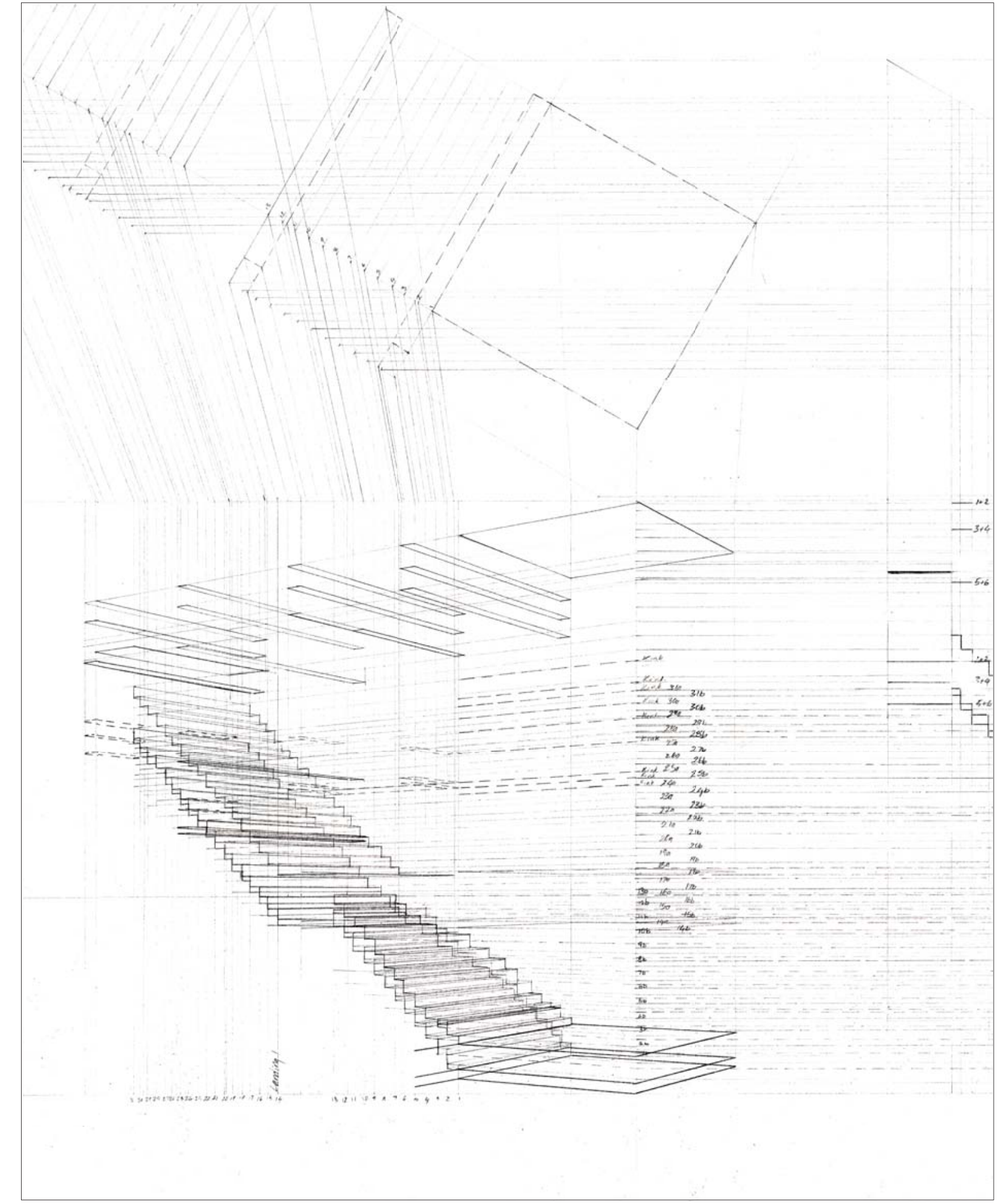




\section{Technogram}

Pallasmaa suggests that the line drawn with the pencil is inhabited by the author's hand. ${ }^{134}$ Thus, the technogram demonstrates the tactile relationship between the drawer and maker, which is present in the hand drawing. The author can physically move through the structure of the designed object, touching the lines, ${ }^{135}$ and materiality of the drawings surface, implicating the relationship as described by Chard, between representation and habitation.

The act of drawing by hand demonstrates two spatial relationships, the physical relationship between the author, pencil and board, and the embodied relationship of the author within the picture plane. ${ }^{136}$ The first can be read as a technogram, the latter, a calligram. The technogram is the drawings surface, it 'reveals how architects are compelled and bounded by images locked in a hall of mirroring horizons'. ${ }^{137}$ Within the manual drawing the author occupies the horizon, as the drawing is physically penetrated by the authors hand and body. Within the digital drawing the author is unable to occupy the horizon, operating at a distance to the computer screen.

In the mid twentieth century, drawing offices in America employed technicians to draw cars and aeroplanes at one to one scale, implicating the body within the picture plane. A one to one scale car could be drawn with a vertical board, draftsmen using their own height as a measuring device against the drawing. The body functioned as a calibrator for the draftsmen making the drawing and for the observer reading the drawing. ${ }^{138}$ To draw an aeroplane at one to one, introduced a different body board relationship, as the scale required it be drawn on a horizontal plane. Draftsmen lay flat on the drawing surface implicating the body's relationship to the board in a completely different way. For some draftsmen this meant their drawing view became anamorphic, except for what was right below their eyes, ${ }^{139}$ their optical engagement with the picture was, therefore, limited. Other draftsmen were limited by the use of an apparatus (the mattress) to prevent smudging of the drawing. In positioning the body at a greater distance from the drawing surface the body's physical relationship to the drawing was different

134. Pallasmaa, 2009, p. 60

135. Ibid, p. 59.

136. Chard, 2005, p. 35.

138. Chard, 2005, p. 37.

139. libid, p. 39 . again. ${ }^{140}$ Figures 36 to 39 illustrate a drawing office in Ford's Willow Run, Ypsilanti, Michigan. ${ }^{141}$ The draftsmen's engagement with the surface implicates the drawing as both an image and a physical entity, occupying the drawing space beyond what is pictorial. The drawing demonstrates that images can be both occupied and represented. ${ }^{142}$ While these drawings were orthographic projections of the vehicle a likeness can be made between the technogram and calligram. The body of the technicians implicated in such a way as described by Chard that the drawers inhabit the drawing as it will be inhabited in occupation. While the orthographic set allows for drawings of true measure and, therefore, a tactile representation of body and drawing, the perspective drawing allows one to place author or viewer into the space through optical inhabitation. This is explored in the calligram. 


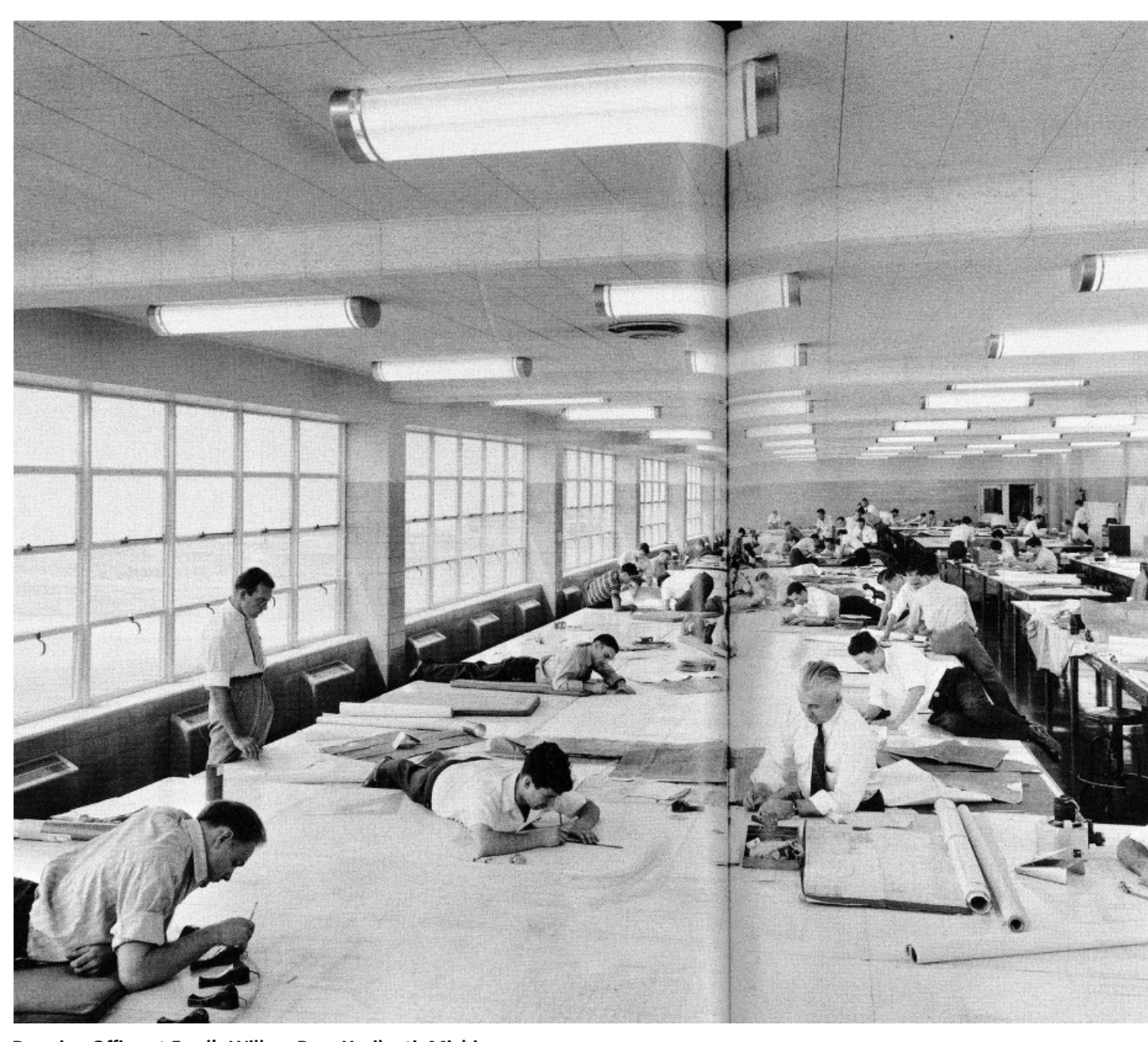

Figure 36 -

The techlons leor sit on he

left patrols the perimeter, his view of the drawing different to those physically penetrating the picture plane. minate Drawings of Architecture, by Nat Chard (New York, Springer Wien New York, 2005) pp. 38-39.

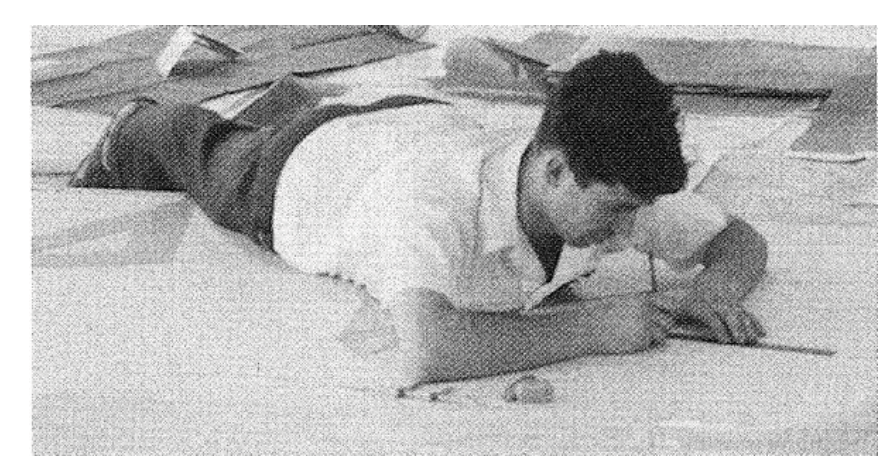

\section{Figure 37-}

The above technician chooses not to use a mattress, his body directly ing is different to picture plane. The relationship between body and drawdistance from the picture plane due to the mattress.

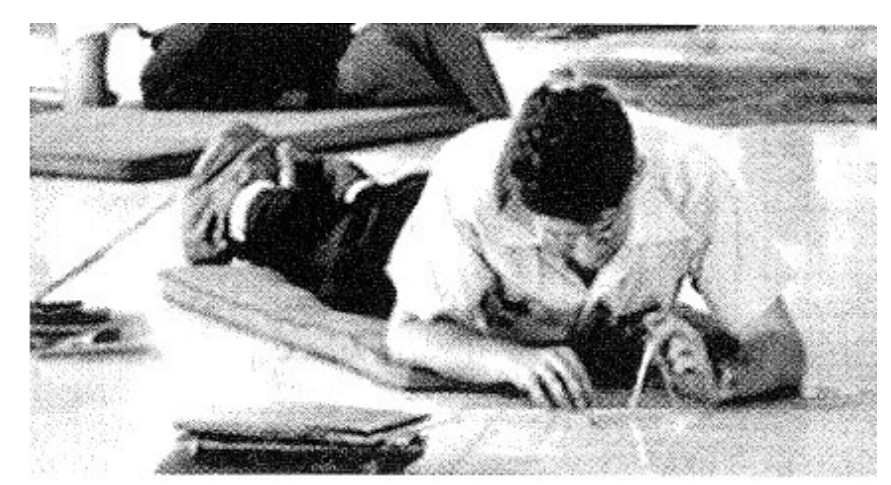

Figure 38

Nat Chard, 2005, p. 39.

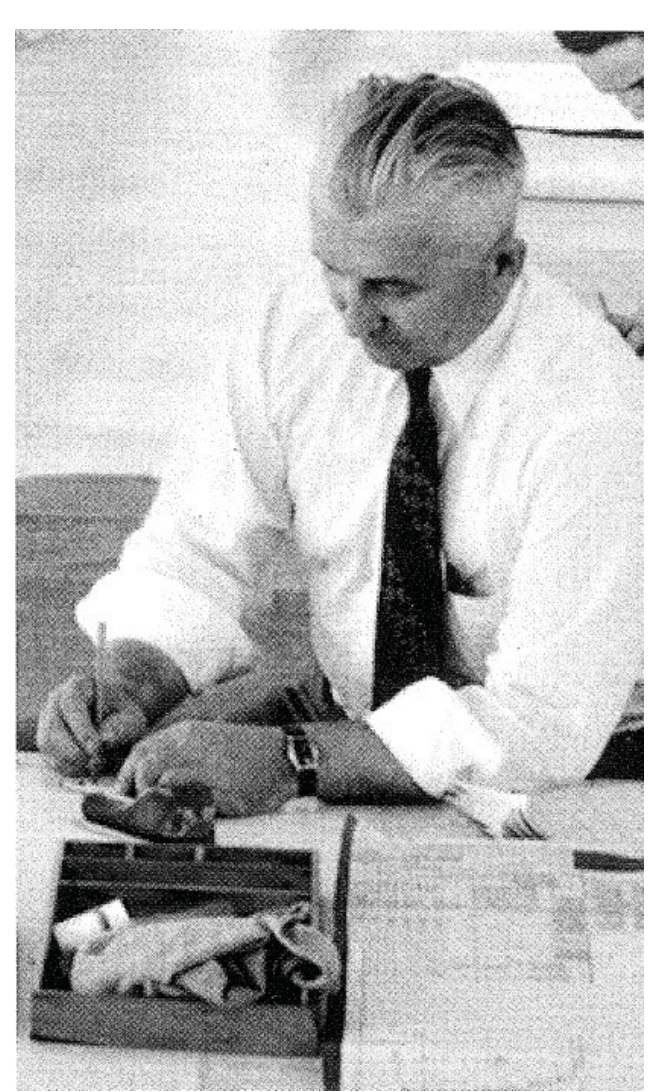

Figure 39-

(hicture plane by sitting within it. This technician's view of the drawing is similar to that of the gentleman who is standing at the perimeter, however, closer to the picture plane. He has the most normal view.
Nat Chard, 2005, p. 41 . 


\section{Calligram}

The calligram is a term that describes the ingrained personal and cultural history within a drawing. These histories are demonstrated in the culturally conditioned relationship between observer an representation. ${ }^{143}$ The calligram embodies the author or observer within the drawing in a non physical way, illustrating the view point and cone of vision within the picture plane. Similar to the cryptogram, hand drawing provides the opportunity to manipulate the relationship between observer and representation, again, by interpreting the code outside of Brunelleschi's convention.

The position the author takes within the picture plane, implicates the observer. Frascari describes this eloquently as, 'Readers of architectural drawings cannot reach the eidetic essence embodied in the graphic representation unless they are given the means to enter the horizons within which the drawings have been traced. ${ }^{144}$ In Horizons at the Drafting Table Frascari offers two examples of architects who allow the author entrance through these horizons, Filarete, an instrumental character of the Renaissance, and Saul Steinberg, a twentieth century architect better known for his cartoons. ${ }^{145}$ Frascari argues that despite the decades that separate Filarete from Steinberg they were working with the same set of issues presented by the architectural drawing, predominately, the implication of the body within the picture plane.

Filarete, the Renaissance architect, wrote twenty-five books on architecture. The twenty-third book explains how to make a drawing for a future building, paying tribute to Brunelleschi and Alberti, yet suggesting an alternative drafting procedure. ${ }^{146}$ Manipulating Alberti's construzione legittima by placing the viewpoint above the drafting table (rather than in front of the perspective window), Filarete presented a 'cosmopoietic twist' ${ }^{147}$ into the horizon of the build-able space. The shift of the horizon line implicates the viewer in a new way, observing the perspective from above, rather than standing at the level of the ground plane, thus, presenting a new engagement between observer and representation.

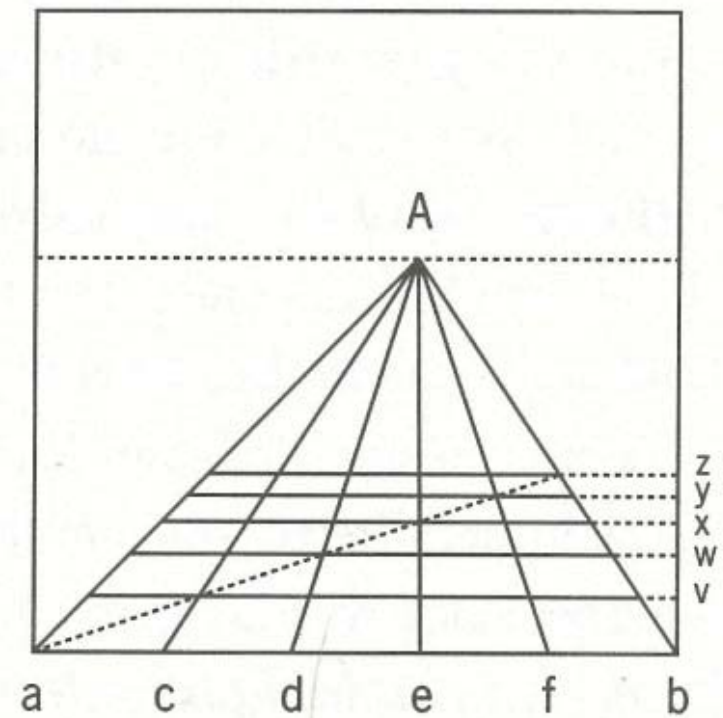

Construzione legittima

Figure 40-

Alberti's means of constructing perspective. The chequered ground plane is drawn as a device for placing figures.

Leon Battista Alberti, Perspectival construction of the

checkerboard-type, c. 1435-1436, in Perspective as Symbolic Form, by Erwin Panofsky (New York: Zone Books, 1991) p. 64.

143. Crary, 1992, p. 1.

144. Frascari, 2007, p. 187

145. Ibid, p. 182. 


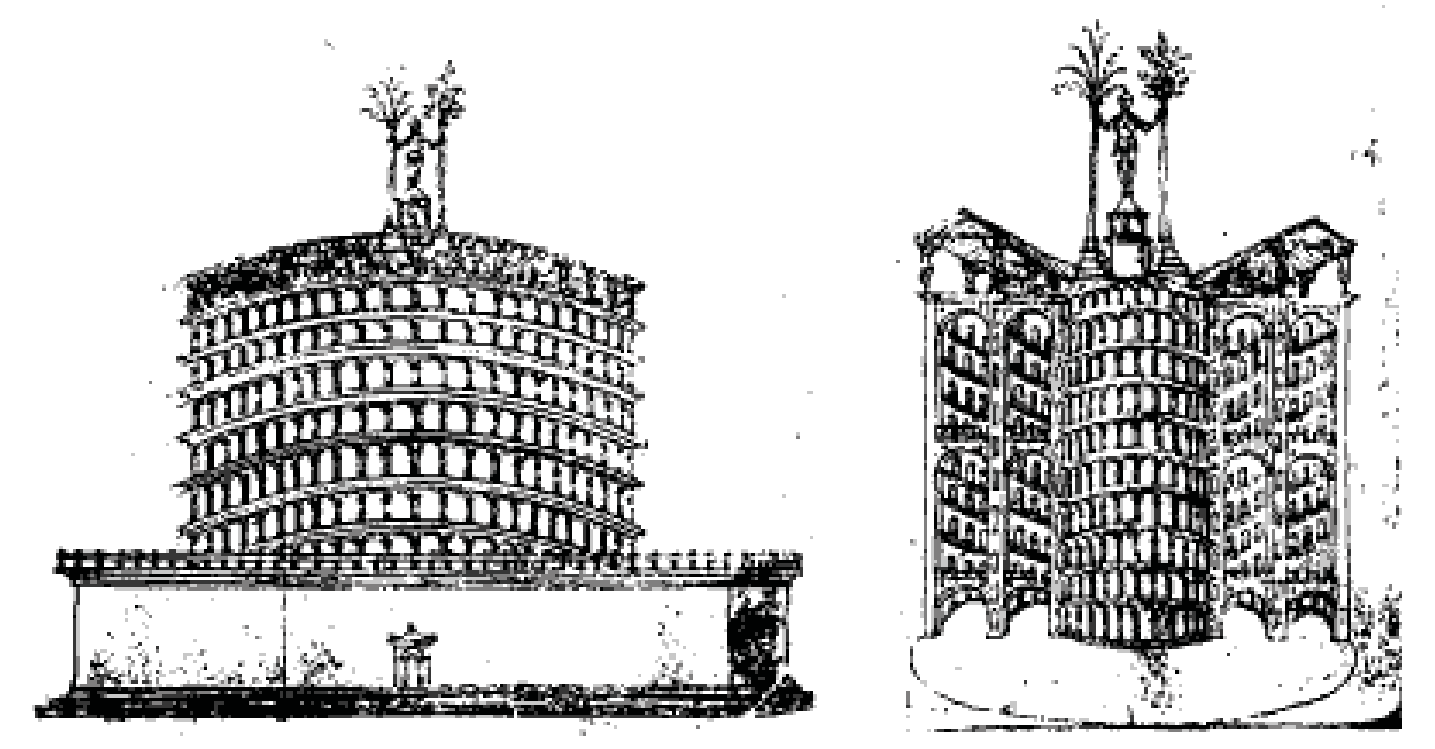

Sforzinda

Figure 41- (left)

House of Virtue and of Vice

Figure 42- (right)

Filarete's perspectives communicates a shift from construzione legittima. The building drawn by Filarete is captured from

an obscure vantage point rather than at the pavement level. The comparison between Alberti's construction and Filarete's

enables one to understand the 'cosmopoietic twist'.

Drawings by Filarete, in, 'The Anamorphic Phallus within Ledoux's Dismembered Plan of Chaux', Paulette Singley, in Journal of

Architectural Education, v. 46, n. 3, 1993, p. 186 
Steinberg's interpretation of perspective was similarly based on, but not constrained by construzione legittima. Interpreting the horizon to offer a new "view of the world", ${ }^{148}$ Steinberg positioned the vanishing point within his own, new, cone of vision. His highly renowned drawing, "View of the World from $9^{\text {th }}$ Avenue", appeared on the cover of the New Yorker on the $29^{\text {th }}$ of March, 1976..$^{149}$ The drawing was born from a series of preparatory drawings which began with construzione legittima but became a '...cosmopoietic urban macro-micro view... ${ }^{150}$ offering a more thorough vision than that offered by normal perspective projection. ${ }^{151}$ The spatial relationship to the drawing has changed for the viewer, as they are encapsulated within a much grander perspective than the one of vision constructed from the height of the viewer on Alberti's chequered ground plane. These perspective drawings indicate a shift within representation, one that changes the viewpoint of the 'mechanical eye', to point outside of normal spatial understanding. Thus, like the cryptogram, the architect is better able to impose their own 'view of the world' through manual drawing which allows manipulation of construzione legittima (or perspectiva artificialis).

Frascari's positioning of both Filarete and Steinberg in his text situates the architect's as cosmographers, ${ }^{152}$ who translate their cultural and individual studies through graphic means, once more demonstrating a tactile understanding of space. Filarete and Steinberg's drawings are not prescriptive drawings for the making of buildings, but rather describe how to construct within a certain horizon, therefore contrasting between the intuitions of an imagined world with that which is material in architectural practice. ${ }^{153}$ The drawings of both Filarete and Steinberg encapsulate architectural representation as more than a rudimentary tool for the production of buildings, rather using the construc of perspective to communicate their ideology. In contrast to the computer, which produces photo-realistic representations of a 'real world', the manual drawing allows what is conventional in the drawing to be destabilized ${ }^{154}$ and thus illustrate a new spatial understanding. Filarete and Steinberg illustrate that which is 'unknown' conceiving an architecture that is more concerned with the observer's position in space, or the implication of design on a certain horizon. And while the images could read to distance the observer,

\section{Ibid, 192.}

151. lbid, 192 .

52. Designers of the universe.

154. Ibid, p. 192. both 'cosmopoietic' perspective views demonstrate a greater concern for natural vision and psychophysiological space than the baptistry demonstration ever did. 
View of the World from 9th Avenue

Figure 43-

Steinberg's original drawing which appeared on the cover of the New Yorker. His perspective illustrates that

which is known to the observer, and that which is unknown across the horizon line.

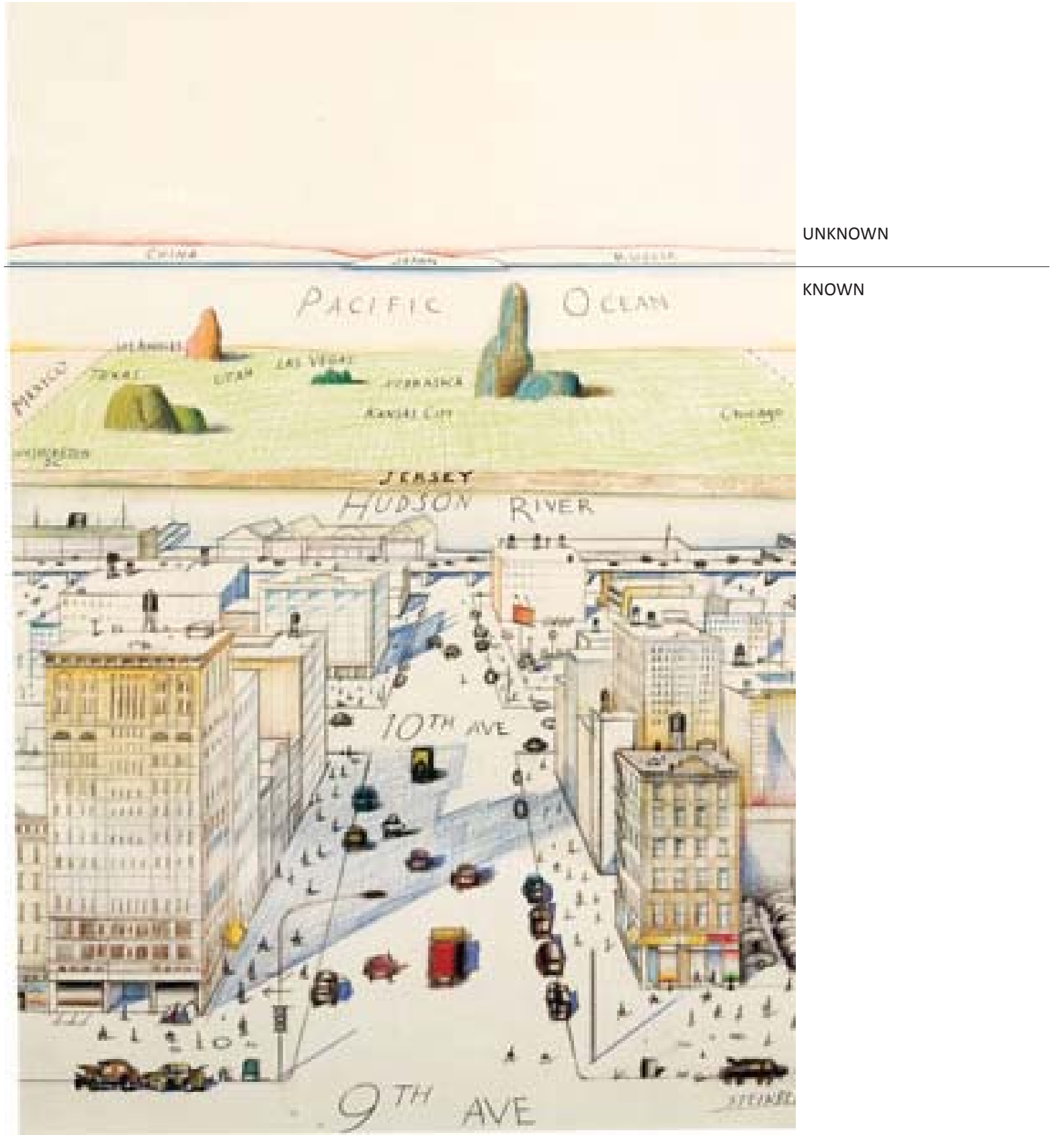





\section{Unpacking the Cryptogram}



To produce the perspective drawing manually one is reliant on the projection between plan and elevation. Thus, every line has a purpose. The plan is situated above the picture plane (within my drawings on a thirty/sixty degree angle), the projection of lines from the plan yield the widths for the perspective. The elevation is situated on the ground line, to the side of where the perspective will be formed. The elevation provides the heights for the perspective. The three drawing systems on a single sheet offer evidence as to how the three dimensional image is produced, illustrating the relationships that occur between orthography and perspectival projection. In a more detailed drawing the lines of projection come to the foreground, situating the line of both process and product as equal. The evidence of working processes within the drawing offer the architect a means to challenge the design output and role of drawing in architecture. ${ }^{155}$ Such processes have been explored in the work of Peter Eisenman who sets up conditions or strategies for a project and then draws into them, attempting to uncover form within the ideas. ${ }^{156}$ This approach positions the drawing as a design problem of its own right. ${ }^{157}$ Within this research the process of constructing the instrumental perspective is challenged by interpreting the perspective code ${ }^{158}$ erroneously.

The perspective drawing is treated as an academic subject within the realm of scientific research. The drawing components, picture plane, horizon line and ground plane remain constant within all the drawings. These points are well documented, dependent on where the viewer is positioned in the space and where their angle of view is focused. Easily manipulated with the computer by changing the height or direction of the camera icon, the fundamentals of these components are reasonably flexible. The more speculative components of the drawing, the vanishing point and stationary point are more involved in the drawings mechanics, forming the independent variables in the study. The relationship between these two points is of chief concern, as this relationship determines one of the greatest assumptions of perspective, the single immobile eye.

The research comprised three series of drawings, the first two, preliminary studies for the third. The first series investigated the object, a not quite cube. The simplicity of the object allowed many iterations of perspective to quickly develop, providing knowledge of which errors produced more critical outcomes. This was pushed further in the second series, building, which began to establish a design methodology. In the second series perspective was pushed to its limits far more than in the object study, presenting the author with complex drawing issues. ${ }^{159}$ The third and culminative series started with site. This began with a site selection that was more concerned with physical parameters than programmatic or climatic qualities. The site was to act as the tabula rasa for the third study.

The first perspective image was constructed through a reading of site photographs. This drawing was not an exclusive translation of photograph into perspective, but relied on drawing plan, elevation and perspective simultaneously. It was essential that the first drawing was in correct perspective so that the abula rasa began within the convention, therefore acting as a control in the experiment. The first drawing $(0)^{160}$ was designed to demonstrate the entire site, however, whilst drawing it became quite complex. From the previous studies evidence proved that once the perspective was constructed incorrectly the drawing became even more complicated. For this reason three qualities were extracted from the drawing and treated separately, those qualities, context, structure and stairway. Drawing 1 details the context of the site in correct perspective projection, meaning, the perspective prescribed by Brunelleschi in the fifteenth century baptistry demonstration. This drawing begins to detail the qualities of the site, a corridor between two buildings running perpendicular to two prominent streets, the two streets have different ground levels creating the need for a staircase (Drawing 3) at the western end. 155. Daniel. M. Herbert, Architectural Study Drawings, New York: Van Nostrant Reinhold, 1993, p. 34.
156. Herbert, 1993, p. 33.
157. Ibid, p. 34 .
158. The erspective code is that which controls how one draws linear perspective manually, how the camera functions as a
viewing device and the restrictions of this device such as keeping the device still while the single eve looks through the viewfinder.
It also refers to the computer programme that produces perspective images defined by a geometry written by a programmer not an architect.
159. The most significant issue in the second study was scale. This was particularly evident when working back from the perspective drawing into the orthographic set. One drawing surpassed three drawing boards on its way from perspective to plan,




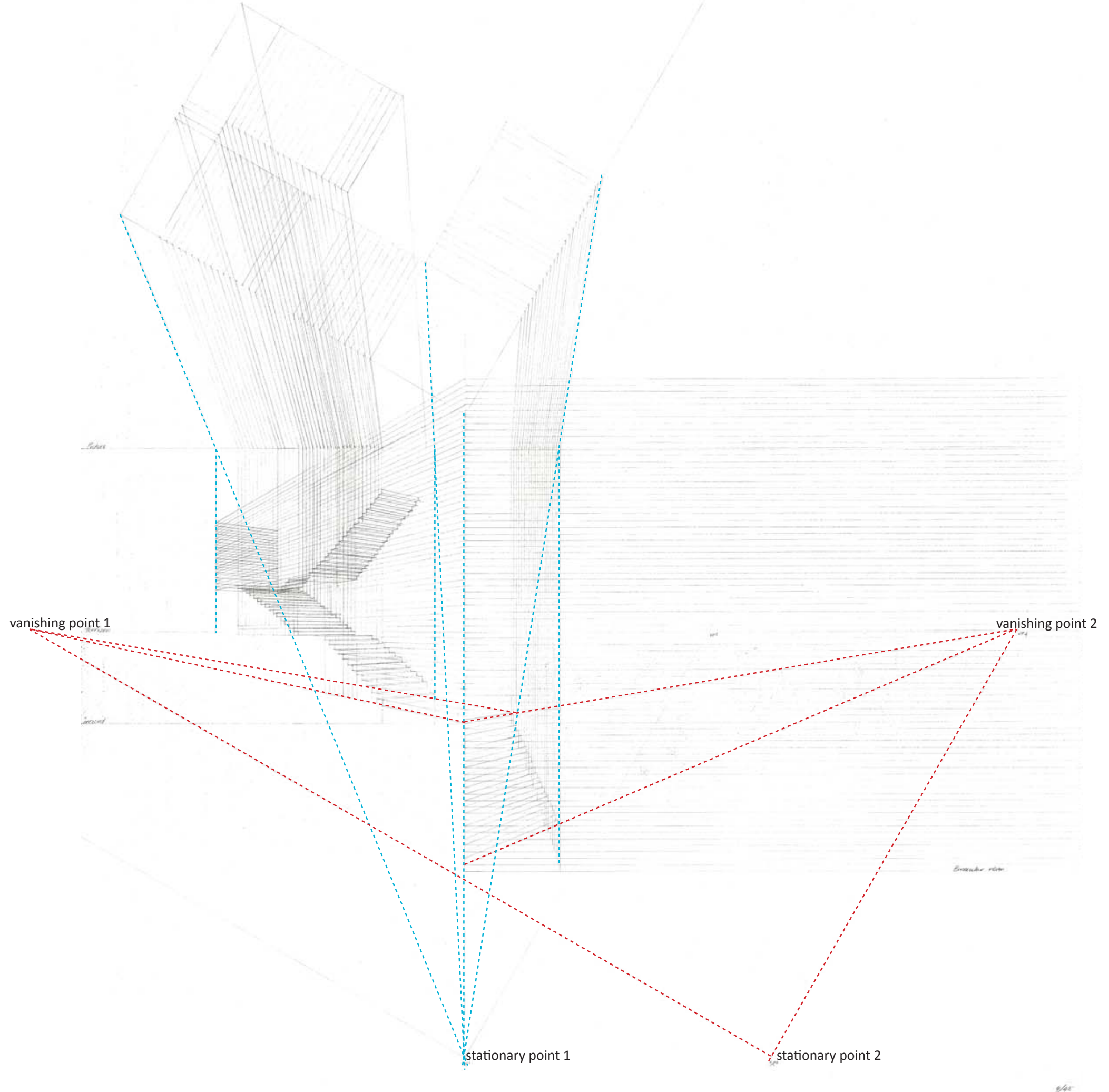

Drawing 4

Figure 44-

Illustration of binocular vision. The diagram demonstrates the two stationary points, showing that stationary point 1 is responsible for for the projected heights (thus, the vanishing points). 
Drawing 4 marks the beginning of the critical perspective. The perspective drawing is now constructed incorrectly using the same inputs (plan and elevation) as Drawing 3. This drawing explores the issue of the single immobile eye, the monocular nature of perspective drawings, by changing the relationship between the stationary point and vanishing points. In perspective drawing, 'The viewpoint ${ }^{160}$ and the vanishing point are inseparable: there is no viewpoint without vanishing point, and no vanishing point without viewing point ${ }^{161}$ Correct methods of projection define this relationship so that the eye is static, or singular. The representation of the stationary point in the drawing demonstrates the eye; the vanishing points demonstrate the cone of vision, or what the eye sees when standing in the illustrated position. In instrumental perspective the stationary point is demonstrated as a ninety degree line from where one would be standing in the plan (Figure 45). The vanishing points project from this point at the same angle at which the plan is drawn, in these examples thirty and sixty degrees (Figure 46). At the poin these lines intersect with the picture plane they are projected down by ninety degrees, the correct vanishing points are where these lines cross the horizon (Figure 47). The stationary point is responsible for foreshortening all the widths from the plan. Points from the plan are projected to the stationary point, where these lines meet the picture plane they are projected down by ninety degrees (Figure 48). In Drawing 4 the widths were defined by the stationary point, however the vanishing points were not. A second stationary point was drawn to find alternative vanishing points some distance from those that were correct. The implication of this shift means the angles at which all horizontal lines are projected is no longer correct. The difference between Drawings 3 and 4 may appear negligible, yet the concept of the shift means the drawing is no longer '...a fully rational- that is, infinite, un-changing and homogeneousspace... ${ }^{162}$ By separating the "point of view" from the "vanishing point" I am disregarding Brunelleschi's major discovery, yet in doing so I eliminate the problem of the single immobile eye; the drawing demonstrating a non-static and binocular vision. Drawing 5 demonstrates the same concept but pushes it further by creating more distance between the first and second stationary point. Because of this, one of the new vanishing points is placed within the verticals projected from the plan, meaning the image must cross through the vanishing point. Visually this is not possible, but it does present a new form, distorting the staircase in orientation and axis. The implications of such a move reach beyond geometry. In this case the stairs are being built in very close proximity to the vanishing point, (where all lines converge), the negligible distance between each line making the drawing increasingly complex and impossible to

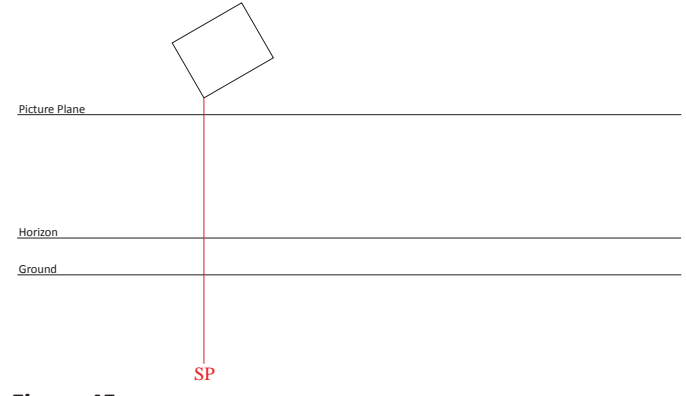

Figure 45-

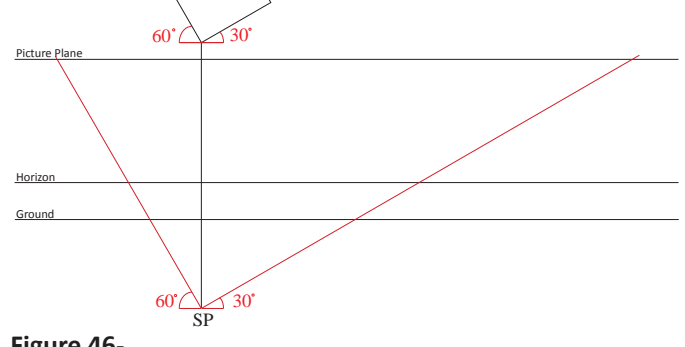

Figure 46-
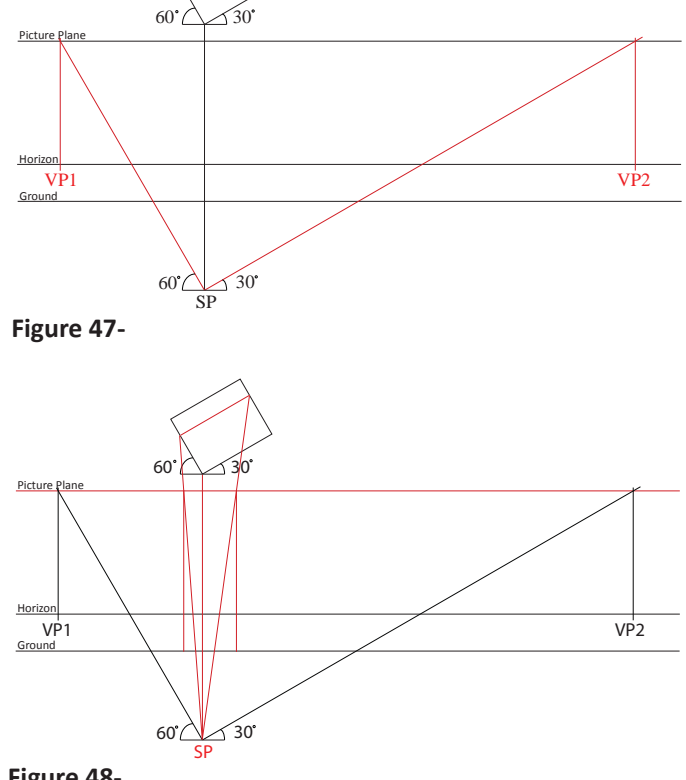

Figure 48-

Wustrations of the correct method of constructing the instrumental perspective 


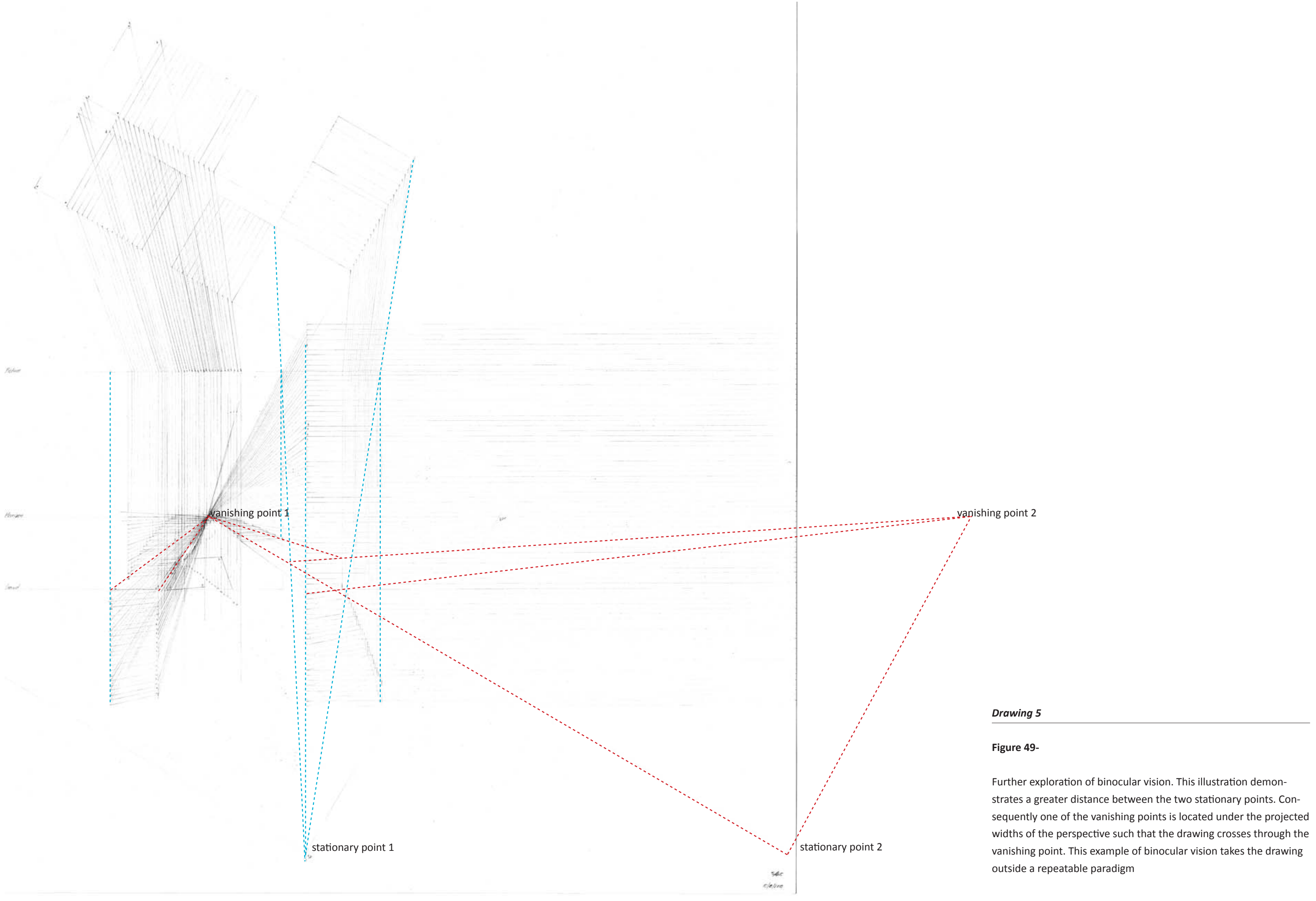


complete with assured precision. Drawing 6 demonstrates the same concept as 4 and 5 but moves the second stationary point both across and up. This resulted in crossing through the vanishing point again

and produced very similar results to Drawing 5. When producing Drawing 6 it became evident that due to the errors in the perspective construction, planes no longer formed closed loops, meaning the ground plan, which was originally a square, no longer matched at all four corners. The implications of this caused one line to wind upwards and another to wind downwards toward infinity. This implication became the subject of Drawing 8.

Drawing 6

Figure 50-

Similar to Drawing 5, Drawing 6 is also outside the repeatable para-

digm. This time the separation of the stationary points occured on

both the horizontal and vertical axes. Consequently vanishing point

1 is situated similarly to in Drawing 5 . The perspective resultis

similar to Drawing

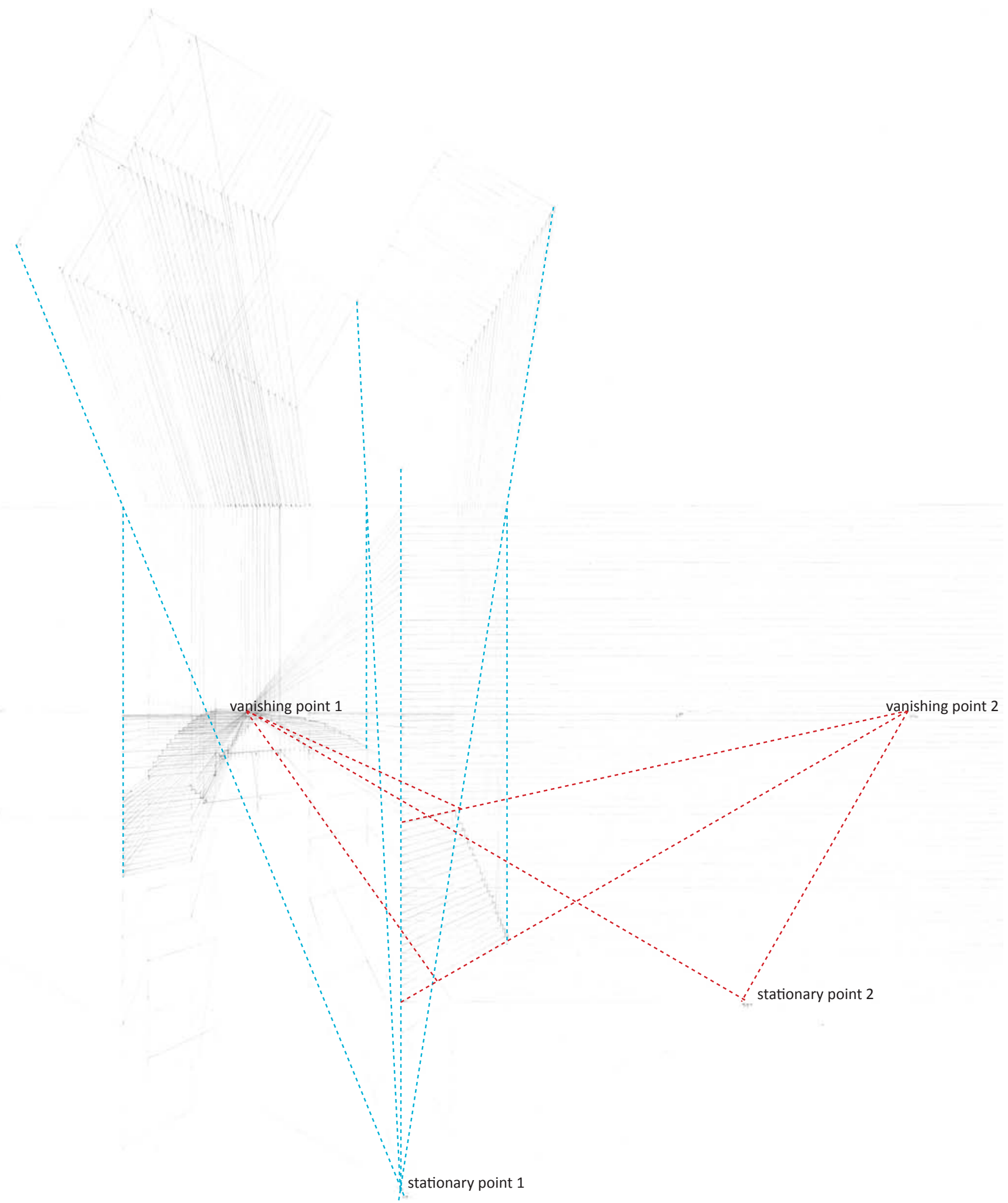




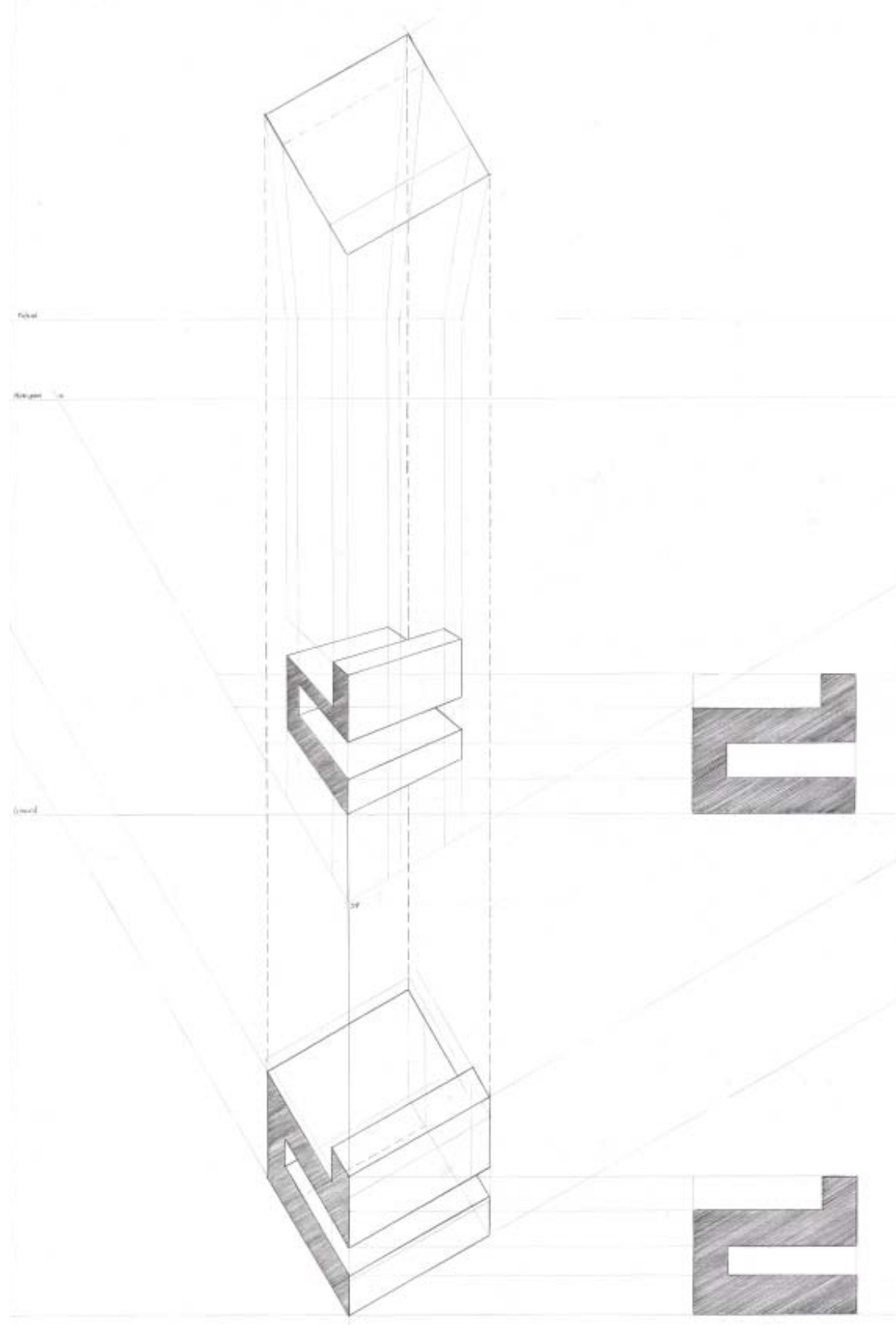

Figure 51-

Illustration of cube drawn in perspective projection (top) and axonometric (bottom). The drawing demonstrates that the perspective projects to a point, while the parallel sides of the axonometric continue indefinitely.

\section{Infinity}

Most historians define perspective as infinite because all lines converge to a point on the horizon, a credible description for how the eye sees. However, the perspective image is in itself finite, 'The world is put into a cubic box and transformed within the picture plane into something resembling a pyramidal form' ${ }^{163}$ The notion of infinity was the subject of critique for many $20^{\text {th }}$ century artists. El Lissitzky, a Suprematist artist and architect described perspective as limiting space, by making it finite and closed. ${ }^{164}$ Suprematism, on the other hand, 'has extended the apex of the finite visual cone of perspective into infinity'. ${ }^{165}$ This was accomplished using the technique of axonometric where lines are parallel and do not converge to a point of infinity, as infinity cannot be reached. In Drawing 8 the incorrect formation of the vanishing points meant all lines no longer converged to these points. What would correctly form planes (Drawing 7) and therefore closed loops, now forms a continuous line that spirals both up and down for as long as the sheet allows. In one direction the spacing between the lines grows ever smaller, and the other larger. The plane being translated to the line introduced a new surface to the drawing and a new interpretation of that surface as form. This type of working process allows the author to read certain qualities into the line. Daniel Herbert, in Architectural Study Drawings, suggests that the line could be interpreted as something other than a line, such as a solid object, new surface or a screen. ${ }^{166}$ The implications of this shift the paradigm of design from static, where the architect does a drawing of architecture, to dynamic, where the drawing is followed to architecture. 
Drawing 8

Figure 52-
The errors within the drawing meant the relationship between projected widths and heights changed. Therefore, the perspective
was not bein for was not being formed through a cohesive reading of the orthography, thus discrepancies occurred. This drawing demonstrates the
implications of separating the stationary point from the vanishing points, where the reading of planes in the drawing shifts to a implications of sep
reading of surface.

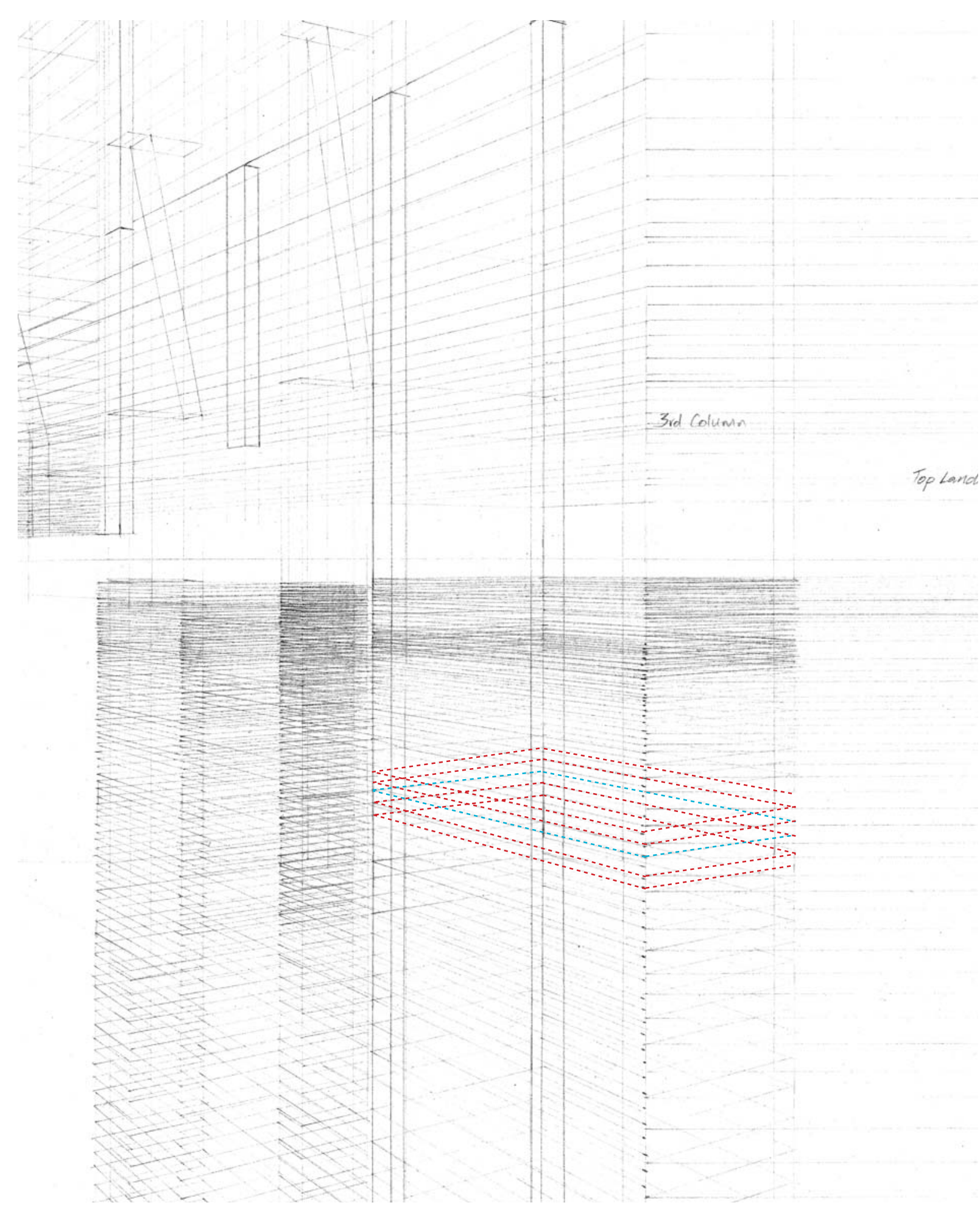


In Drawing 9 the mechanics of perspective were once more critiqued by forming the vanishing points in ways that are regarded as incorrect. This drawing demonstrates two incorrect methods of finding the vanishing points, and the correct (control) method. The correct vanishing points are interesting in this work as prior to this drawing they were being formed incorrectly, when thought correct. This was because without a drawing as reference it is difficult to pick up on all the eccentricities of instrumental perspective. Additionally, the method of finding the points was still rational and close to the correct method, therefore, the only real implication was a drawing that was foreshortened to a greater degree. By including the control vanishing points in Drawing 8, it made it possible to gauge the difference between slight discrepancies in forming the points. Vanishing points 5 and 6 were formed incorrectly, the lines of projection (angle of vision) intersecting the horizon line to locate the points, this produces a foreshortened image as the vanishing points are closer to where the image is formed than they should be. Vanishing point's 1 and 2 produce a more distorted image. These points were found by the lines of projection meeting the picture plane. The planes read as isometric more than perspectival, with an extreme angle of projection between the image and the vanishing point. Vanishing point's 1 and 2 were formed on the same vertical plane as the correct vanishing points, while vanishing point's 5 and 6 were on the same horizontal plane. When looking at the image it seems fair to conclude that the displacement is greater when the position of the vanishing points is shifted vertically.

Once the perspective of Drawing 9 was complete a new elevation was formed atop the old one. This was through a process I've titled 'reverse engineering', which refers to producing orthogonal drawings from the perspective, rather than perspective from orthography. Because there are three perspective drawing formed from their respective vanishing points, the elevation of Drawing 9 differs greatly that of Drawing 8. Only one set of vanishing points are required to gauge the heights that are then projected horizontally on the sheet, for Drawing 9, the correct vanishing points were used (vanishing point's 3 and 4). All the planes formed perspectivally in Drawing 9 were projected back to the vanishing point to determine the height of that plane on the elevation. Since what was drawn with incorrect vanishing points is 'reverse engineered' with the correct vanishing points (different points than it was drawn with), the plane is displaced vertically, positioning those planes at different heights than they were originally drawn from.

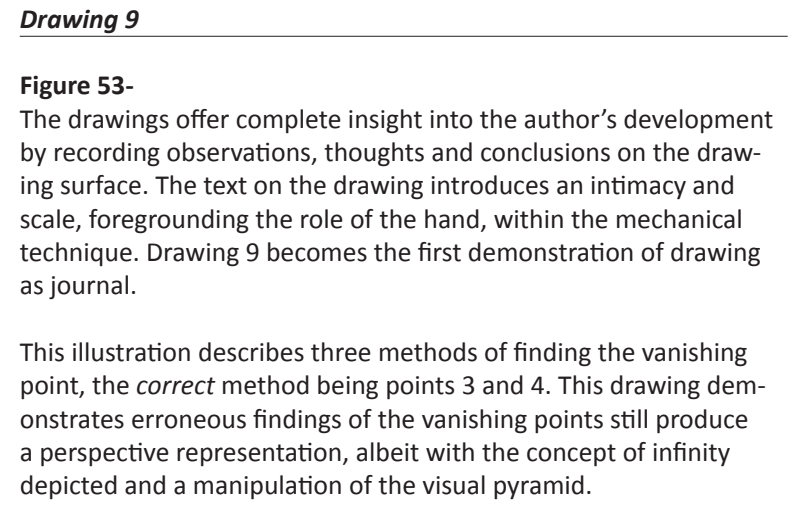

This illustration describes three methods of finding the vanishing onstrates erroneous findings of the vanishing points still produce depicted and a manipulation of the visual pyramid. 


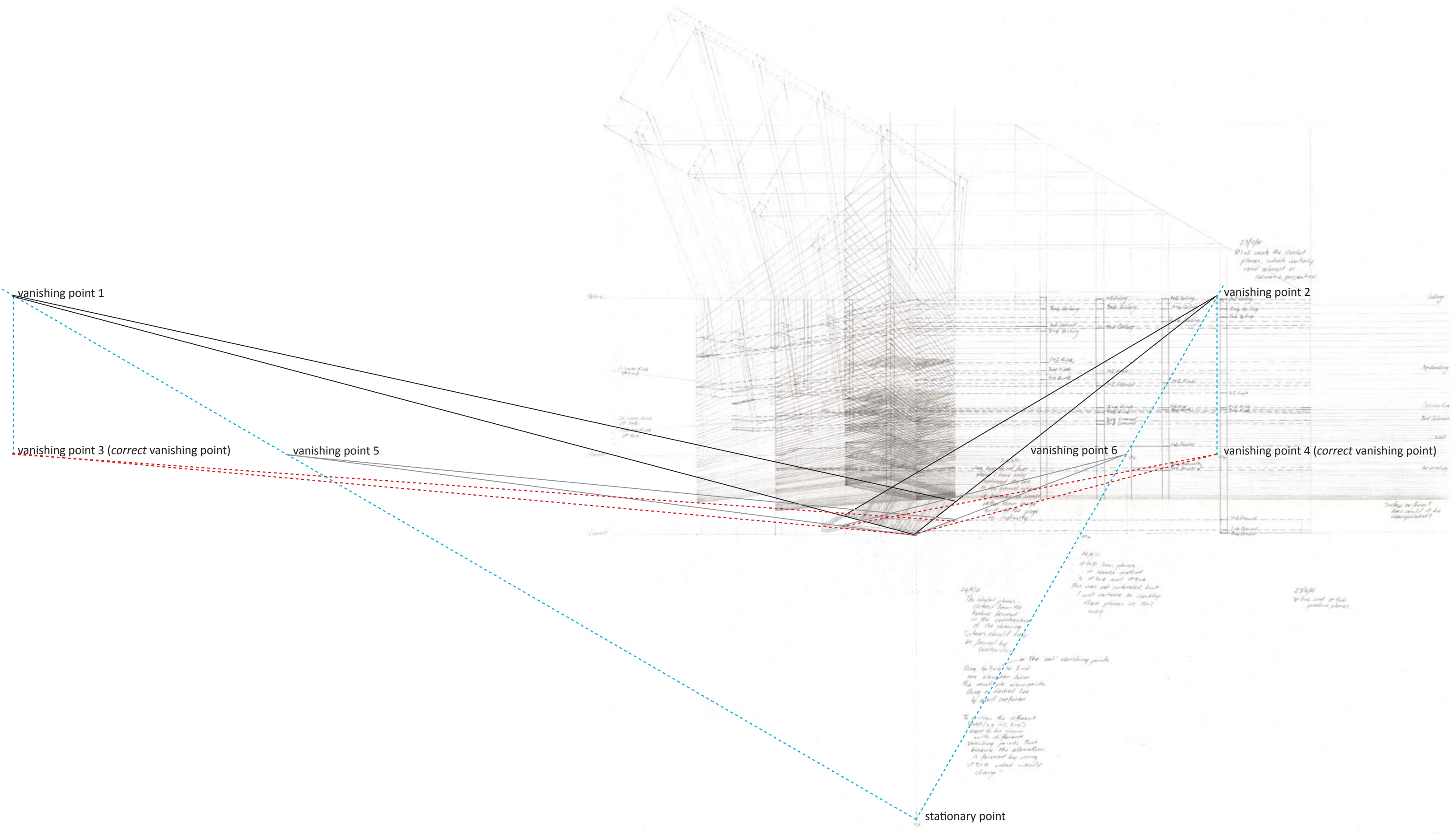




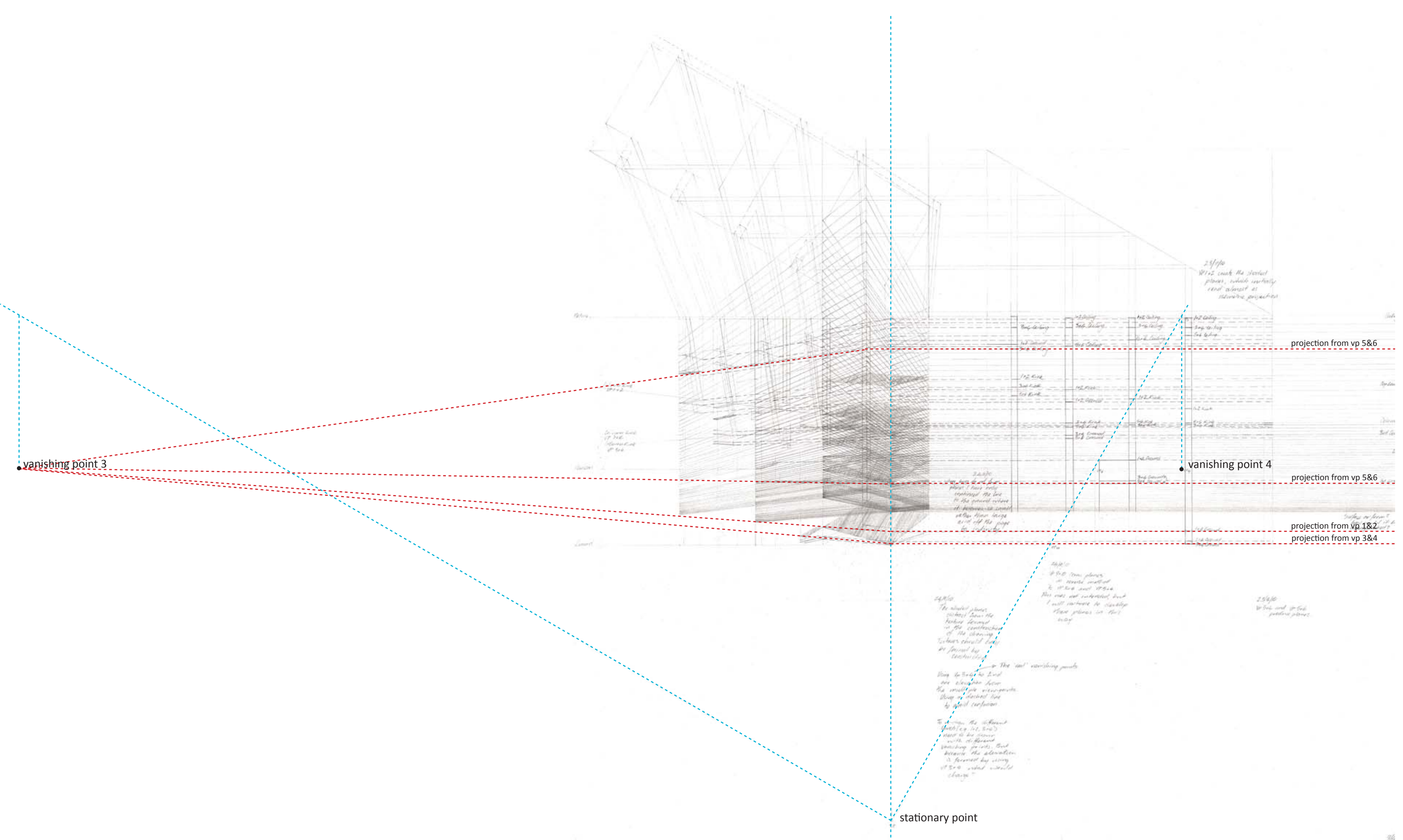


In Drawing 10 this new elevation was drawn with the same plan as Drawing 9, therefore producing a perspective drawing where plan and elevation are not a conclusive set, meaning the projected widths and heights yielded from plan and elevation will not coincide. The new elevations relationship with the plan is manipulated; as such, the spaces between ceiling and floor no longer exhibit the characteristics one would expect. For example, at the top landing a floor which was once below a ceiling is now above the ceiling. The new reading of floor levels provided the appropriate condition to re-insert the staircase, from previous drawings. This moment was identified as a time to include more complexity so as to keep momentum. In addition, the familiarity the staircase offered for the observer to understan their scale within the image allowed me to re-consider the relationship between observer an representation.

Drawing 9

Figure 54-(facing page)

作 and 4 . Thus introducing new levels sinto the drawing

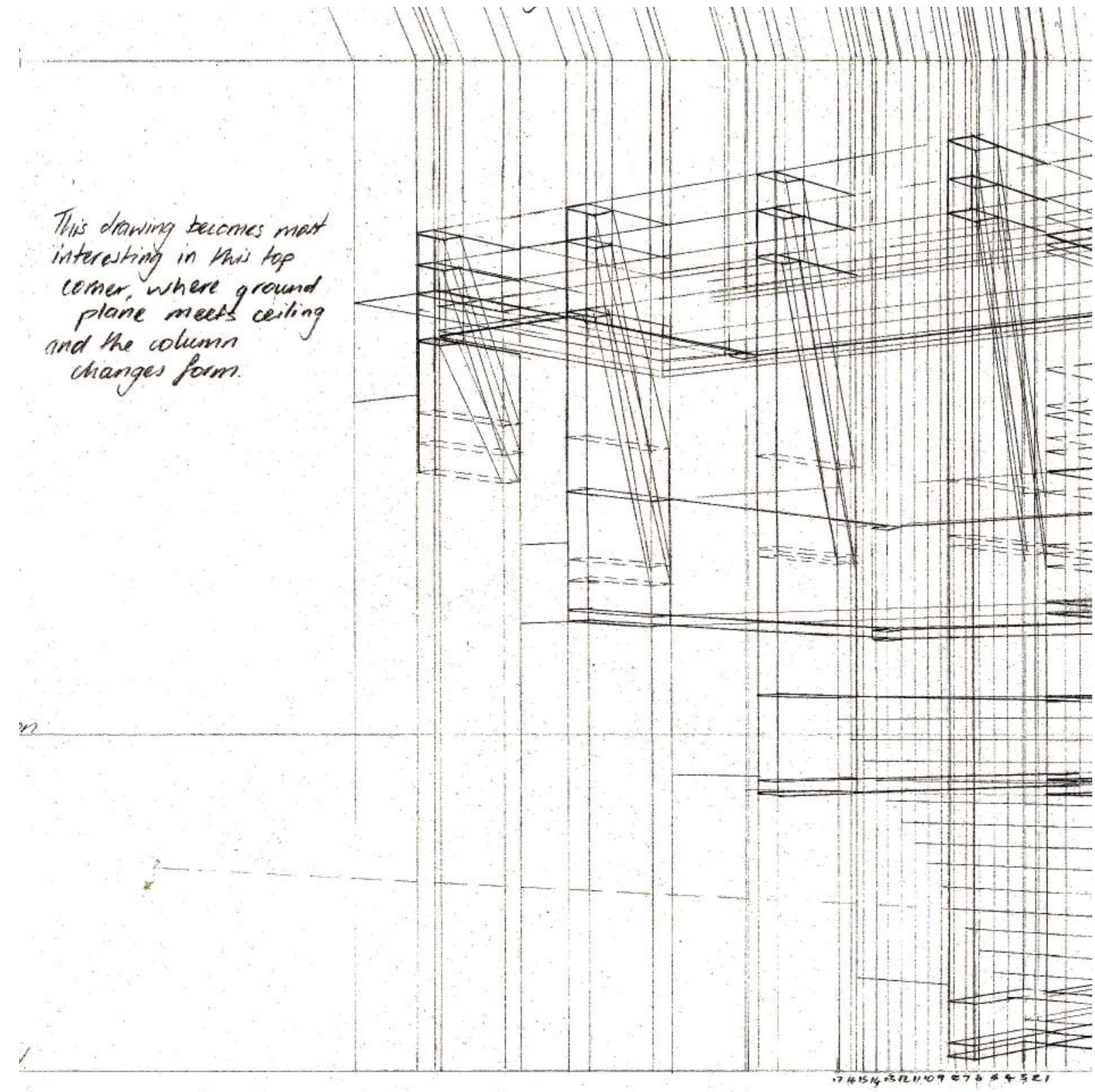

\section{Drawing 10 detail}

Figure 55

wing by author illustrating the condition of the level of vanishing points the eleverstion is is displaced, the ceiling positioned of vanishing points the eleval
above the ground level. 


\section{Re-introducing the Stair}

Drawing 11 re-introduced the staircase. The stairs were drawn in elevation using the column levels from Drawing 10 as a guide. Because the new levels proposed three heights for each column, each run of stairs was drawn for a corresponding height, resulting in stairs three runs high. The most interesting junctions occur at the landings where gaps or strange changes in level result in a stair meeting a landing above it. The ceiling and floor junction from Drawing 10 becomes more apparent, as the top staircase is drawn very close to the ceiling. This drawing begins to question how the drawing is interpreted by the author when there is not one definitive method for interpretation. This is because when the drawing is incorrect there are multiple answers. ${ }^{167}$ Drawing 12 demonstrates a different interpretation of the plan and elevation drawn in 11. While Drawing 11 interpreted the planes as different levels even though there was only one plan level, Drawing 12 interpreted the elevation as a series of longitudinal planes. Because linear perspective is usually comprised of a plan and elevation that match geometrically there is no need for this type of interpretation. In Drawing's 11 and 12 the plan and elevation no longer matched, hence the two different results. Due to multiple interpretations the perspective image can be 'reverse engineered' to find a plan different to the one that drew the perspective initially.

Drawing 11

Figure 56- (top) 

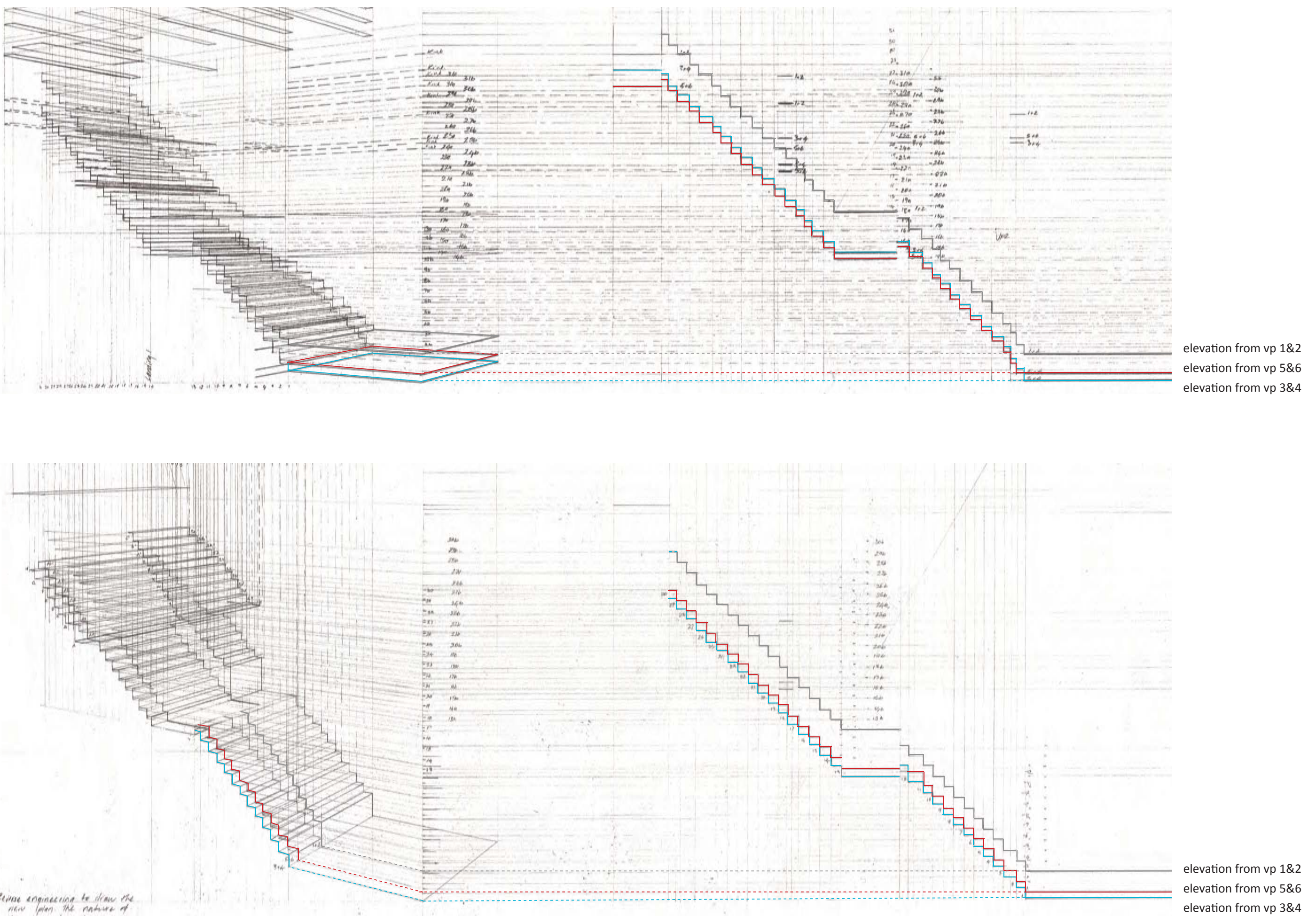
Drawing 13 demonstrates the same plan and elevation as Drawing 12 and a similar perspective. The focus in this drawing shifted back to that of drawing technique. When a perspective image is drawn correctly assumptions can be made. For example a stair need only have its east elevation projected in plan, not its west as well. By the system of projection a correct stair should form through the use of the vanishing points. When the mechanics of the drawing system are manipulated, these assumptions no longer hold true. In Drawing 13 points from both axis of the staircase needed to be projected. In doing this the vanishing points no longer formed a line connecting the two, therefore dismissing the two vanishing points from their drawing duty. Again this move opened the image up to interpretation, the stair could be interpreted as having hundreds of vanishing points, or the stair could no longer resemble what one believes a stair to look like by the manipulation of geometry. To fully explore the condition of the staircase, interest was drawn to the drawings construction lines, and consideration for how these line could be part of the image by being modelled in three dimensions. Perspective was used as a tool to resolve a translation from three dimensional drawing to three dimensional object. The perspective wa then 'reverse engineered' to find the four elevations that would form plates in the model. This was where coding and the section became essential components of the drawing. Because the plan of the stair has multiple planes and all the stairs along each plane project to different vanishing points each section need to be interpreted individually and translated onto the elevation plates. The model did not house the stair, just the construction of the stair. This interest in construction came from necessity through manual drawing, yet it is interesting to contrast with the digital drawing, where working process and the construction of images is concealed. The model experiment failed to achieve more than the drawing of the model showed and, therefore was unsuccessful. However, the coding process of the elevation planes that defined the construction lines, which was necessary to produce the model, offered a new elevation for Drawing 14

In Drawing 14 the new plan (from Drawing 12) was used and the remaining stairs from the original plan were re-introduced. The elevation for Drawing 14 was formed from the elevation planes made for the model of Drawing 13. The elevation planes in Drawing 13 were transverse and the drawing required a ongitudinal elevation. To construct the longitudinal elevation both transverse elevations were drawn and spaced according to the plan, and, by connecting the coordinates from the two elevations in combination with the projected widths from the plan, the elevation was formed (Figure 58)
In these examples the drawing became a method of solving problems in advance of constructing the model. Drawing 13 replicates the perspective of the model, meaning the planes were formed through a system of 'reverse engineering'.

The process and duration of the drawing process came to the fore in Drawing 14, the construction and the object became as important as each other, the elevation and plan also becoming part of the perspective image. The issue with the drawing became its complexity, no doubt affected by the uniformity of line weights and sheer number of lines. Due to these conditions human error became a problem. The system, sually so simple, was becoming difficult to navigate for the author and, no doubt, the viewer. However, the lines and the detail inserted a new dimension into the drawing; the real time of constructing.

\section{Building the Drawing ${ }^{168}$}

When Drawing 14 was complete it singled an end to the exploration of perspective. This was because Drawing 14 took perspective so far from the convention that it could no longer be called systematic space, nor could Drawing 14 be repeated for the same outcome. The research could span many places from this concluding point. The possibilities included producing a taxonomy of incorrect perspective or a detailed description of how the manipulations create new forms and spatial understanding. Alternatively, the drawings suggested that each one could be interpreted and concluded as in Drawing 14, by retracing steps and committing to reinterpreting each drawing, until the outcome was more tree-like than linear. Both of these demonstrations would continue to test the architect's control of the perspective image, through flawed or plural demonstrations. However, the dynamic paradigm within the work, that of building drawings toward an architecture, suggested that the conclusion should be built and taken into nother realm of representation. Thus to build the drawing, from a singular perspective view I once more needed to engage in the process of 'reverse engineering' and take the drawing back to the orthographic set, to produce drawings static enough to be built. 


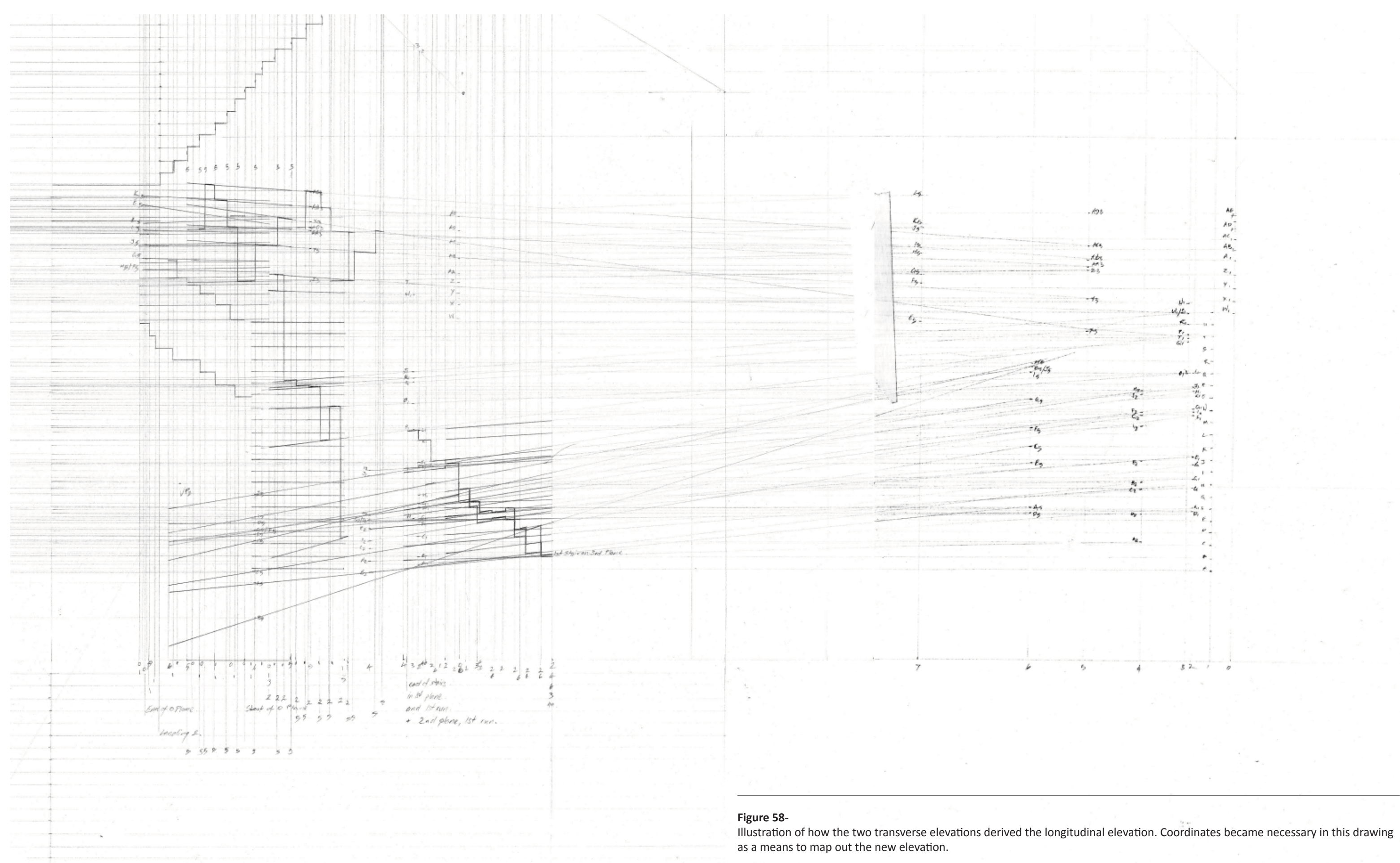

Illustration of how the two transverse elevations derived the longitudinal elevation. Coordinates became necessary in this drawing 
Drawing 15, a direct reproduction of the perspective image produced in Drawing 14 was a necessary start point to find the orthographic set. The plan and elevation revealed in Drawing 15 are different to that in Drawing 14, because the system of perspective is no longer repeatable and rational. In re-drawing the elevation all the sections of the stair plans were drawn on individual sheets, with the hope of making the translation from drawing to model simple and methodical. The exercise of 'extracting' the section by hand was translated to the computer to gain consistency between the sections and plan. When developing the design methodology the construction of the drawing became as important as the outcome, so, to build the drawing was also to build the construction of the drawing rather than just build the perspective object. To produce the perspective object within the construction lines on the sheet, the section planes were pulled out so the drawing would appear to float within the line. Because of this every set of stairs needed to be drawn correctly first and then extended along the same magnitude to the location of the model planes. After this every line could be specified and coded. Making the drawing in three dimensions was a methodical exercise of matching each built line with the corresponding codes on the model planes. When the drawing was built in three dimensions it was the first time that the author engaged with the perspective from alternative angles. The process of making the model could be likened to Dürer's method of drawing a lute, which too was a methodical exercise which formed the image through the projection of filament.

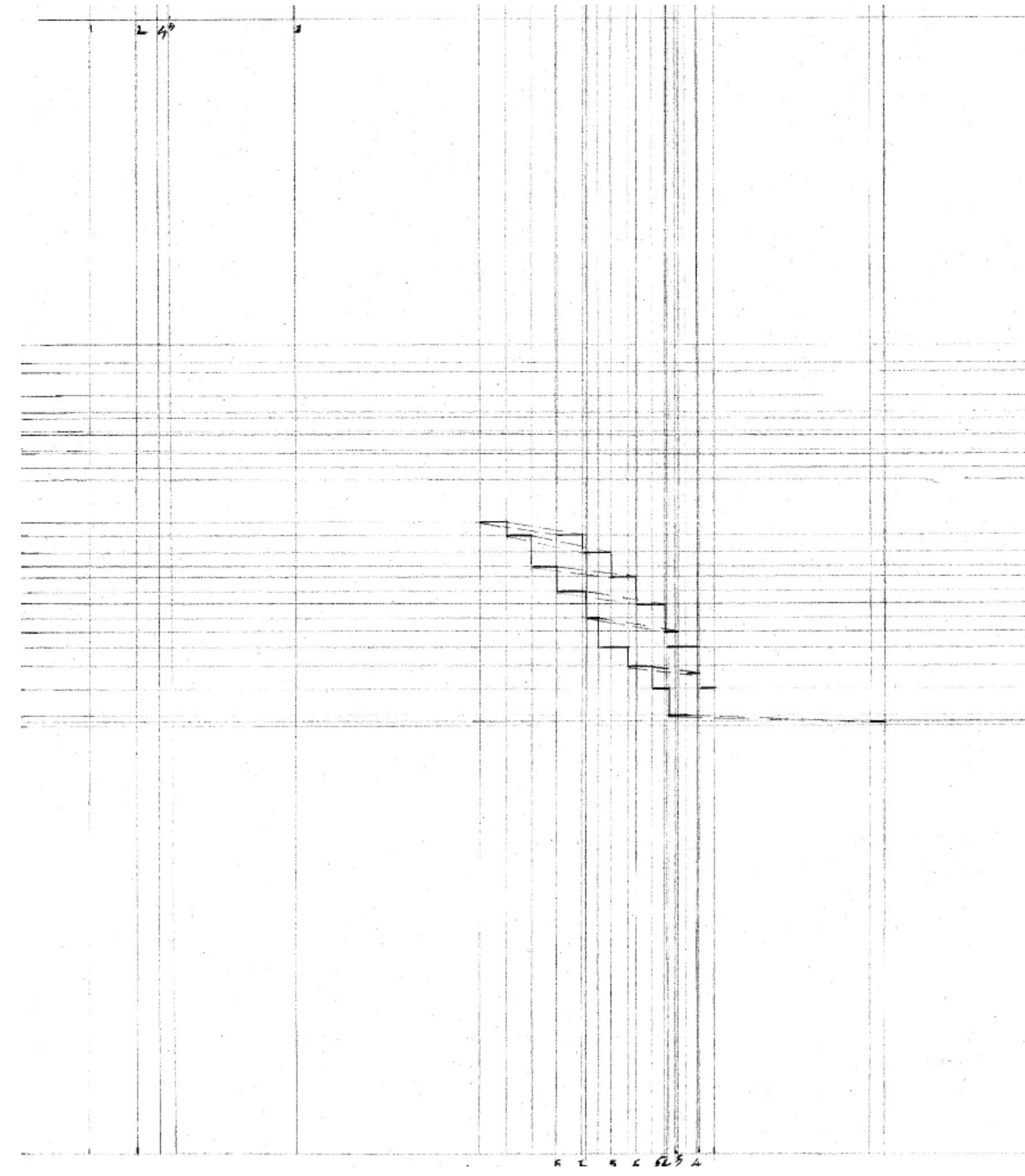

Figure 59-

One of the section drawings 'reverse engineered' from Drawing 15.

The section drawings were required to buld the drawing. 

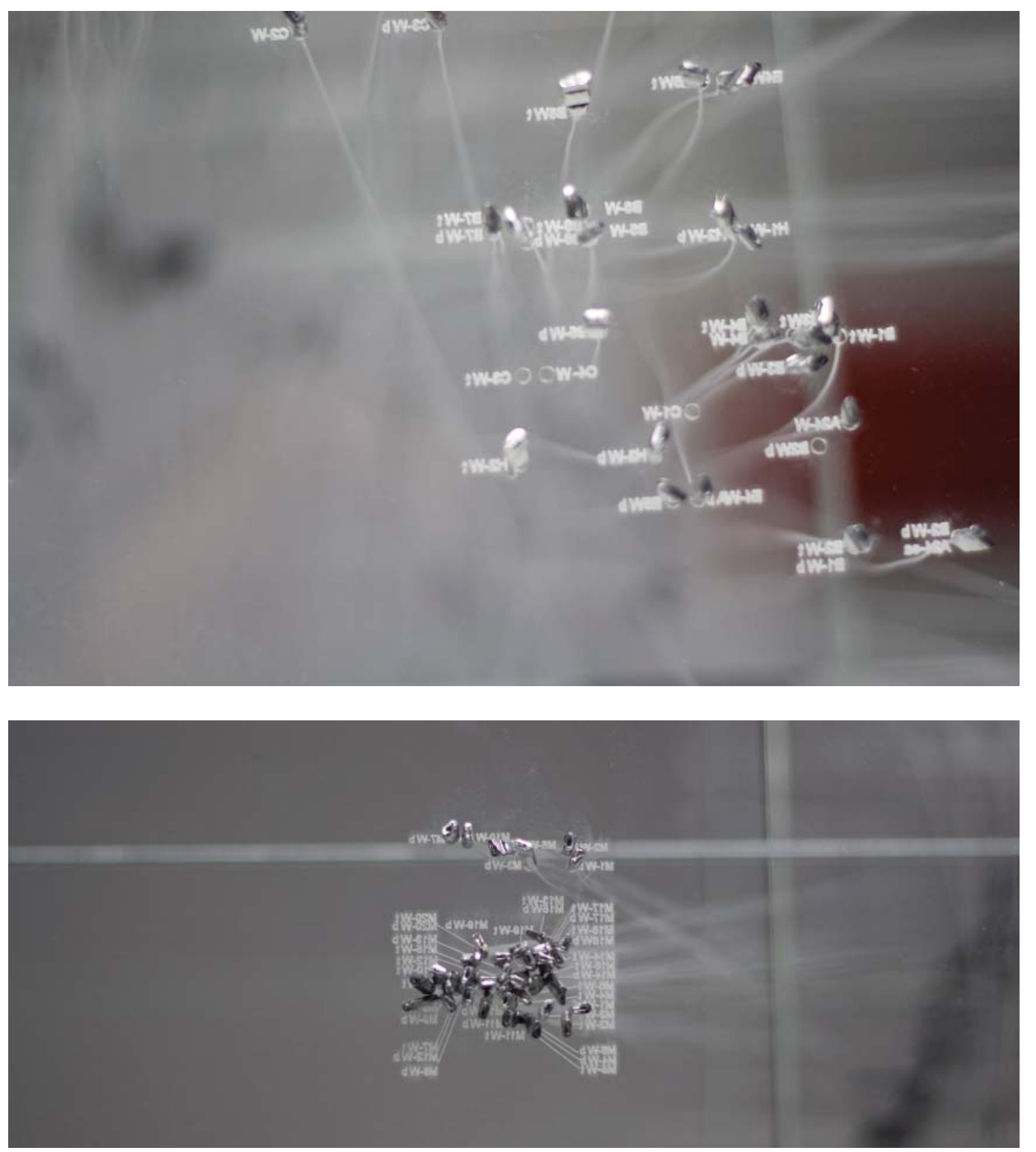

Model : details

Figures $60,61,62$ -

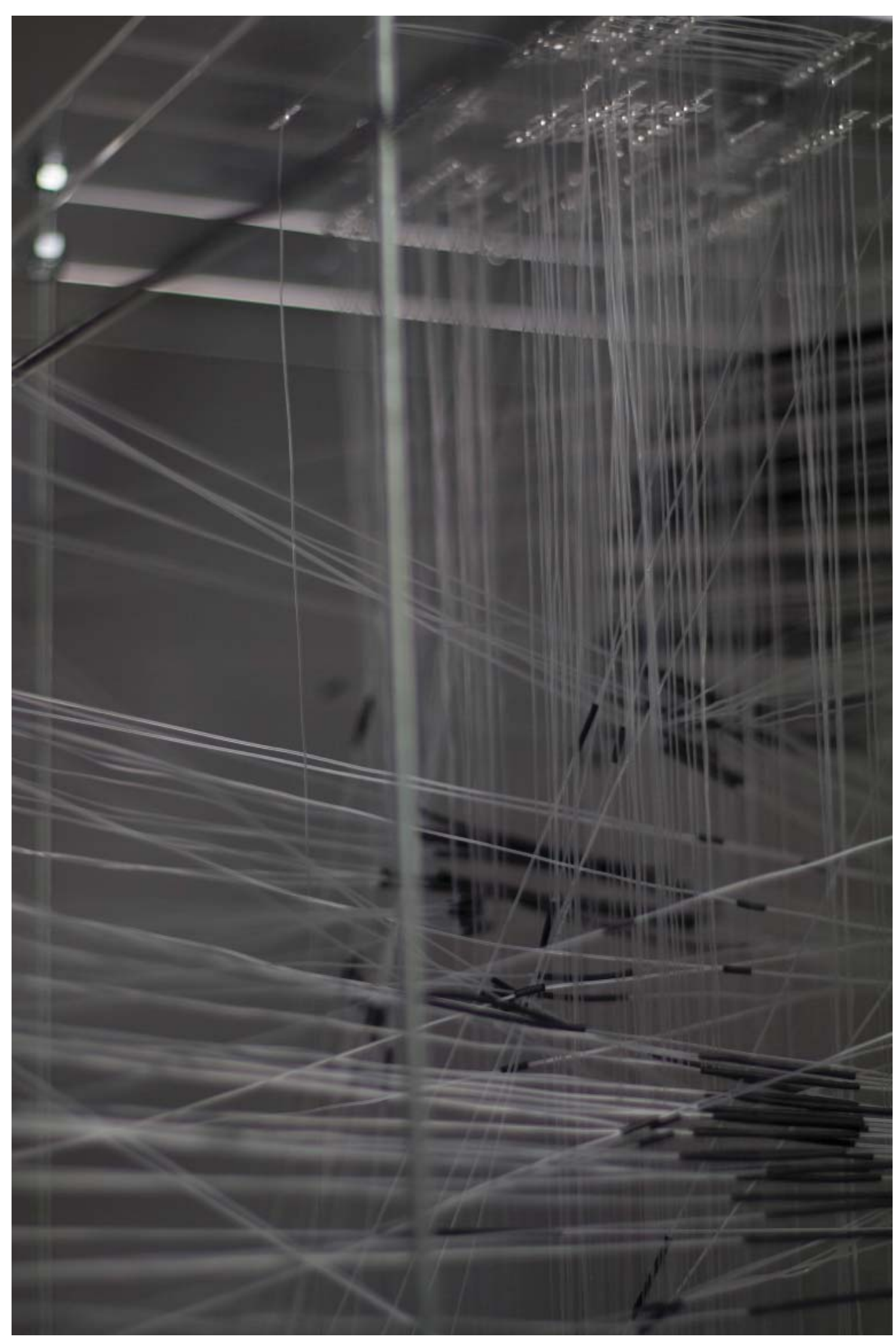

drawing, meeting in the middle. 
This work demonstrates the possibilities the drawing offers to '... become the "project", or hypothesis, of a new reality that we wish to create ${ }^{169}$ The model demonstrates how the drawing can be considered as an end in itself. This is because the model and the drawing are both built in much the same way as architecture, positioning the architect as builder and drawing as building. As architecture, the drawing follows the rules of gravity, and begins with setting out the page rather than setting out the site. The model was the same, first building the planes and structure that will then support the stairs (. Both drawing and model are built as physical entities, the hand present in the construction of both. These analogue processes celebrate the hand of the maker, demonstrating a direct and tactile relationship to the making of space. Whilst the physical three dimensional drawing is inhabited by the maker and subsequently the observer (as the drawings are too) this research aims to demonstrate that such relationships are impossible within the digital drawing, where one only engages optically with the representation. The optical engagement limited by the cryptogram, technogram and most especially the calligram
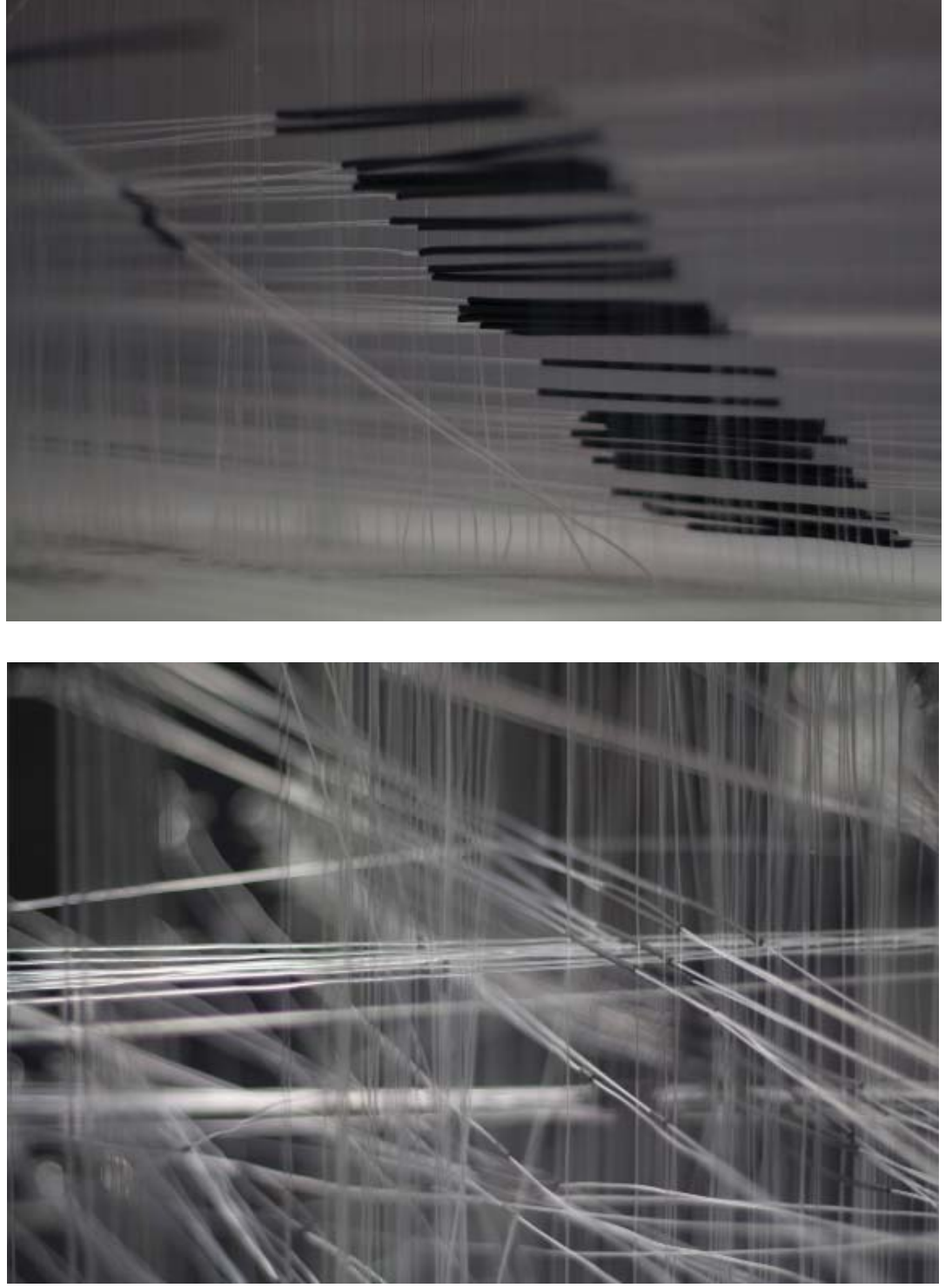

Model

Figure 63, and Figure 64- (above)

Photographs demonstrating inhabtation of the drawing through the observer's eye. The camera was positioned outside the one perspective view the image was designed within

Figure 65- (facing page)

The model in its entirety, demonstrating the perspective drawing from a similar vantage poin as he draw 


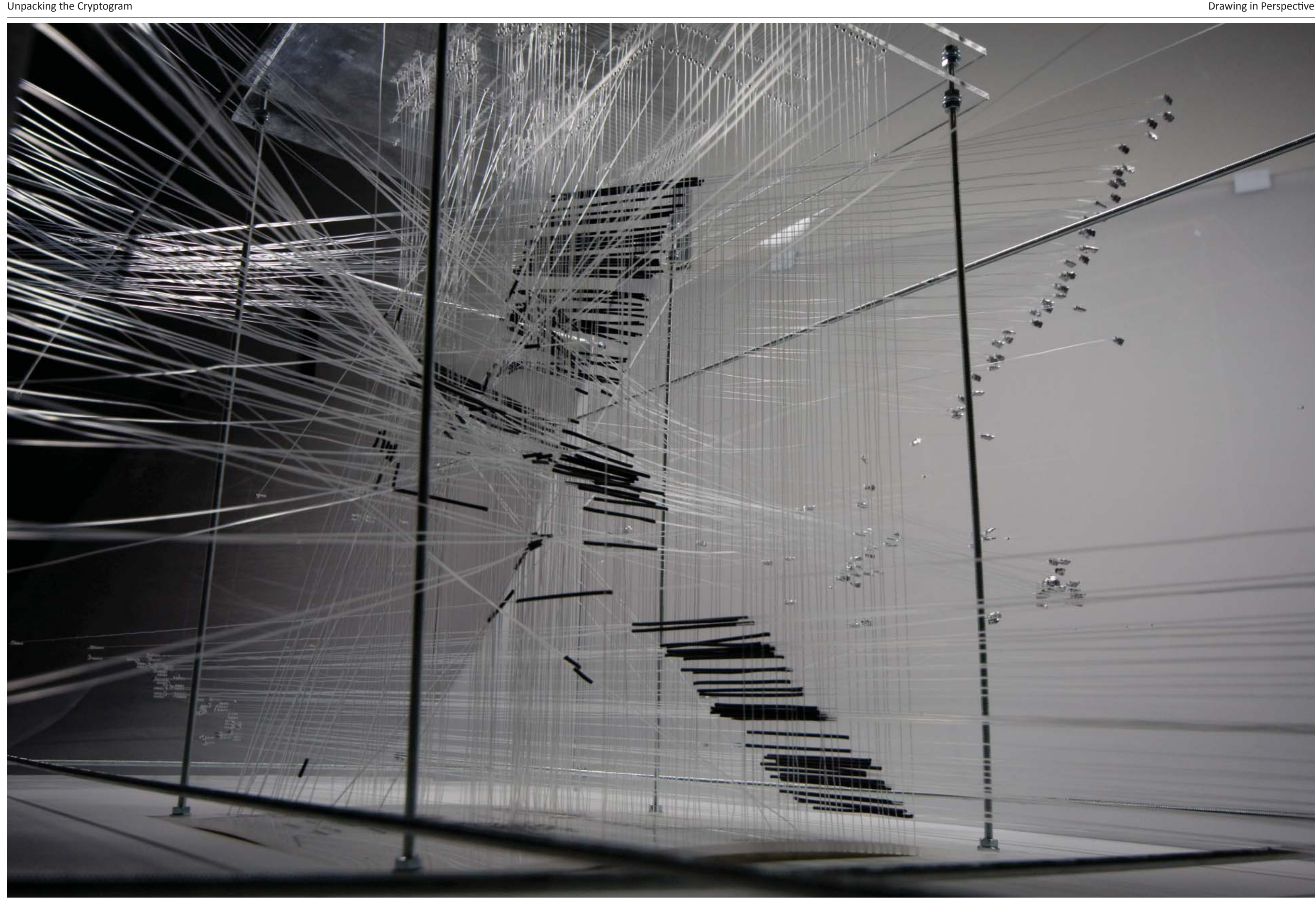



Discussion 
This research suggests that by manipulating the codes of linear perspective one can produce a more discursive spatial appreciation and critical use of the perspective image. Such manipulation demonstrate a willingness to uncover the paradoxes that define our representation. These interpretations require methods of construction to be considered as a means, rather than result, of design, engaging in a dynamic paradigm of finding architecture through drawing, rather than drawing architecture conceived from an external reality. The drawings propose that modes of representation are vital to creative architectural practice and thus should be understood in all their complexity rather than as utilitarian.

\section{Binocular Vision}

Observations within the research demonstrate that by manipulating rules of linear perspective a representation can be better understood as symbolically true to vision. The limitations of Brunelleschi's assumptions become evident and can be rectified through the erroneous interpretation, such as the drawings which demonstrate a binocular or kinetic vision by positioning the vanishing point and stationary point on differing perpendicular planes. Drawing 4 shows rational and repeatable space can still be achieved through this differing interpretation of the drawing components. It demonstrates a more critical understanding of the fixed perspective image. However, binocular vision is demonstrated in the work as being within a system that remains repeatable and rational (like linear perspective) but also system which ceases to be repeatable and rational. This is due to the distance between the two stationary points. These differences are highlighted in the different results of drawings 4,5 and 6 , informed by the same concept. Drawing 5 and 6 extend the convention more than drawing 4 by situating the vanishing point at a greater distance from the stationary point, thus, taking the drawing outside of the rational paradigm. Therefore, any interpretation of the drawing enters into the discourse, meaning the identical image is impossible to reproduce. This misinterpretation of the perspective code finds similarities to the nineteenth century stereoscope; yet, the stereoscope has never found its way into the architectura drawing, rather, finding its position in discourse as a physical looking device, much like binoculars, or amongst mechanisms for vision such as the camera obscura and photographic camera. The most prominent research into stereoscopic vision with reference to architecture is through Haralambidou's thesis; however, her means of communication were in model form, focusing on binocular vision through physical engagement with the three dimensional object. Drawing 4, therefore, presents a new method of producing the perspective drawing, whilst remaining a repeatable formula, demonstrating a more corporeal vision than correct linear perspective. Drawing 5 and 6 indicates how the world we live in is neither fixed, nor repeatable and therefore still demonstrate a credible representation of space.

\section{Ambiguity and Abstraction}

The re-coding of Brunelleschi's rule demonstrates a new spatial representation in keeping with the ambiguity and abstraction one relates to design processes, rather than the static fixed view of built architecture found in an architectural photograph. For example this reading of the results suggests an architecture conceived at the drawing board could be considered a more critical method of design as it fully encompasses ambiguities and abstractions within the design process. The computer, which codifies every step into a recognisable software package, fails to reference such ambiguities. Every line drawn onto the computer is either permanently present or permanently erased. There is no evident process, nor duration. The architect's control of working processes is defined by the code and drop down menus, shutting down a conceptual thought process. In exploring the hand drawing it was hoped that representational tools would become more critical over the design process rather than understood as explanatory material for the making of buildings. Inadvertently, the representational method becomes a vital part of the design process. These interpretations find precedence in the scholarship of Kenzari and Pallasmaa who argue the hand is a tool which has evolved in such a way that its relationship to the design process or drawing medium is almost intuitive. The mouse, however, is a fundamentally different tool that is not yet fine tuned in the process of design. ${ }^{170}$ This observation is in keeping with Mallgrave's argument in the The Architect Brain, albeit for different reasons. These reasons recall the use of the brain is different for each tool, the mouse only encapsulating a singular part of the brain, while the hand engages with many areas and is, therefore, a more varied neurological experience. ${ }^{171}$ The critique of the computer suggests an architecture produced by the hand is more able to occupy the 'grey' territory; that which is undefined, speculative or experimental. 


\section{Controlling Representation}

The significance of these results encourages one to reconsider the tradition of conceiving architecture which materialised in the Renaissance. Different from other creative disciplines whose labour is directly reflected on the object, the architectural drawing is an intervening medium, and it is where the architect executes complete control over what is built. ${ }^{172}$ The fundamental differences between digital representation and manual representation refer to the architect's control of the representational system and an understanding of how the system produces the image. This understanding is decreasing with an increased reliance on digital tools. The orthographic set for example, is explicitly linked to the perspective image. In digital drawing systems the plan and elevation are separated onto different 'sheets' conceived of separately, and apart from the perspective. An understanding of projection techniques is absent, as is the close relationship fused between plan, elevation and perspective projection. The computer removes an need to understand these relationships meaning the system of representation cannot be used in the architects favour. The physical model is an example of understanding the relationship that occurs between orthography and perspective, alike Piero della Francesca, showing that in orthography, as in real life, the perspective is formed through such relationships. ${ }^{173}$ The orthographic drawings which on the sheet interrelate through their alignment and dimensions, have been re-arranged to form a three dimensional box, the relationship between the drawing components identical to if it was drawn on a planar sheet.

\section{Dynamic paradigm}

Like the drawings the model can be understood through a dynamic paradigm of finding architecture. This is due to the models 'means of construction'. Constructed through a singular perspective view and then re-drawn through the orthographic set, the model was only understood through orthography and a singular penetration of the picture plane. In traditional representation the other perspectives could be understood through the orthography, however, because the drawing was no longer repeatable and rational due to discrepancies between plan and elevation this was not the case, the other perspectives outside one's spatial imagination. The model's construction, much like the drawings was revealed through a labyrinth of lines, every line first codified in its length, and location. Because the model demonstrates both the

172. Robin Evans, 'Translations from Drawing to Building', in Translations from Drawing to Building and Other Essays, by. Robin ciation: London, 1997, p. 156 drawings construction and the drawn object the means of emphasising the object line on the construction was also preconceived. In considering the model as a built perspective drawing it should not be understood as the artefact of a process, but rather a means to re-interpret the perspective drawing in another representational medium. The model demonstrates that through an understanding of perspective and orthography the drawing can be physically built. By using 'manual' techniques one is better equipped to understand the convention and, therefore, can manipulate or rearrange it to suit a certain means of representation. Thus, the 'tactile' drawing can be considered a more discursive method of design, one where the architect executes complete control over the design process and representational outcome. 

Conclusion 

This research introduced the implications of a fixed and static system and how the rules which Brunelleschi prescribed are adverse to natural vision, instead, rationalizing representation. Architecture is limited by representation; historically, the limitations of perspective as a static system for representation were understood by the author's. With the use of linear perspective growing exponentially, first due to the camera and now the digital image, perspective is presently understood as a credible explanation of visio and is thus used in this means by architects. The digital image is a direct reproduction of Brunelleschi's baptistry demonstration, and therefore, abides to the single immobile eye and the planar cross section. This representation of space is, therefore, mathematical. I have argued perception to be outside of mathematics and natural vision to be psychophysiological. The idea of psychophysiological rather than mathematical space is understood through both the hand drawing and a manipulation of perspectives rigic code. By interpreting the hand drawing to illustrate the 'grey' region, it becomes closer to the fundamenta senses of the body and therefore can better be interpreted as psychophysiological.

Architects who submit to the persuasive method of computer aided design are controlled by the representational systems prescribed by the software. Whilst a fixed and static system of representatio may be necessary to produce buildings, the process of design involves more abstract thought and ambiguity. The computer removes such ambiguity and the architect inadvertently becomes controlled by a representational programme. There is a risk that architects will become more concerned with such representational modes be that traditional or digital, than critically using representation as a means to translate thinking (or drawing) into real life. My design work attempts to correct the representationa image as passive, by demonstrating complete control over a representational code in manual drawings. The drawings present an argument to advance an architecture in keeping with a corporal view of the world, as fragmented, contradictory and dislocated. The drawings demonstrate with rigour that representation need not be fixed, rather demonstrating a number of modes of spatial representation are possible, signifying the representational system as a critical component of the design programme rathe than merely a tool. While digital technologies threaten to override manual drawing and technique within architectural practise and education, these drawings throw doubt on the advancement of computer generated design.

This research tested the bias of perspective. This has become even more necessary today due to most perspective images being produced digitally. In drawing a number of perspectives which willingly 'violate' Brunelleschi's convention, the fixed perspective image, which is written into computer software, is challenged. Thus the author of the 'tactile' drawing is demonstrated to fully control their means and results of representation.

I suggest that common modes of architectural perspective are flawed. What else, then, might be taken for granted within architectural representation? Perhaps the discipline is better suited to rules of thumb than definite black and white systems, which restrict the architect's creativity. If the architect continues to work in the field of representation as they have for the last five hundred years they must too attempt to question their means and systems of representation. If the computer continues to be the dominant mode within architectural representation, it must be addressed critically, otherwise architects may fall into its autonomy and produce architecture that is both mediocre and familiar. 

Bibliography 
Bryson, Norman. 'The Gaze in the Expanded Field'. In Foster, H. (ed), Vision and Visuality, Seattle: Bay Press, 1988, pp. 87-108

Cassirer, Ernst, The Philosophy of Symbolic Forms, vol. two: Mythical Thought, Manheim. R. (trans), New Haven: Yale University Press, 1955

Chard, Nat, Drawing Indeterminate Architecture, Indeterminate Drawings of Architecture. New York: Springer Wien New York, 2005

Chard, Nat, 'Drawing Instrumemts', Architectural Design , 75 (4), 2005, pp. 22-29

Crary, Jonathan, Techniques of the Observer: On Vision and Modernity in the Nineteenth Century. Cambridge, Massachusetts: MIT Press, 1992.

Damisch, Hubert. 'Notes for a Phenomenology of the Photographic Image'. In Trachtenberg. A (ed) Classic Essays on Photography, Stony Creek: Leete's Island Books, 1980, pp. 287-290.

Damisch, Hubert, The Origin of Perspective, Goodman, J. (trans), Cambridge, Massachusetts: MIT Press, 1994.

Demos, T. J. 'Seeing Double', 2007,

Attp///www.domobaal.com/resources/penelopeharalambidou/penelope-haralambidou-ti-demos-

domobaal.pdf

Dubery, Frank and John Willats, Perspective and other Drawing Systems. New York: Van Nostrand Reinhold Company Inc, 1972.

Edwards, Jeffery, and George Whale, 'Defining an Alternative Picture Space'. Digital Creativity , 15 (3), 2004, pp. 129-142.

Elkins, James, 'Renaissance Perspectives', Journal of the History of Ideas , 53 (2), 1992, pp. 209-230.
Evans, Robin, The Projective Cast. Cambridge, Massachusetts: MIT Press, 1995.

Evans, Robin, 'Translations from Drawing to Building' In Evans, R (ed), Translations from Drawing to Building and other Essays, London: Architectural Association, 1997, pp. 153-193.

Field, J. V., 'Piero della Francesca's Perspective Treatise' In Massey, L (ed), The Treatise on Perspective: Published and Unpublished, Washington, D.C.: National Gallery of Art, 2003, pp. 63-77.

Frascari, Marco, 'Horizons at the Drafting Table: Filarete and Steinburg'. In Perez-Gomez, Alberto and Stephen Parcell (eds), Chora Five: Intervals in the Philosophy of Architecture, Montreal: McGill-Queen's University Press, 2007, pp. 179-200.

Goodman, Nelson, Languages of Art: An Approach to a theory of Symbols. Indianapolis: Bobbs-Merrill, 1968

Haralambidou, Penelope, ‘The Stereoscopic Veil’, Arq , 11 (1), 2007, pp. 36-49.

Haralmabidou, Penelope 'Given: The Corridor, the Tower and the Fall...' , 2007, http://www.domobaal.com/resources/penelopeharalambidou/penelope-haralambidou-essay-domobaal.pdf

Herbert, Daniel, M., Architectural Study Drawings. New York: Van Nostrand Reinhold, 1993.

Hill, Jonathan, 'Allegories of Architecture', 2007,

http://www.domobaal.com/resources/penelopeharalambidou/penelope-haralambidou-jonathan-hilldomobaal.pd

Hill, Jonathan, 'Building the drawing', Architectural Design, 75 (4), 2006, pp.13-21

Kenzari, M. B., 'Sketching, Computing and Knowledge Engineering', Architectural Science Review, 4 (2), 1998, pp. 81-87.

Kepes, Gyorgy, Language of Vision. Chicago: Theobald, 1961. 
Kipnis, Jeffery, Perfect Acts of Architecture. New York: Musuem of Modern Art, 2001.

Lissitzky, El, Russia: An Architecture for World Revolution, Dluhosch, E. (trans) London: Lund Humphries Publishers Limited, 1970

Mallgrave, H. F, The Architect's Brain: Neuroscience, Creativity, and Architecture. West Sussex: John Wiley \& Sons, 2010.

Manetti, Antonio, The Life of Brunelleschi. London: The Pennsylvania State University Press, 1970.

McGrath, Brian, and Jean Gardner, Cinemetrics: Architectural Drawing Today. Great Britian: WileyAcademy, 2007

Pallasmaa, Juhani, The Thinking Hand: Existential and Embodied Wisdom in Architecture. West Sussex: John Wiley \& Sons Ltd, 2009.

Panofsky, Erwin, Perspective as Symbolic Form, Wood, C. S (trans), New York: Zone Books, 1991.

Perez-Gomez, Alberti and Louise Pelletier, Architectural Represenation and the Perspective Hinge. Cambridge, Massachusetts: MIT Press, 1997.

Spankie, Ro, 'Exhibition and book reviews', The Journal of Architecture, 14 (4), 2009, pp. 533-537.

The National Gallery, 'A Peepshow with Views of the Interior of a Dutch House', [n.d], http://www.nationalgallery.org.uk/paintings/samuel-van-hoogstraten-a-peepshow-with-views-of-theinterior-of-a-dutch-house

Zambonini, Giuseppe, 'Representation and/or the making of Form' In R. Miller (ed), Implementing architecture: exposing the paradigm surrounding the implements and the implementation of architecture Atlanta: Architecture Society of Atlanta in collaboration with Nexus Press, 1988, pp. 41-45. 

Appendix 


$\begin{array}{ll}\text { FIGURE } 1 & \text { Author: Drawing 0, } 2010 \\ \text { FIGURE 2 } & \text { Author: Drawing 1, } 2010 \\ \text { FIGURE } 3 & \text { Author: Drawing 3, } 2010 \\ \text { FIGURE } 4 & \text { Author: Drawing 4, } 2010 \\ \text { FIGURE 5 } & \text { Author: Drawing 5, 2010 } \\ \text { FIGURE 6 } & \text { Author: Drawing 6, 2010 } \\ \text { FIGURE 7 } & \text { Author: Drawing 7, 2010 } \\ \text { FIGURE 8 } & \text { Author: Drawing 8, 2010 } \\ \text { FIGURE 9 } & \text { Author: Drawing 9, 2010 } \\ \text { FIGURE 10 } & \text { Author: Drawing 10, 2010 } \\ \text { FIGURE 11 } & \text { Author: Drawing 11, 2010 } \\ \text { FIGURE 12 } & \text { Author: Drawing 12, 2010 } \\ \text { FIGURE 13 } & \text { Author: Drawing 13, 2010 } \\ \text { FIGURE 14 } & \text { Author: Drawing 14, 2010 } \\ \text { FIGURE 15 } & \text { Author: Drawing 15, 2010 }\end{array}$





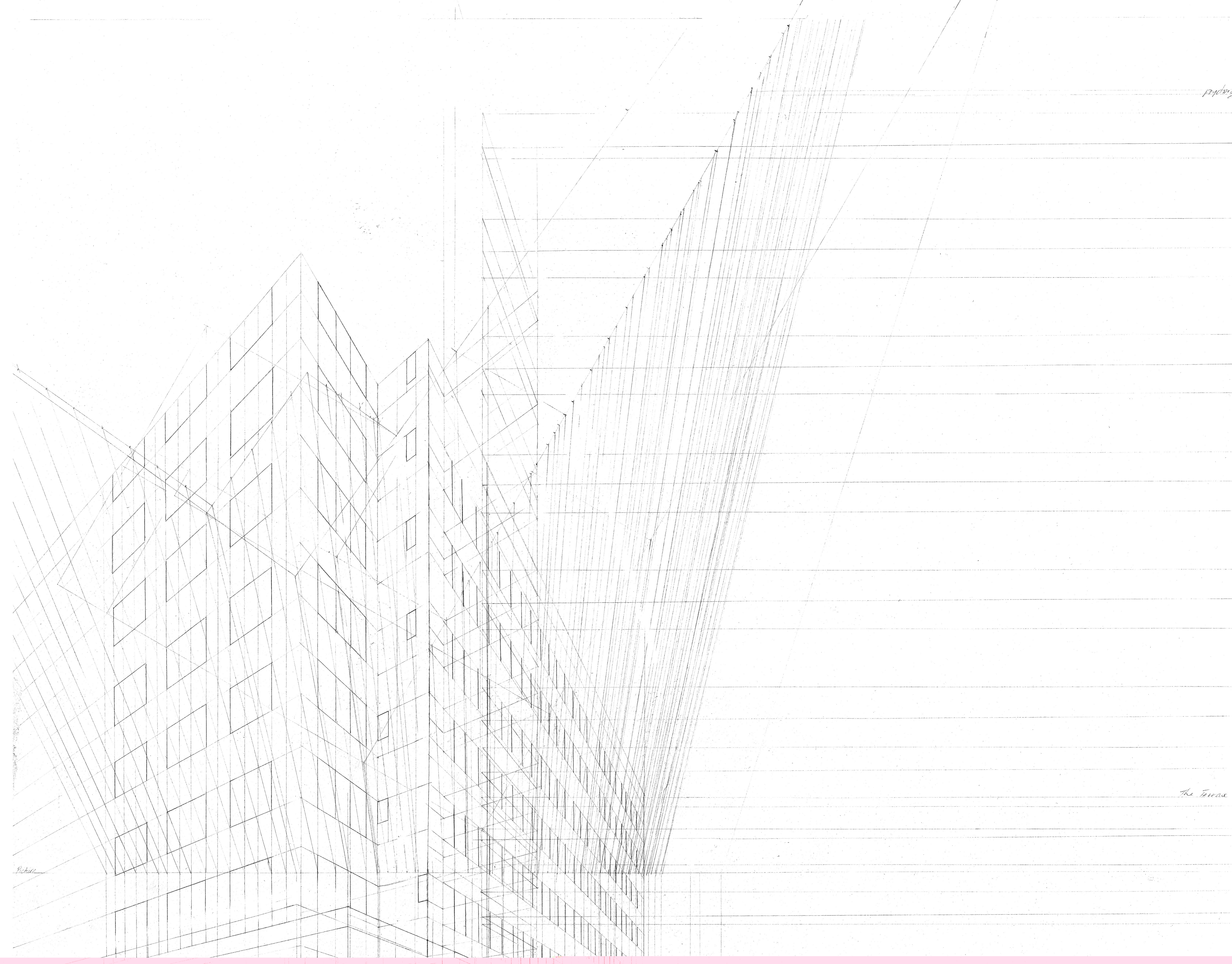




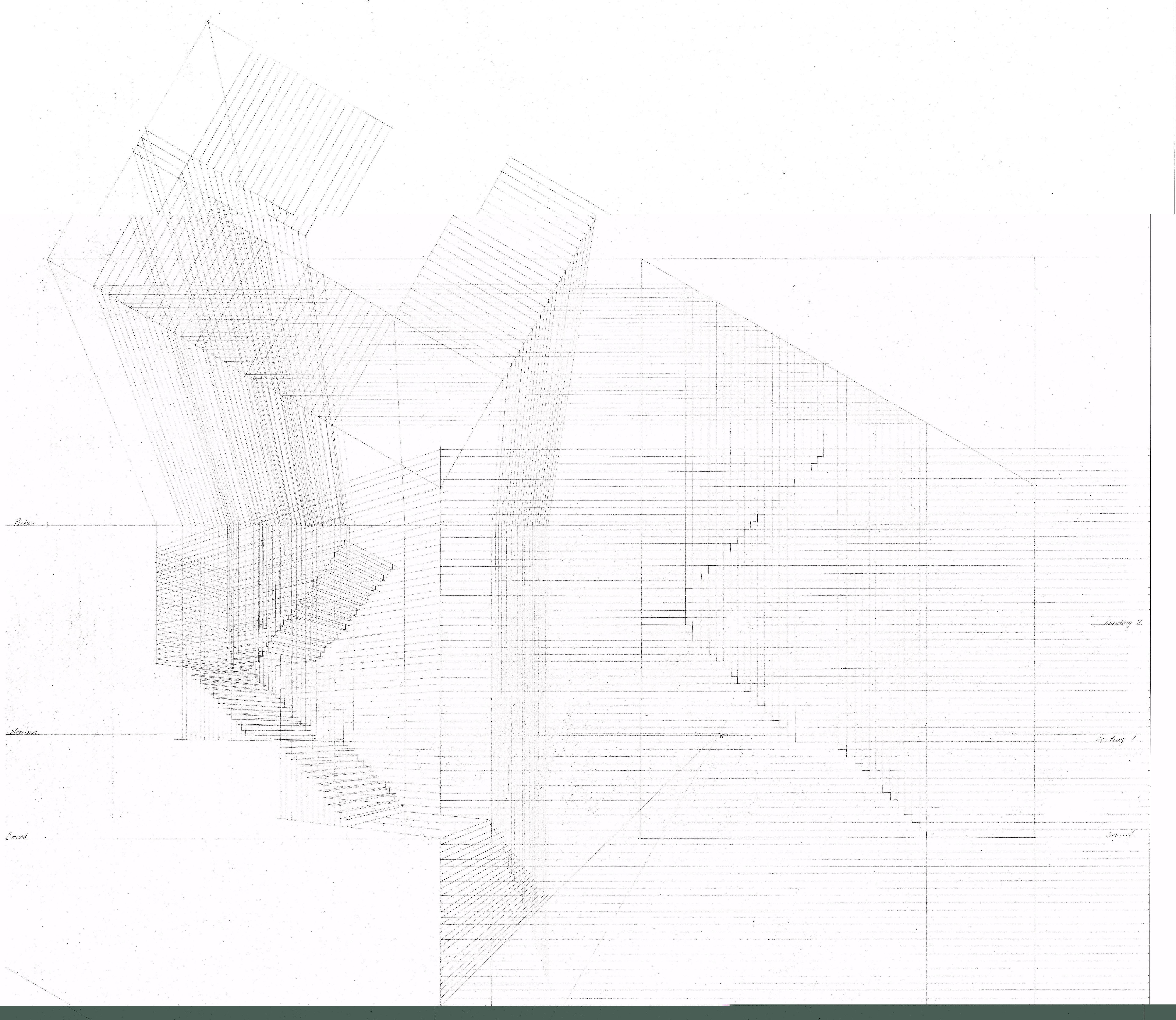



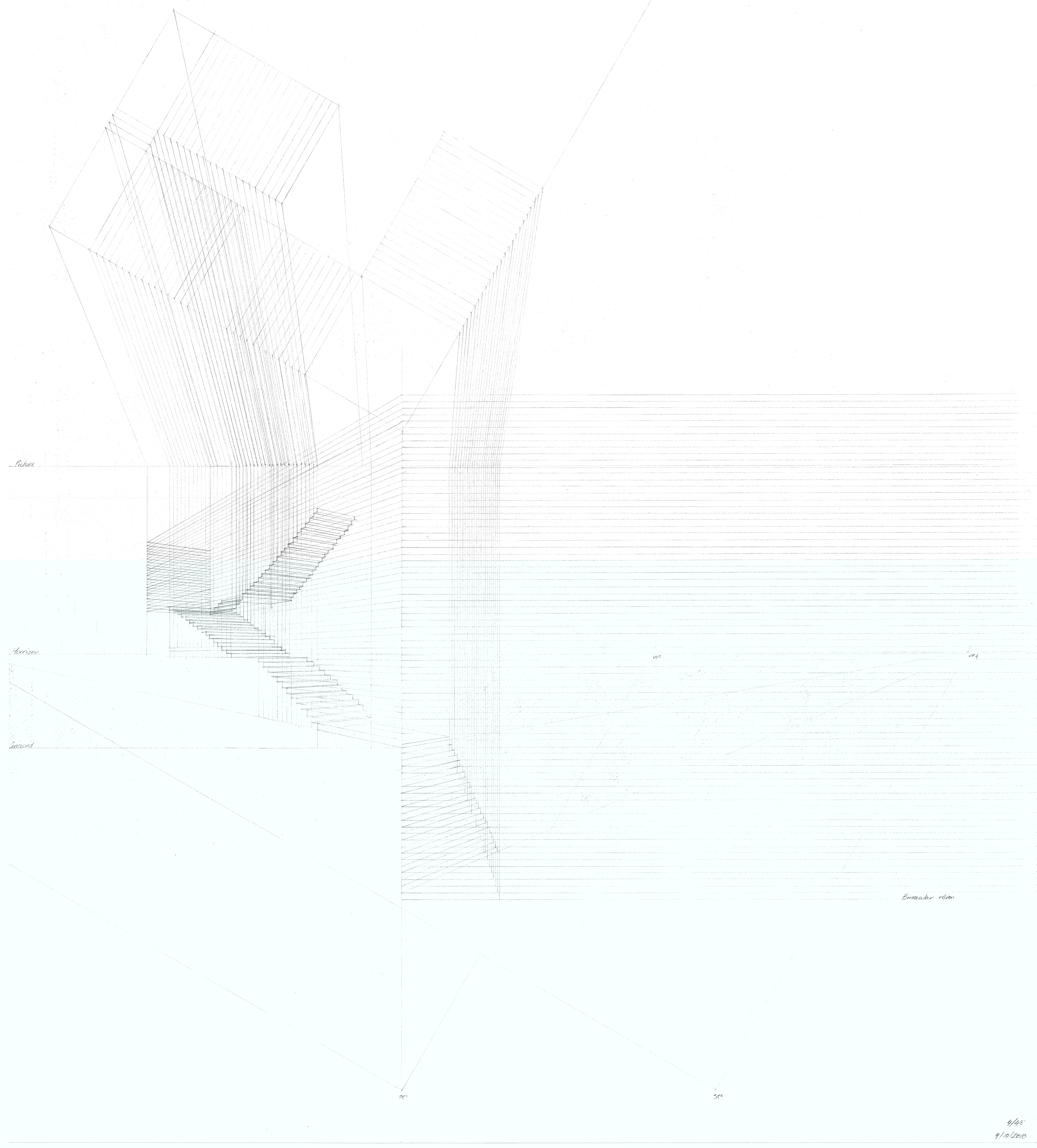




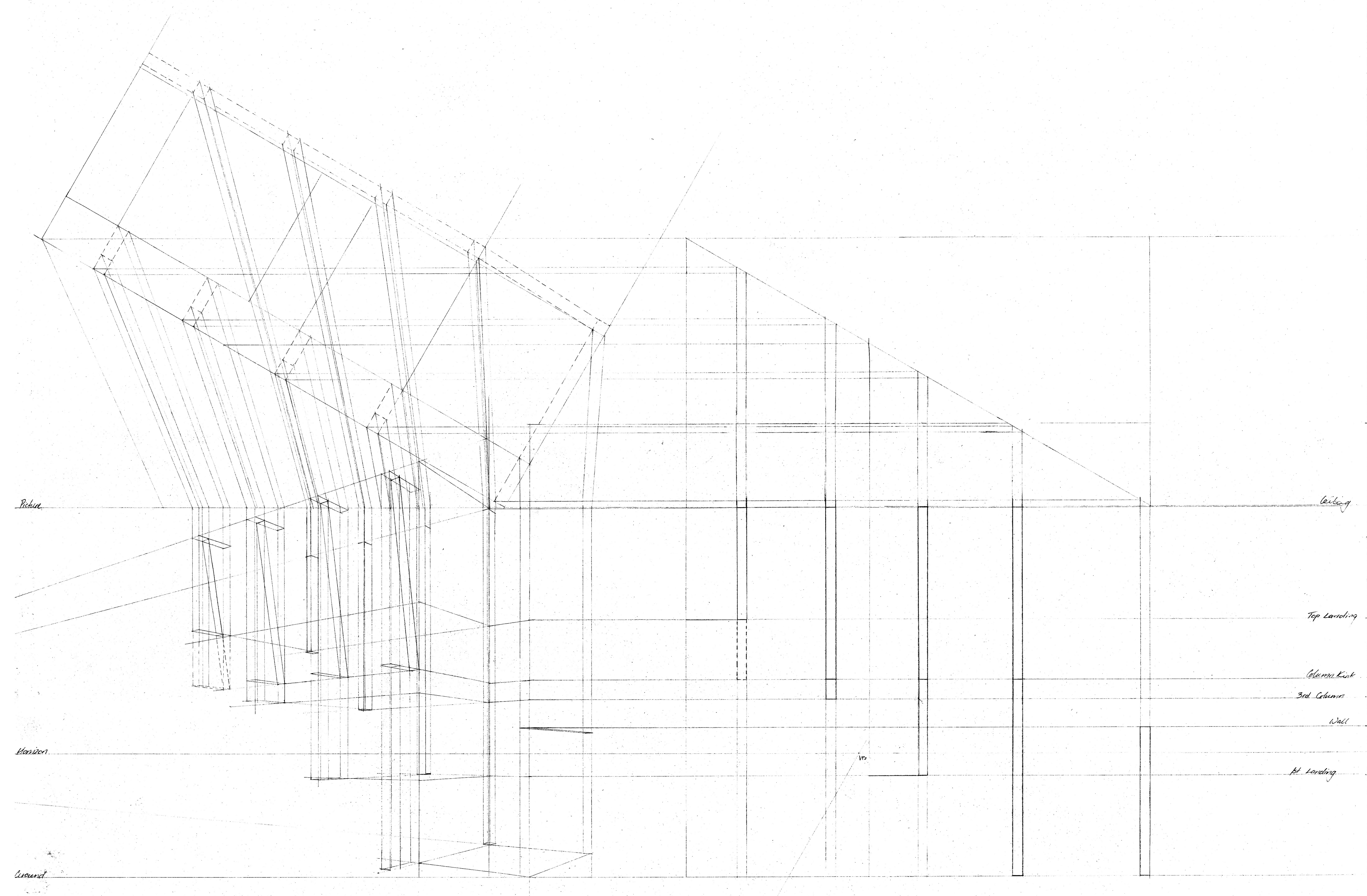




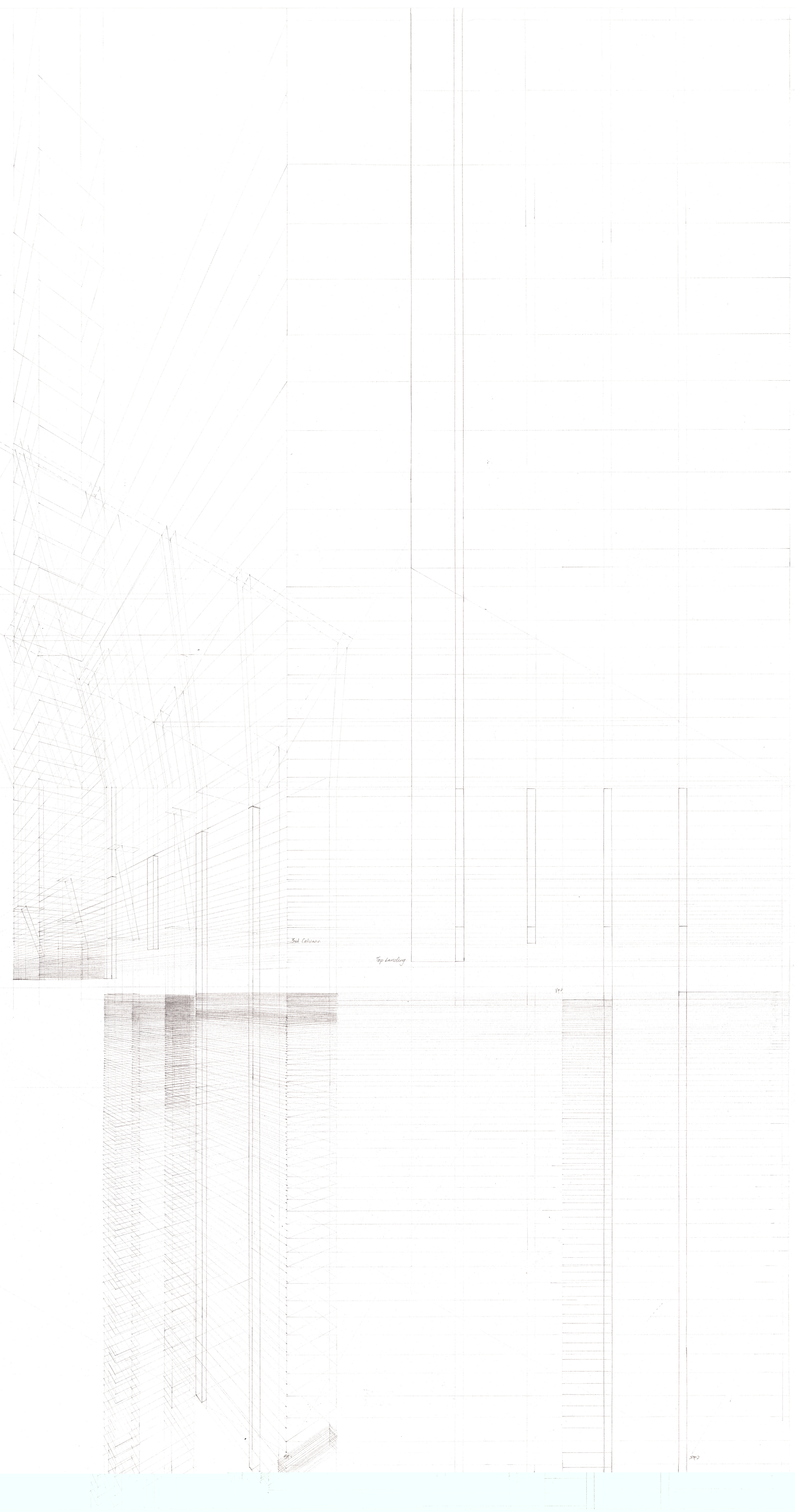



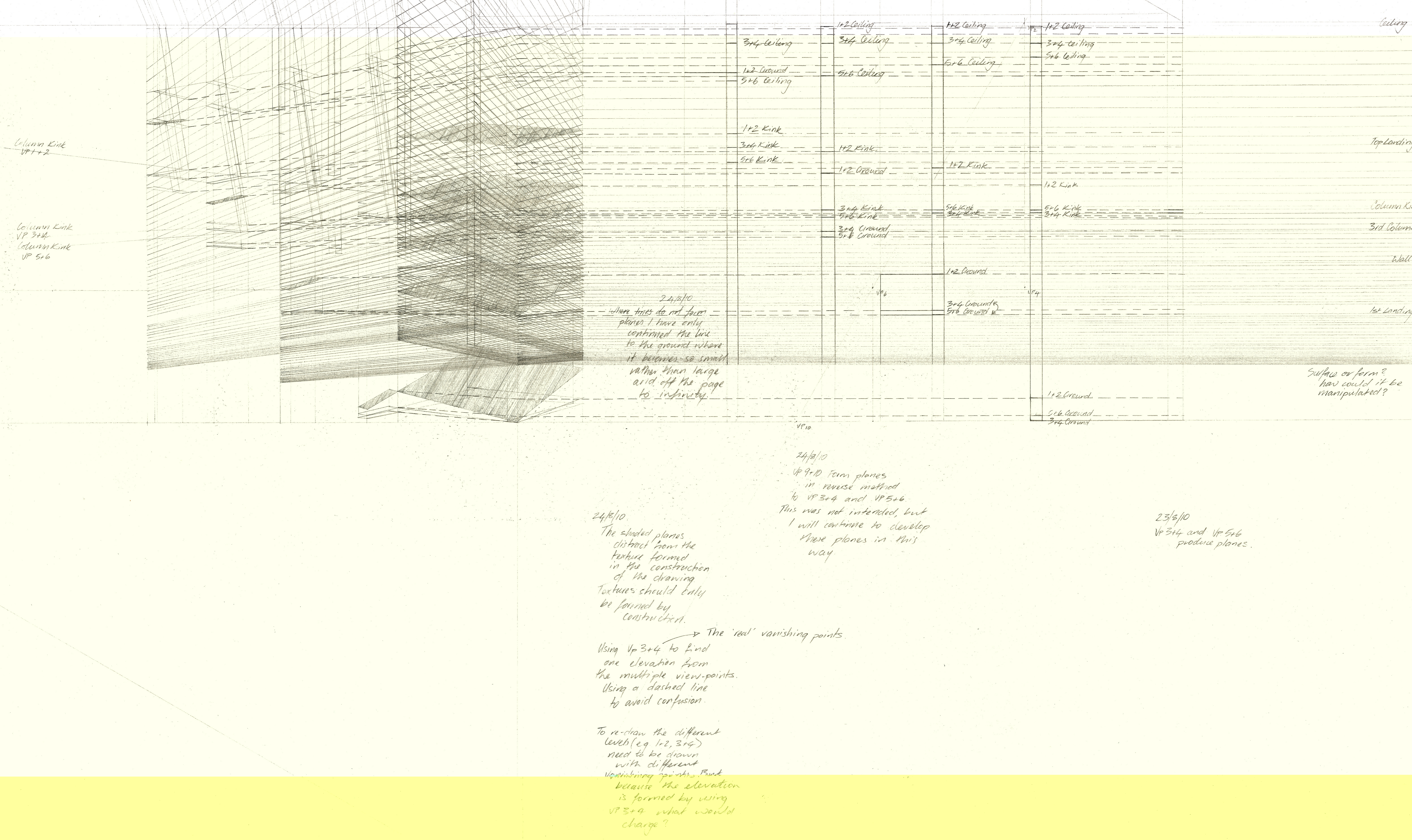


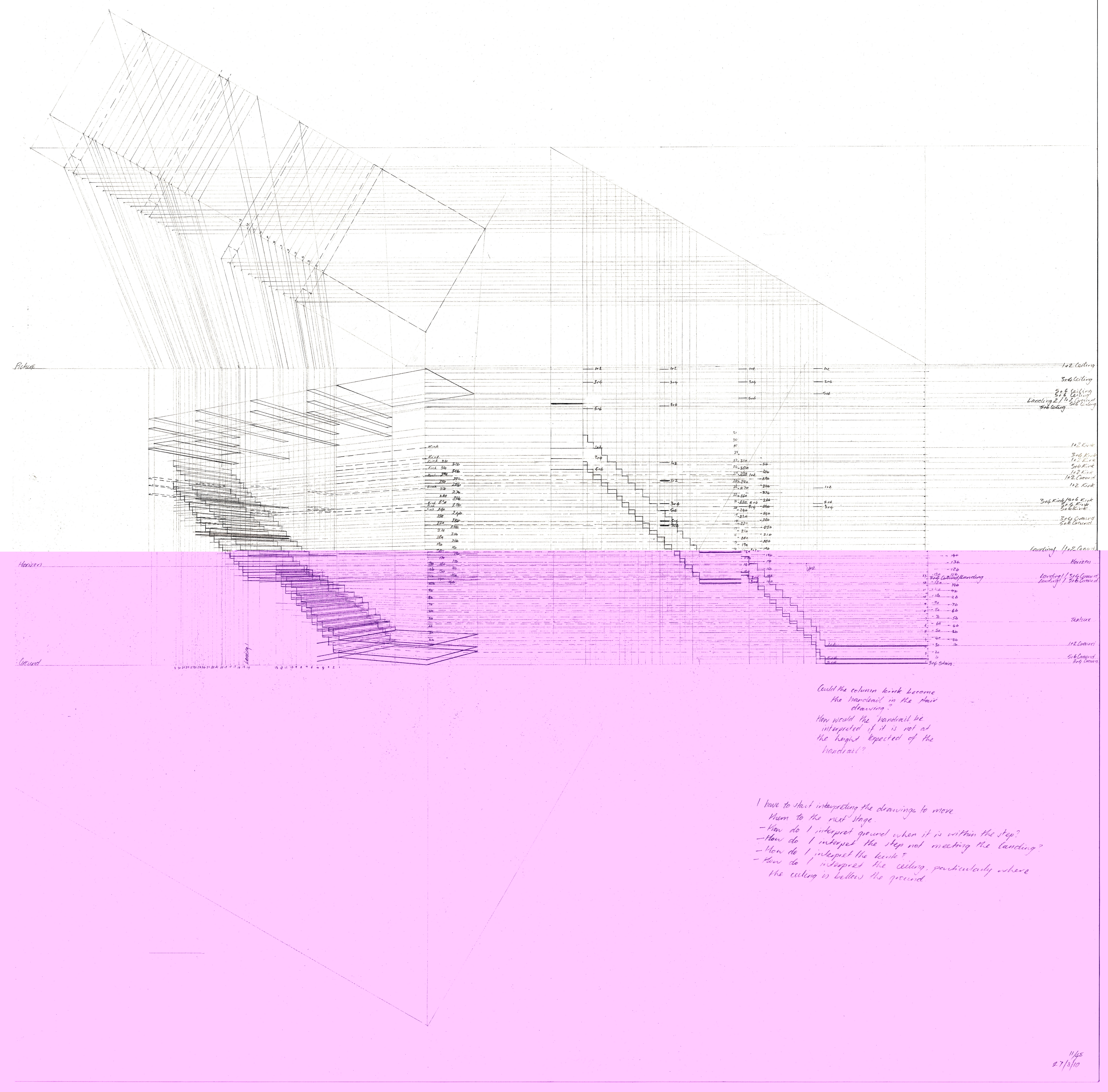





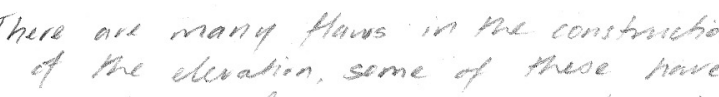

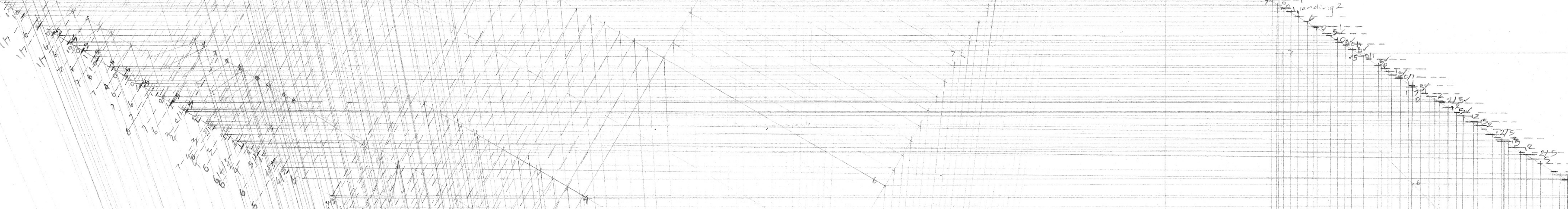




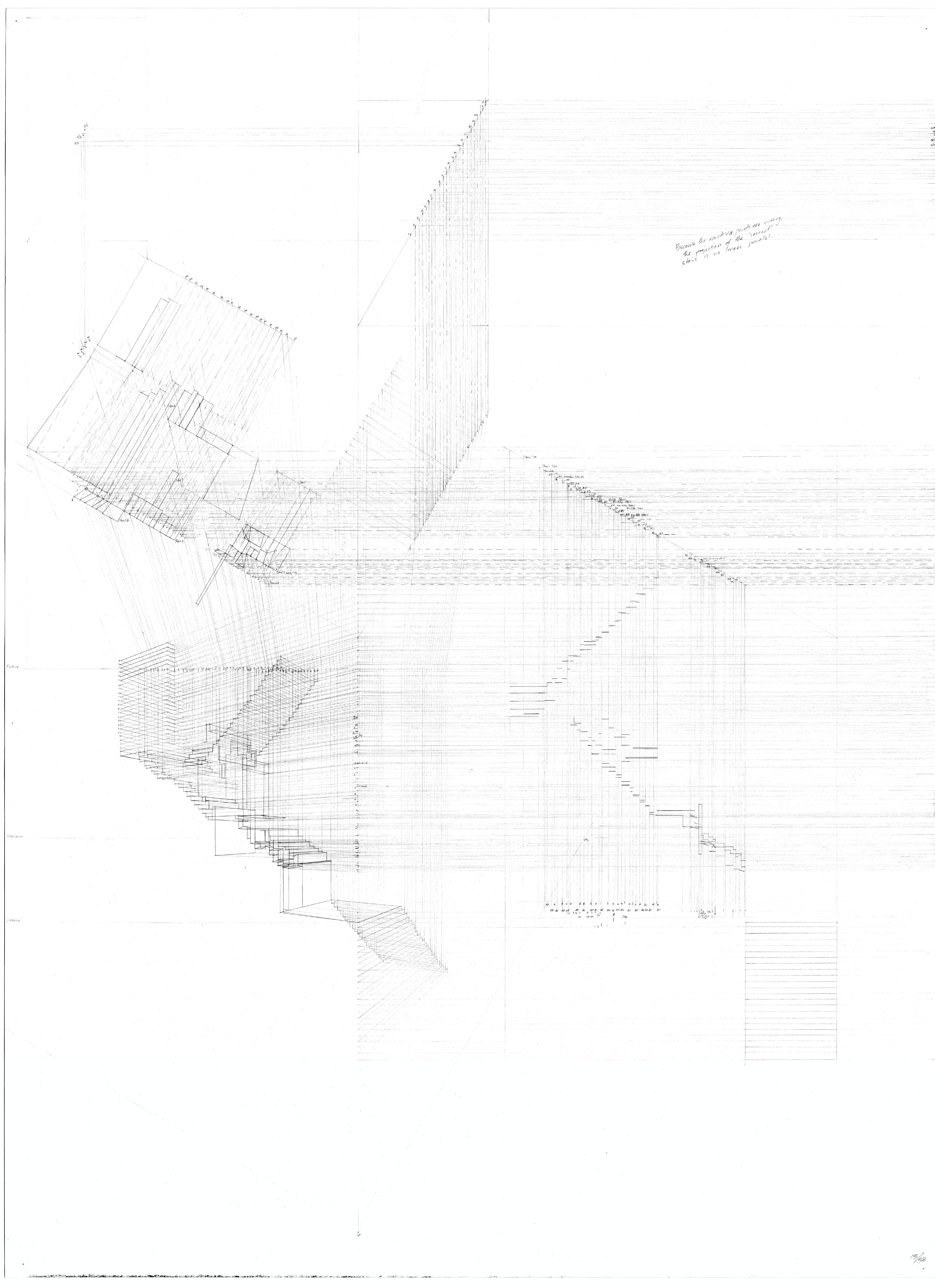

